\title{
MULTI-OBJECTIVE OPTIMIZATION OF SINGLE- LANE ROUNDABOUT GEOMETRIC DESIGN: SAFETY, MOBILITY, AND ENVIRONMENTAL SUSTAINABILITY
}

\author{
By \\ Hend Ahmed \\ B.Eng., Cairo University, Cairo, Egypt, 2000
}

\author{
A thesis \\ presented to Ryerson University \\ in partial fulfillment of the \\ requirements for the degree of \\ Master of Applied Science \\ in the program of \\ Civil Engineering
}

Toronto, Ontario, Canada, 2018

CHend Ahmed, 2018 


\section{Author's Declaration}

\section{AUTHOR'S DECLARATION FOR ELECTRONIC SUBMISSION OF A THESIS}

I hereby declare that I am the sole author of this thesis. This is a true copy of the thesis, including any required final revisions, as accepted by my examiners.

I authorize Ryerson University to lend this thesis to other institutions or individuals for the purpose of scholarly research.

I further authorize Ryerson University to reproduce this thesis by photocopying or by other means, in total or in part, at the request of other institutions or individuals for the purpose of scholarly research.

I understand that my thesis may be made electronically available to the public. 


\title{
MULTI-OBJECTIVE OPTIMIZATION OF SINGLE- LANE ROUNDABOUT GEOMETRIC DESIGN: MOBILITY, SAFETY AND ENVIRONMENTAL SUSTAINABILITY
}

\author{
Hend Ahmed \\ Master of Applied Science, 2018 \\ Department of Civil Engineering \\ Ryerson University
}

\begin{abstract}
Mobility, safety performance and environmental sustainability are priorities in the geometric design of roundabouts. This thesis presents a multi-objective optimization methodology for the geometric design of single-lane roundabouts. Mobility is defined in terms of roundabout delay and modeled using the (UK) empirical model. The collision frequency represents the safety objective, and modeled using the methodology outlined in the Highway Safety Manual. Environmental sustainability is represented by $\mathrm{NOX}, \mathrm{HC}, \mathrm{CO} 2$, and $\mathrm{CO}$ vehicle emissions and is modeled using the vehicle specific power (VSP) methodology. The presented model directly identifies the optimal geometric parameters of roundabouts. Traffic data, site conditions, and guidelines limitations were used as input data while the output decision values that minimize delay, collisions, and vehicle emissions are the optimal geometric parameters. The practical application of the proposed model is illustrated using an application example. The model was validated using an actual location, and a sensitivity analysis was conducted.
\end{abstract}




\section{Acknowledgments}

In the name of Allah, the most gracious and the most merciful. Alhamdulillah, all praises to Allah almighty whom ultimately we depend on for sustenance, guidance and strength and His blessing in completing this thesis. I could never have done this without the faith I have in Him. Foremost, I would like to express my sincere appreciation to my supervisor Dr. Said, M. Easa for his unceasing support, motivation, knowledge, patience, continued guidance, and his precious advice throughout my research. I am extremely grateful to Dr. Easa for increasing my knowledge and opening my mind to countless life lessons. I am so thankful to him for sparing his valuable time and promptly responding to my questions whenever I approached him. It was a great privilege and honor to work and study under his guidance.

I would also like to thank Dr. Ahmed El-Rabbany for his support as he was the first helping hand at Ryerson. Without his help boosting my GPA, I would not be a graduate student.

I would like to give special thanks to my examination committee, Dr. Bilal Farooq and Dr. Haitham Aboshosha for their time.

I am extending my thanks to Holly Kents, Marcos Kroker, and Malcolm Lister at the Regional Municipality of Waterloo for providing the data required for my research. I am also thankful to Daniel Jakubek and Noel Ryerson at the library for helping me retrieve the aerial photographs. I am extremely grateful to my mother for her love and prayers. I am very thankful for a very special person, my steadfast husband Mohammed, who has been a constant source of support and encouragement during the challenges of graduate school and life. Thank you for believing in me when I didn't belief in myself. Words cannot express how thankful I am to have you in my life. I would like to thank my children, Sarah, Yousef, Malak and Mariam for abiding my ignorance and the patience they showed during the writing of my thesis. Words could never express how grateful I am to all of you. I consider myself the luckiest woman in the world to have such a lovely and caring family standing beside me with their love and unconditional support. I would also like to say a heartfelt thank you to my sister, Azza, for her love, prayers, and support. A special thank you goes out to my brother, Ahmed, who offered invaluable support and humor over the years. 
I gratefully acknowledge the Natural Sciences and Engineering Research Council of Canada (NSERC) for their financial support. 


\section{Table of Contents}

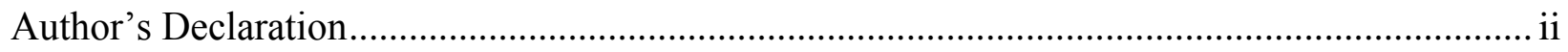

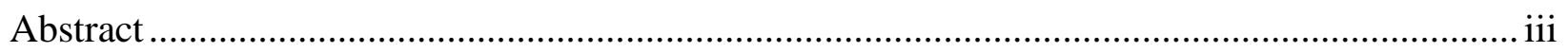

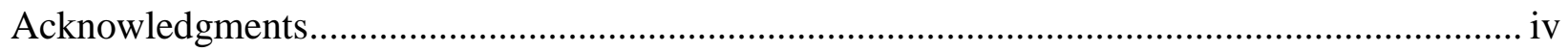

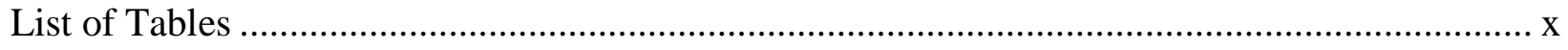

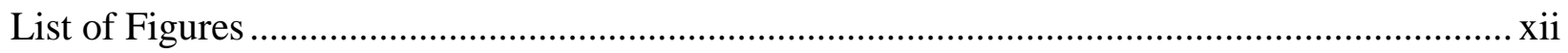

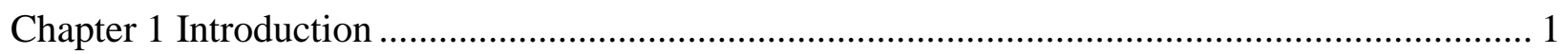

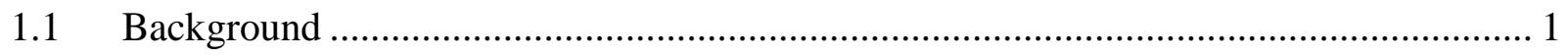

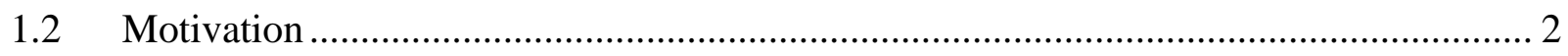

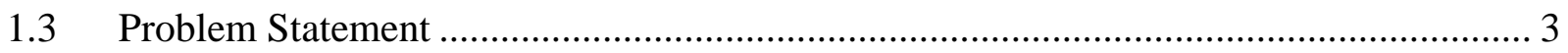

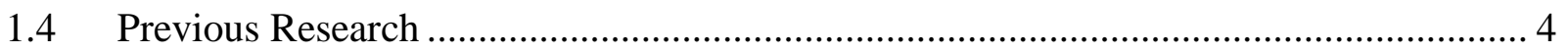

1.5 Objectives and Research Questions ....................................................................... 5

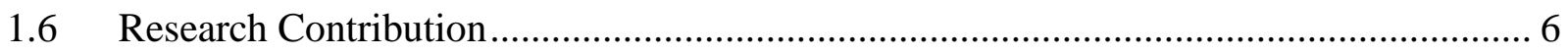

$1.7 \quad$ Thesis Organization ................................................................................................. 7

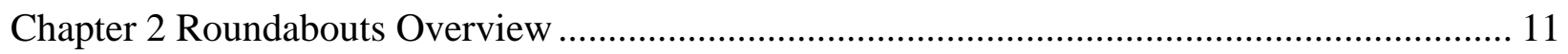

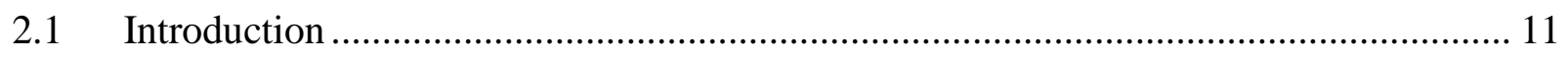

2.2 Circular Intersection Types ................................................................................... 11

2.3 Modern Roundabout Characteristics ........................................................................ 12

$2.4 \quad$ Modern Roundabouts Categories ......................................................................... 13

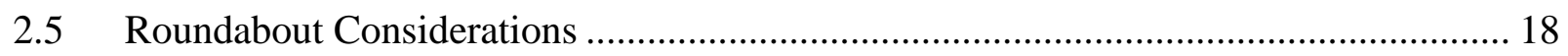

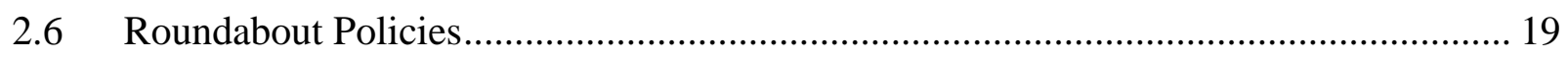

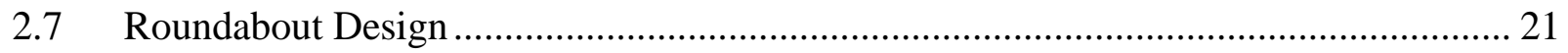

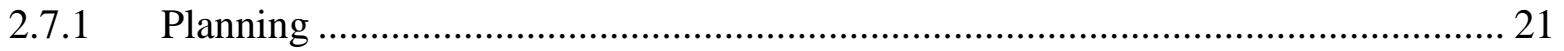




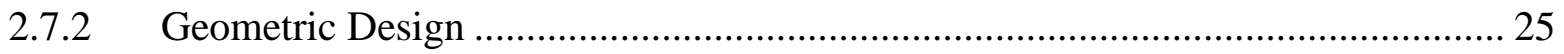

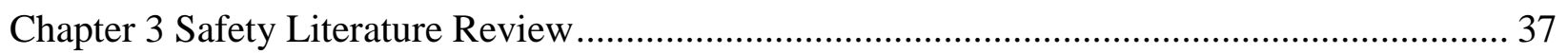

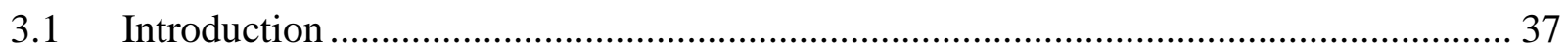

3.2 Vehicular conflicts in roundabouts vs. conventional intersections ................................ 37

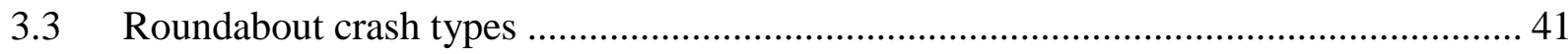

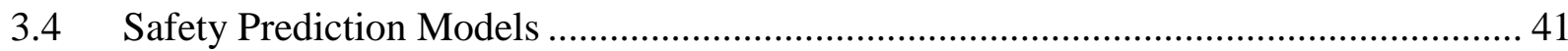

3.4.1 United Kingdom Model ................................................................................... 41

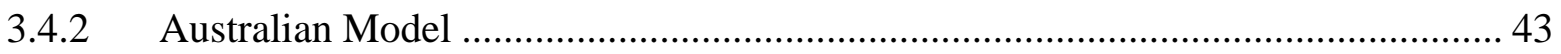

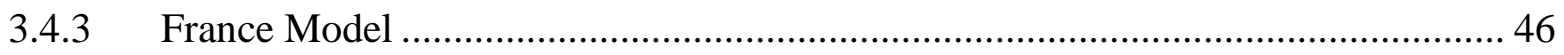

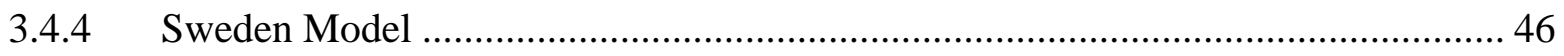

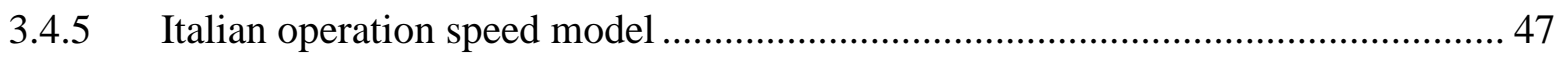

3.4.6 United States Models ........................................................................................ 48

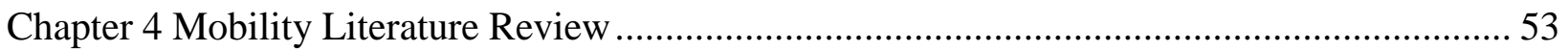

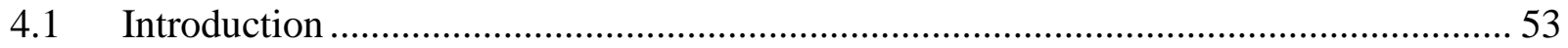

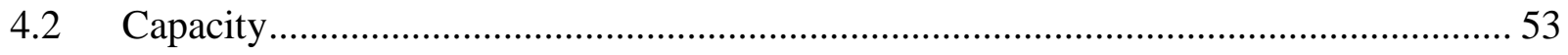

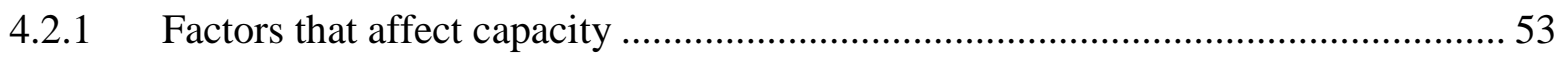

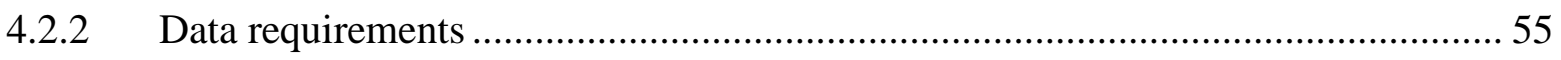

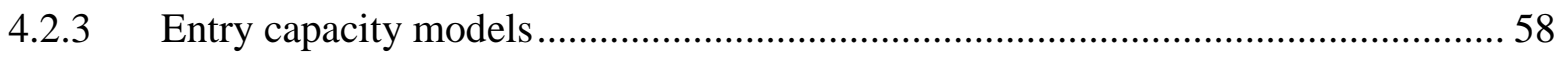

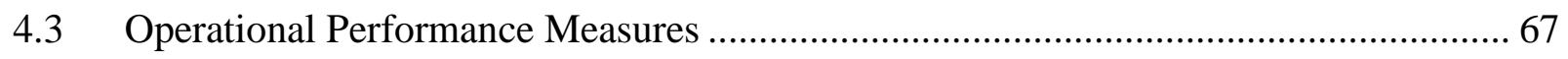

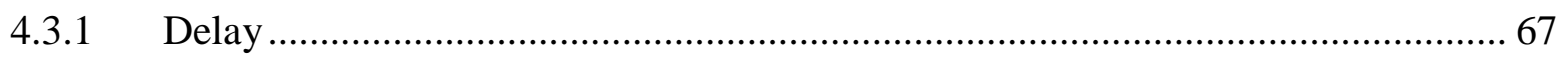

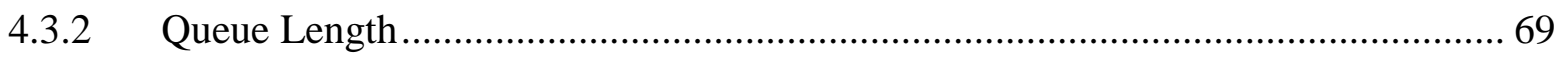

4.3.3 Effect of Pedestrians on Entry Capacity ………....................................................... 70

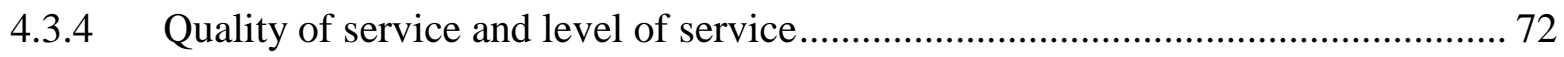


Chapter 5 Environmental Sustainability Literature Review

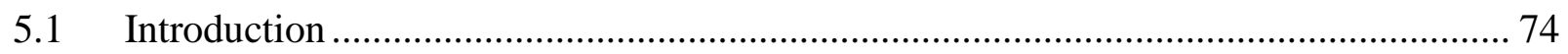

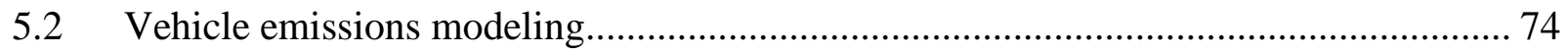

5.2.1 Scale of the input variables modeling .......................................................... 74

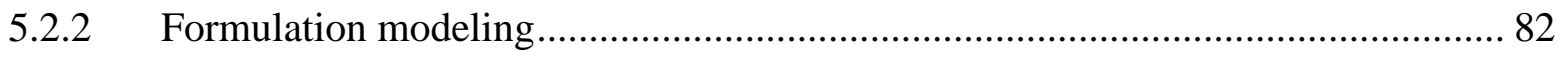

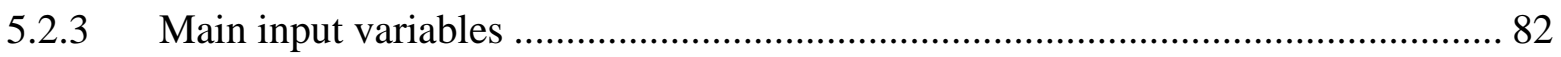

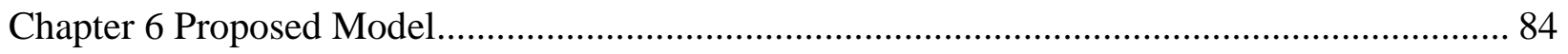

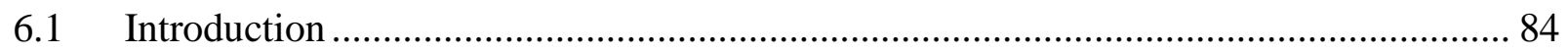

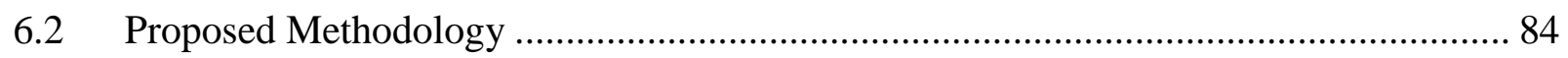

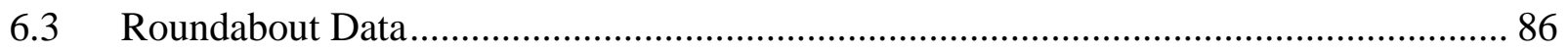

6.4 Modeling the First Objective: Safety Performance .............................................. 87

6.5 Modeling the Second Objective: Mobility .......................................................... 89

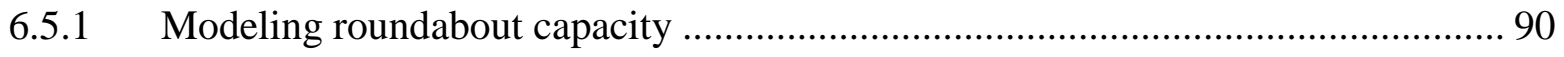

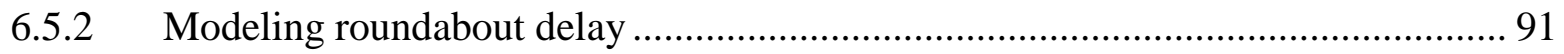

6.6 Modeling the Third Objective: Vehicle Emissions ............................................. 91

6.6.1 Vehicle Specific-Power Model ................................................................. 91

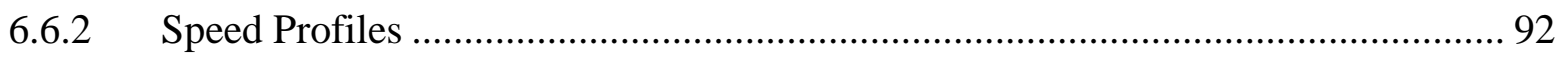

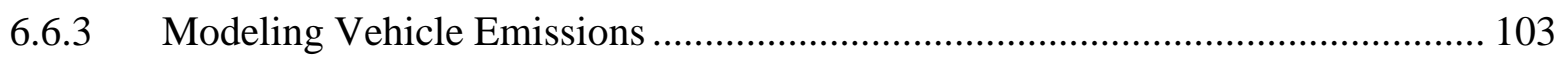

6.7 Geometric Constraints .................................................................................... 105

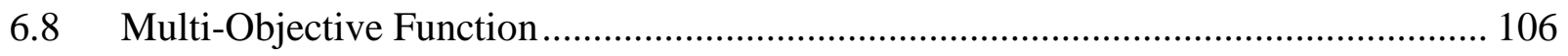

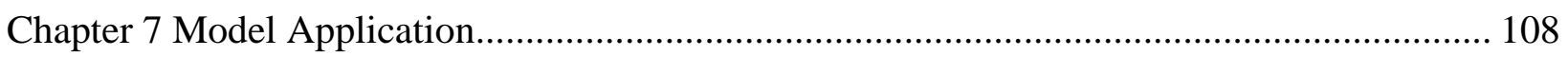

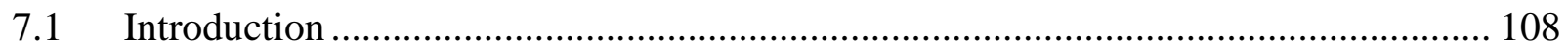

7.2 Traffic Data Preparation............................................................................ 108 


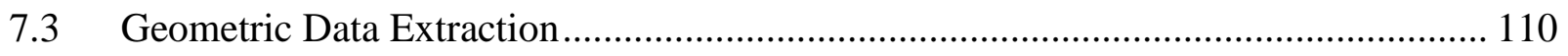

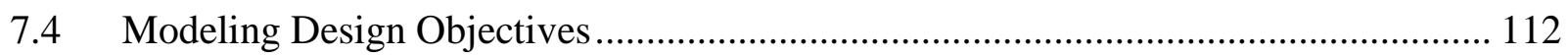

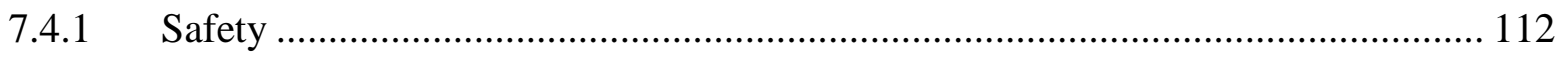

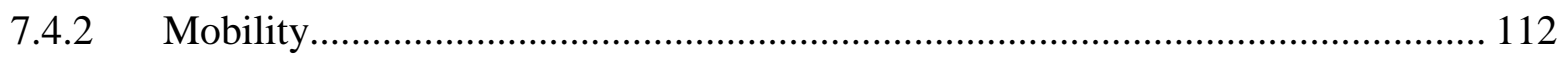

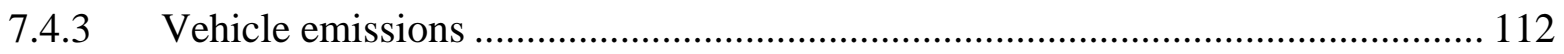

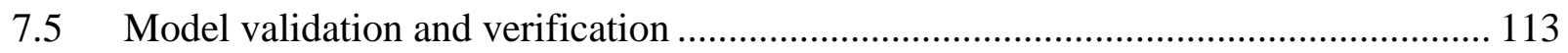

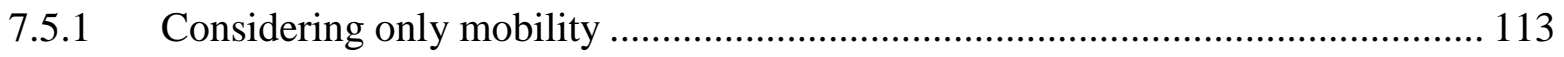

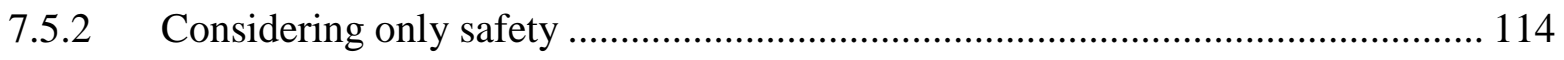

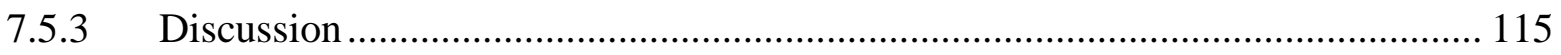

7.5.4 Considering safety and environmental sustainability ………............................ 117

7.5.5 Considering safety, mobility, and environmental sustainability ........................... 119

7.6 Sensitivity analysis and comparison ................................................................... 123

Chapter 8 Concluding Remarks and Future Research ............................................................... 130

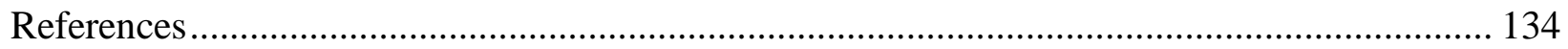




\section{List of Tables}

Table 2-1: Design characteristics of the three types of roundabouts .......................................... 17

Table 2-2: Inscribed circle sizes for roundabout categories based on design vehicle .................. 17

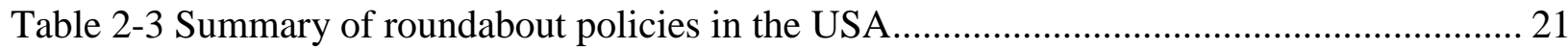

Table 2-4: Traffic flow ranges for roundabout lane configurations ........................................... 25

Table 2-5: Different vehicles dimensions and the effected roundabout feature ........................... 32

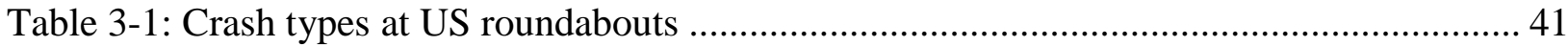

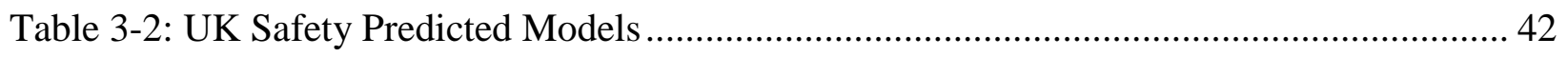

Table 3-3: Models for predicted total crashes frequency per year............................................... 48

Table 3-4: Models for predicted KAB injury crashes frequency per year...................................... 48

Table 3-5: Base Conditions for Design Variables and AMFs .................................................... 51

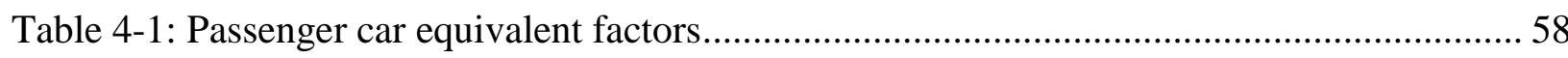

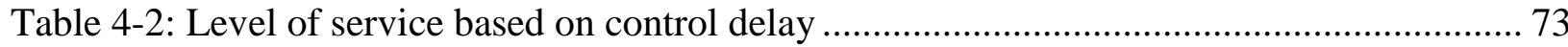

Table 6-1: The main emissions of VSP ranges ....................................................................... 104

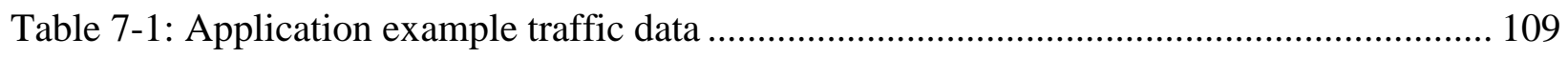

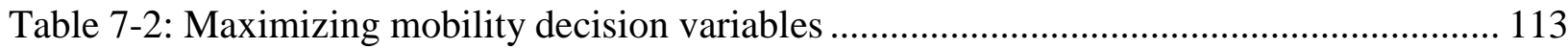

Table 7-3: The impact of maximizing mobility on vehicle emissions and crashes ................... 114

Table 7-4: Considering observed crashes and dispersion factor................................................ 114

Table 7-5: Maximizing safety impact on emissions and delay ................................................. 114

Table 7-6: Considering observed crashes and dispersion factor................................................. 115

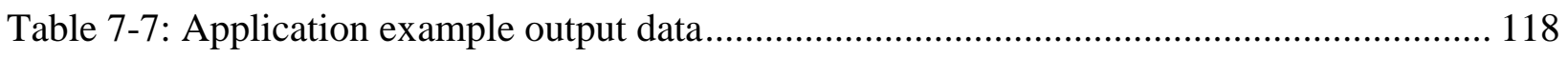

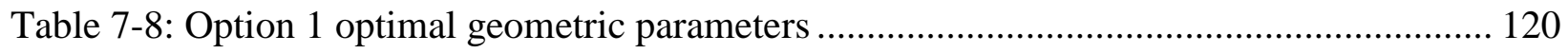

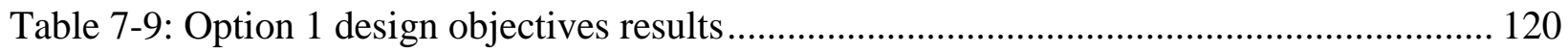

Table 7-10: Option 1 crashes considering the observed crashes and dispersion factor............... 121

Table 7-11: Option 2 optimal geometric parameters ……………………………………....... 121

Table 7-12: Option 2 design objectives results ......................................................................... 121

Table 7-13: Option 2 crashes considering the observed crashes and dispersion factor.............. 122

Table 7-14: The existing geometric parameters of the actual roundabout................................... 122 
Table 7-15: The design objectives given by the model based on the existing geometry........... 123

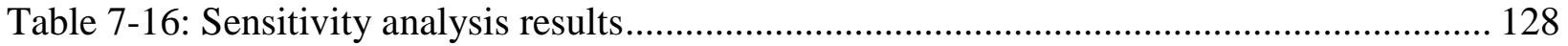




\section{List of Figures}

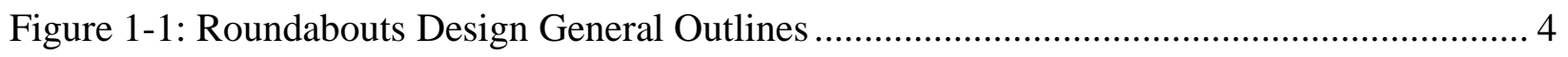

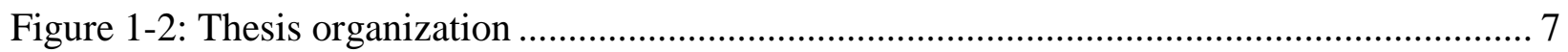

Figure 2-1 Distinguishing Characteristics of single-lane roundabouts ........................................ 12

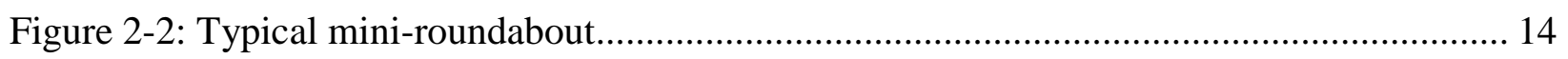

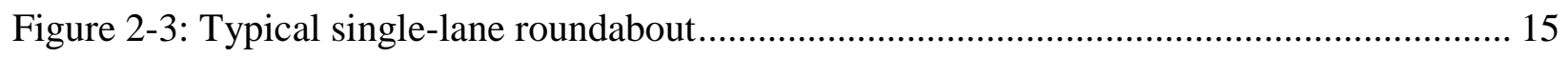

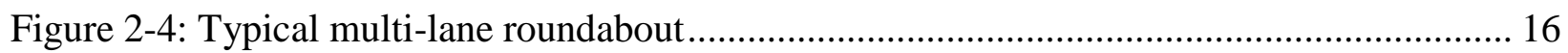

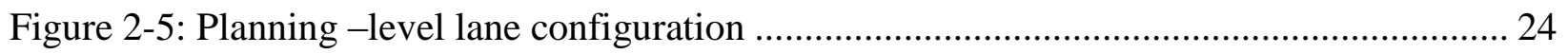

Figure 2-6: General roundabout geometric parameters ....................................................... 26

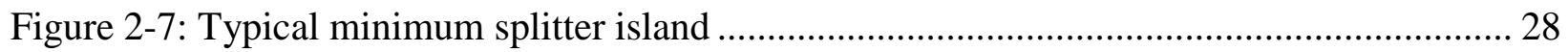

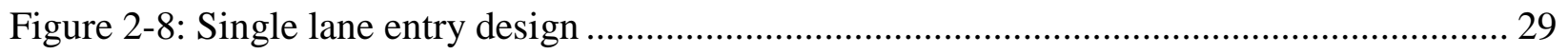

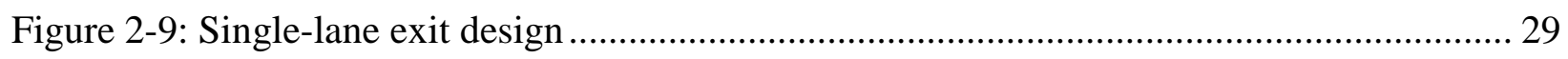

Figure 2-10: Path overlap at a multi-lane roundabout ……………………................................ 31

Figure 2-11: Intersection sight distance .............................................................................. 34

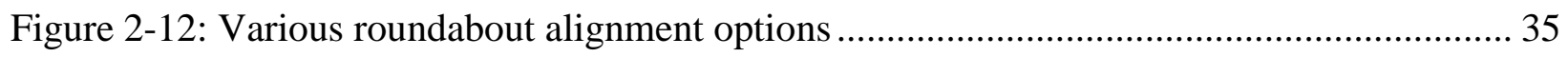

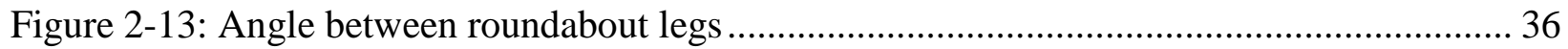

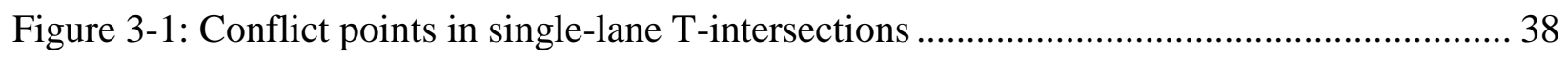

Figure 3-2: Conflict points in single-lane 4 legs-intersections ................................................... 39

Figure 3-3: Total and Injury Crash Experience for U.S. Roundabouts with Four Approaches.... 39

Figure 3-4: Australian Speed Model ................................................................................... 43

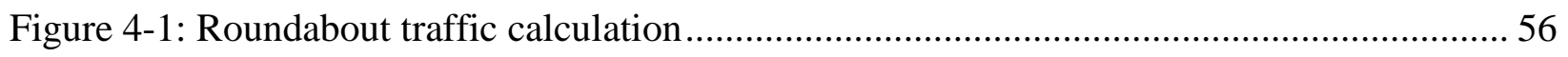

Figure 4-2 Calculating approach exiting flow rate ………..................................................... 57

Figure 4-3 Swiss Measure of the Parameter ' $b$ ' ........................................................................ 67

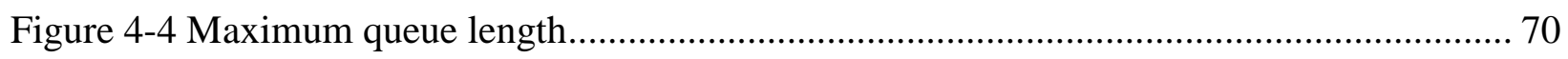

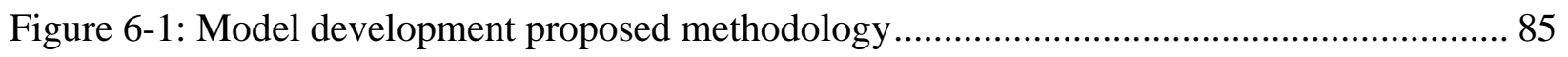

Figure 6-2: A single-lane roundabout typical speed profiles........................................................... 94

Figure 6-3: Through movement vehicle path at single-lane roundabout ...................................... 97

Figure 6-4: Right-turn movement vehicle path....................................................................... 100 


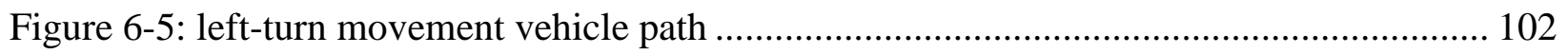

Figure 6-6: The typical nine-speed profiles of a single-lane roundabout ................................... 103

Figure 7-1: Preparation of roundabout traffic data ................................................................. 110

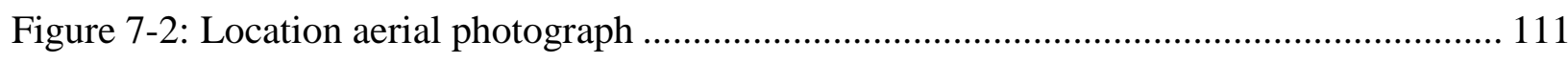

Figure 7-3 Comparing crashes in considering safety vs. considering mobility .......................... 116

Figure 7-4: Comparing delay in considering safety vs. considering mobility ............................ 116

Figure 7-5: Comparing vehicle emissions in considering safety vs. considering mobility …..... 117

Figure 7-6: Optimum geometric design given by the optimization module example 3 ............. 119

Figure 7-7 Predicted crashes comparison between the three options ....................................... 123

Figure 7-8: Crash reduction for option 1 vs. existing geometry ................................................ 124

Figure 7-9-Delay comparison between the three options ....................................................... 125

Figure 7-10: Delay reduction for option 2 vs. the existing geometry option.............................. 126

Figure 7-11: Vehicle emissions comparison between the three options..................................... 127

Figure 7-12: Vehicle emissions reduction for option 1 vs. the existing geometry option ........... 128

Figure 7-13: The sensitivity of vehicle emissions to the geometry ……………….................... 129 


\section{Chapter 1 Introduction}

\subsection{Background}

The most critical problems in road design are safety, mobility, and environmental sustainability. In their 2016 annual report, Ontario Road Safety reported 35,972 collisions, 439 fatal collisions with 483 people killed, and 49,601 collision-related injuries (Ministry of Transportation of Ontario, 2016). Intersection-related crashes are the most serious accidents as they can involve all road users such as drivers, pedestrians, occupants, and cyclists. A significant number of fatal crashes occur at intersections. Pedestrians and cyclists are much more vulnerable in intersection crashes compared to drivers, due to their interactions with vehicles (Dong et al., 2014a; Zhou et al., 2014). A global survey conducted by the World Health Organization indicated that nearly half of all deaths on the road involved various road users. In first-world countries, pedestrians represent between 10 and 20 percent of all road fatalities; Europe and the United States reported that over 10 percent of all road fatalities involve pedestrians; In Switzerland and the UK, 21 percent of all road fatalities involved pedestrians. In Australia, 13 percent of all road fatalities involved pedestrians (World Health Organization, 2009).

Road congestion has become a serious concern for engineers, planners, researchers and policy makers due to the continuous increase in the volume of motorized vehicles. In urban areas, this road congestion leads to other issues of concern including air quality, urban noise, energy consumption, and road safety (Lomax, 1997). Road congestion is one of the most critical problems in urban areas. A study found that congestion was the main source of marginal external costs in the USA the year 2005; $65 \%$ of the marginal external cost resulted from congestion, $6 \%$ from environmental causes, and 25\% from accidents (Small \& Verhoef, 2007). Increases in road capacity is an effective solution to these problems and one that researchers and planners have made a priority. The higher the capacity, the lower the delay, and therefore, capacity is the main key to mobility.

According to the government of Canada, passenger cars are a major contributor to air pollution. Vehicle emissions contribute almost $21 \%$ of the nitrogen dioxide $\left(\mathrm{NO}_{\mathrm{x}}\right), 51 \%$ of the volatile organic compounds (VOC), and 4\% of the fine particle matter (PM 2.5)(Canada, 2017). 
It is therefore critical that road designers adopt more effective techniques to reduce energy consumption and vehicle emissions.

\subsection{Motivation}

Roundabouts are an effective solution to road congestion problems, increasing safety, mobility, and environmental sustainability. Several researchers have found a significant reduction in collisions when comparing roundabouts with other types of intersections in different countries. A US study reported a $35 \%$ reduction in the number of total collisions and a $76 \%$ reduction in the number of collisions resulting in injury following a conversion from conventional intersections to roundabouts. An Australian study reported a 61\% reduction in the number of total collisions and an $87 \%$ reduction in the number of collisions resulting in injury. A French study reported a $78 \%$ reduction in the number of collisions resulting in injury. reduction from 57 to $78 \%$ of injury crashes was reported in France. A 36\% reduction in the total number of collisions was reported in Germany; In the Netherlands, a 47\% reduction in the total number of collisions was reported; the United Kingdom reported a 39\% reduction in the total number of collisions (Garder,1998; Guichet,1997; Rodegerdts et al. 2007).

Roundabouts have improved mobility by reducing delay and queue length due to their geometry. The special geometry of roundabouts adds deflection to control the speed of vehicles which increases mobility. Giving priority to the circulating traffic minimizes queue length, and decreasing delay.

Congested intersections are one of the main causes of increases in vehicle emissions due to stop and go cycles. Roundabouts improve mobility by reducing the total delay compared to other types of controlled intersections. The improvement in mobility led to environmental benefits and savings in fuel consumption, as reported by the Federal Highway Administration (FHWA, 2010). Therefore, roundabouts are an effective method for reducing road congestion by reducing delay and average queue length (Rao et al., 2014).

It is extremely important to provide an effective geometric design for roundabouts that fulfills all of the design objectives and satisfies all of the associated constraints. Researchers have demonstrated the significant effect of the geometric parameters of roundabouts on different 
design objectives, especially safety, mobility, and environmental sustainability. This fact has led many researchers to link safety, mobility, and environmental sustainability to several geometric parameters such as the inscribed circle diameter, the circulated width, the entry width, and the exit width.

\subsection{Problem Statement}

Geometric design is the most complex process due to various constraints. The design process for roundabouts involves alternating between geometric design and performance analysis using an iterative method. The geometric design of roundabouts is typically governed by guidelines and standards such as the FHWA Roundabout Guide 2010 (Rodegerdts et al., 2010) which defines geometric criteria to satisfy safety, operational, and environmental requirements. The initial geometric parameter values are evaluated using performance analysis using one of the existing software tools to ensure that the geometric parameters satisfy the required roundabout performance criteria. If the performance is found to be inadequate, the geometry is adjusted, and the roundabout is re-evaluated. The design process is repeated until all of the objectives are satisfied with effective overall costs. The general outlines of roundabout design provided in the Roundabout an Information guide are summarized in Figure 1-1. The Figure shows the design process involved an iterative method. This method takes time and effort in order to meet the design objectives rather than an optimal solution for satisfying multiple objectives and constraints. More details regarding the geometric design of roundabouts are found in chapter 2. 


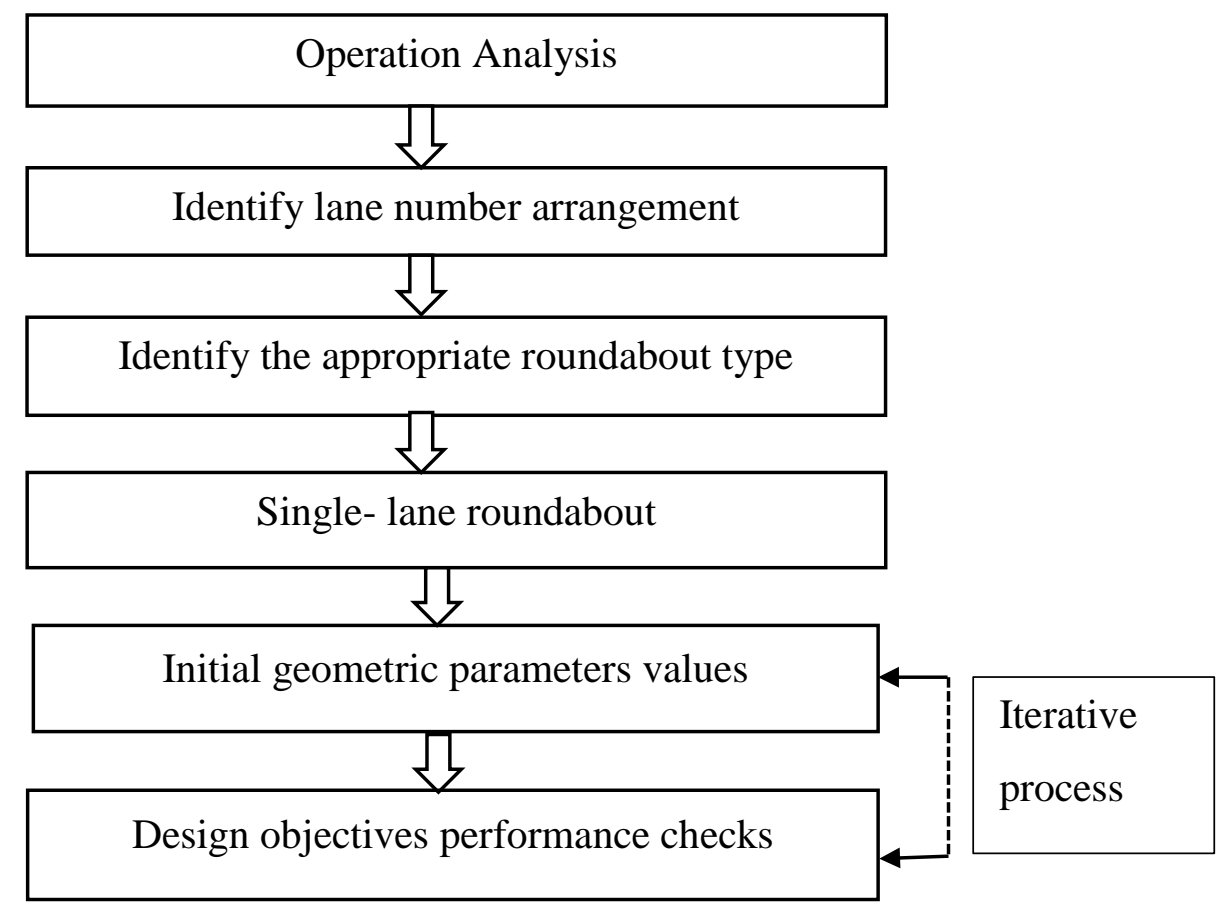

Figure 1-1: Roundabouts Design General Outlines

Source: (Rodegerdts et al 2010)

\subsection{Previous Research}

Optimization has been used in geometric and traffic design. Over the years, optimization methods have grown in their ability to deal with the most complicated transportation problems. The geometric design of road elements such as the different kinds of intersections or highway alignment is a very complex process that requires a balance between the design objectives and the existing constraints. Several studies have been conducted in order to develop optimization models that can solve the most challenging problems and to find the optimal solution that satisfies all the design objectives.

Easa and Mahmood (2007) conducted a study involving the creation of an optimization model to establish a horizontal alignment based on maximizing the speed consistency. The model determines the optimum horizontal curve radius and the speed difference between two successive segments. Another study identified the horizontal alignment geometric parameters 
based on minimizing the frequency of collisions (Easa \& Mahmood, 2008). Two other studies involving the geometric design of roundabouts were conducted. In the first study, the researchers used an optimization model to find the optimal geometric parameters of a single-lane roundabout based on maximizing speed consistency (Easa \& Mahmood, 2004). The second study presented a multi-objective optimization model for a single-lane roundabout maximizing speed consistency and mobility (Mahmood \& Easa, 2006). The multi-objective optimization enhances the geometric design of roundabouts by determining the optimal geometric parameters that satisfy the design objectives. The previous models require less time and are more effective than the iterative method.

\subsection{Objectives and Research Questions}

The principal needs or objectives in the design of roads design and intersections are outlined below:

- Safety performance improvements to reduce the frequency and severity of collisions.

- Mobility improvements by maximizing intersection capacity and minimizing the average delay.

- Environmental sustainability improvements by reducing energy consumption and vehicle emissions.

The purpose of this study is to develop an optimization model for the geometric design of single-lane roundabouts with safety, mobility, and environmental sustainability as primary design objectives. The proposed model can determine the geometric design parameters that minimize the predicted collisions, average delay, and vehicle emissions. This model will enhance the geometric design process as well as road safety, mobility, and environmental sustainability. The proposed model determines the optimal solution for complex design constraints that cannot be solved using the traditional iterative process. The optimization model saves time by using a single model in one direct process instead of several iterations that provide a satisfactory solution rather than an optimal solution. The model is developed by modeling the collision frequencies using a speed based safety performance function, the average delay using the UK empirical model, and the vehicle emissions using the vehicle specific power 
model. The three objectives form the objective function and the geometric, traffic and physical constraints are defined. The model is solved by minimizing the objective function subjected to the defined constraints to provide optimal geometric parameters and satisfy the design objectives. The proposed model is explained in detail in chapter 6 .

The following research questions are addressed:

- Can the iterative method be replaced by an optimization model?

- Does the optimization model provide an improvement in safety, mobility or environmental sustainability?

- If there is an improvement, how significant are the reductions in collisions, delay, and vehicle emissions?

These questions are answered in detail in chapter 7 through the application of the model.

\subsection{Research Contribution}

The thesis led to the development of a multi-objective optimization model for the geometric design of single-lane roundabouts which maximize safety, mobility and environmental sustainability. Although many researchers have linked the geometric features of roundabouts to important design objectives such as safety, mobility, and environmental sustainability, there is a research gap involving the use of variation in geometric parameters to evaluate the performance of roundabouts. Researchers have identified that a minor change in geometric parameters can lead to a major change in design objectives. The Highway Capacity Software (HCS) is one tool used to evaluate the operational performance of roundabouts. HCS implements the steps and models defined in the Highway Capacity Manual (HCM, 2010). HCS takes the geometry into consideration through the lane configuration. In the case of single-lane roundabouts, the software results remain constant despite variations in the geometric parameters. This study adopted a new process that reacts with minor changes in geometric parameters. Moreover, the model identifies the optimal values in one simple step instead of using an iterative approximate method. This research contributes to the geometric design of roundabouts and can be extended to include different types of roundabouts and more design objectives. 


\subsection{Thesis Organization}

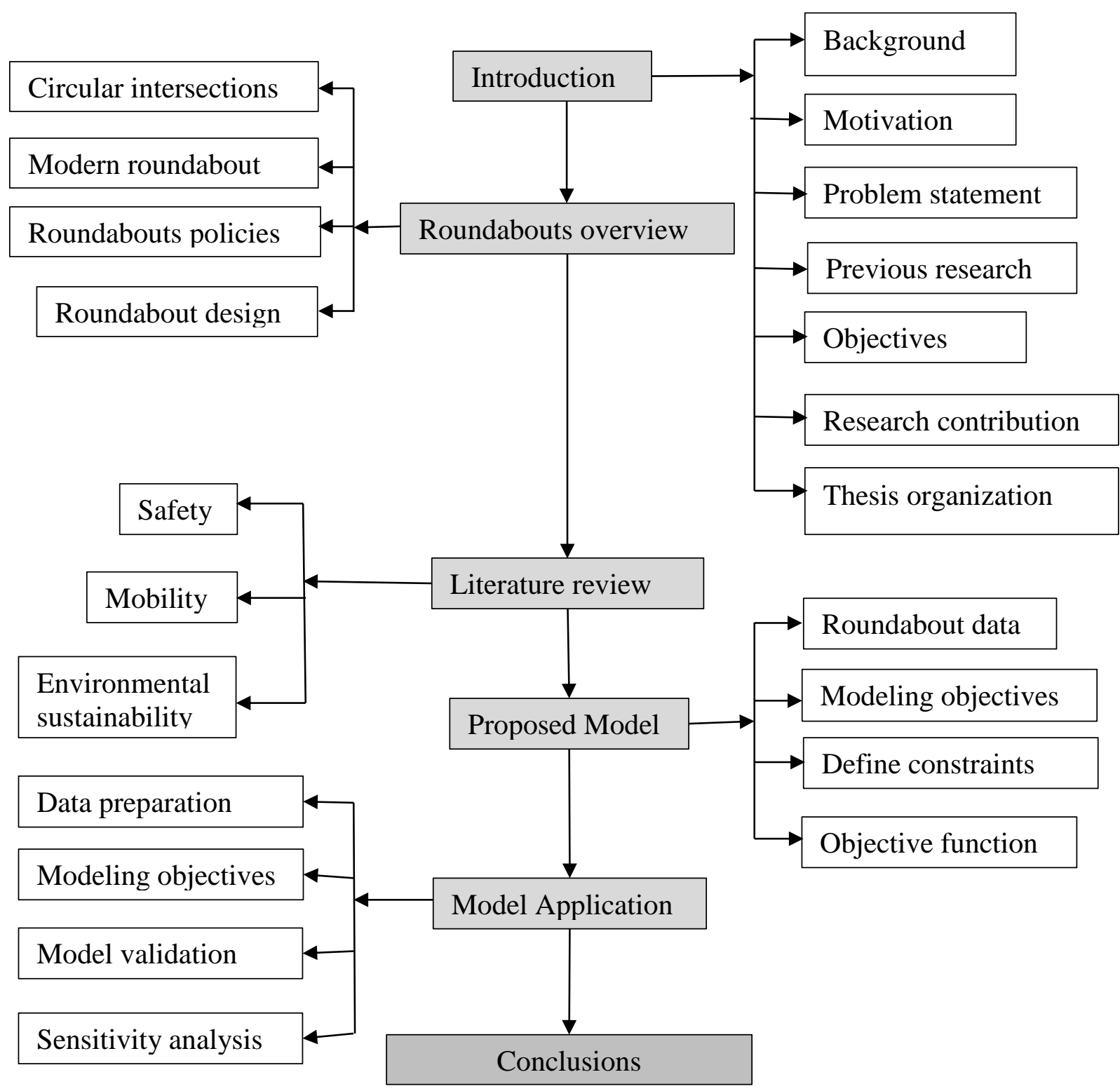

Figure 1-2: Thesis organization

The general thesis structure is illustrated in Figure 1-2; the following section describes the thesis organization in detail.

This thesis consists of 8 chapters summarized as follows: 
Chapter 1 includes an introduction and addresses the three primary road design problems: safety, mobility, and environmental sustainability. This chapter also describes the motivation for doing this research and the specific problem that this research seeks to solve is discussed, as well as some general questions in need of answers. This chapter also covers previous research on this topic as well as the contributions of this study.

Chapter 2 presents an introduction to roundabouts and the differences between them and other types of circular intersections. The three categories of modern roundabouts are described with a special focus on single-lane roundabouts and their geometric features. The advantages of roundabouts and roundabout policies are also covered. This chapter provides a detailed explanation of the geometric design of roundabouts taking context into consideration, as each site has its own unique goals and design objectives. The implementation of a roundabout in a new location is different than implementation in a location where the intersection is controlled by coordinated signals. This chapter also explains the planning-level sizing and space requirements. Sight distances are presented in more detail.

Chapter 3 presents a literature review for the first design objective of this study, safety performance, and explains the vehicular conflict points in roundabouts versus conventional intersections, emphasizing the reduced points in single-lane roundabouts vs. multi-lane roundabouts. This chapter provides evidence that roundabouts lead to increased road safety worldwide. The chapter also presents an intensive literature review regarding safety performance function modeling for various countries including the UK, Australia, France, Sweden, Italy, and the US. This part of the thesis explains the different types of safety performance functions including predicted speed models.

Chapter 4 presents a literature review for the second design objective of the thesis, mobility. This includes the introduction of entry capacity, and the two main factors that affect capacity, geometric characteristic and traffic conditions. This chapter covers the required data for modeling capacity and how to calculate roundabout traffic. This chapter also presents an in-depth 
literature review of international capacity modeling (US, UK, Australia, Germany and France). At the end of this chapter, the operational performance measures are presented including delay, queue length, and level of service.

Chapter 5 addresses the third design objective of this study, environmental sustainability, including an introduction of transportation environmental impact concerns followed by an extensive literature review of vehicle emissions modeling. This chapter covers three main categories of vehicle emissions modeling including the scale of the input, formulation, and main input variables modeling. The chapter presents the three main groups of the scale of the input modeling microscopic, mesoscopic, and macroscopic based on the size of the data aggregate. The corresponding software tool information is provided for each model.

Chapter 6 presents the development of the proposed model including the proposed methodology of this study, data preparation and roundabout traffic calculation, and modeling the three objectives (safety, mobility, and environmental sustainability). The first objective is represented by the total collision frequency using a safety performance function. The mobility objective is represented by the capacity, delay, and level of service. The capacity of roundabouts is modeled using the UK empirical model. The delay is determined and the level of service is defined. Environmental sustainability is represented by vehicle emissions. The specific power model is used to model vehicle emissions. All constraints are defined, and the objective function is developed. A solver is used to solve the model subjected to the defined constraints to minimize the total collisions, total delay, and total vehicle emissions.

Chapter 7 presents the model application including application examples, results and a discussion. In this chapter, the model is applied to an actual location, obtaining the optimal geometric parameters for a single -lane roundabout. The chapter includes two application examples for the same location. The first example involves the application of the model to the 
actual location with safety and environmental sustainability as design objectives. The second example involves the addition of mobility as a design objective.

Chapter 8 presents a summary of the study, conclusions and direction for future research. 


\section{Chapter 2 Roundabouts Overview}

\subsection{Introduction}

A roundabout is a type of intersection in which the traffic circulates counter clockwise around a central island, and the traffic entering the roundabout must yield to the circulating traffic (Rodegerdts et al., 2010). Modern roundabouts differ from the other circular intersections that have been a feature of the transportation system of the United States since the year 1905. The design of these large traffic circles or rotaries allows high speed entry as priority is given to the entering vehicles. Uncontrolled high entry speed leads to a high level of collisions in addition to a high delay. These safety concerns and the congestion at traffic circles led to the discontinuation of this kind of intersections in the US in the mid-1950s. The experience of traffic circles was internationally falling out of favor. Modern roundabouts were introduced in the United Kingdom as a solution to the problem. In 1966, they changed the rules at the existing traffic circles to give priority to the circulating traffic instead of the traffic entering the roundabout. Smaller circles have been proposed to allow geometric curvature limits the entering speed. These changes have improved the safety performance of roundabouts by decreasing the number and severity of collisions.

\subsection{Circular Intersection Types}

There are four types of circular intersections:

1. Roundabouts are a type of circular intersection that provide slow entry speed, and yield for the circulating traffic due to specific geometric features, improving safety and mobility.

2. Rotaries are large traffic circles with diameters as large as $100 \mathrm{~m}$ that were common in the US before 1966. The yield is given to the vehicles entering the rotary, and lane changes are required in order for the circulating traffic to maneuver the intersection. The large diameter allows for high entry and circulated speed, resulting in congestion and more collisions.

3. Signalized traffic circles are traffic circles that are controlled by a traffic sign which causes storing queue in a circulated way. 
4. Neighborhood traffic circles are small circles at local intersections that are uncontrolled or stop-controlled. These small traffic circles are constructed for traffic calming or esthetic reasons. The neighborhood traffic circles might not have a channelized approach or raised central islands, causing more conflict between vehicles

\subsection{Modern Roundabout Characteristics}

Modern roundabouts are characterized by distinguishing features that differentiate them from the traffic centers and ensure the desired speed. Some of the aspects of yield controlled roundabouts are shown in Figure 2-1:

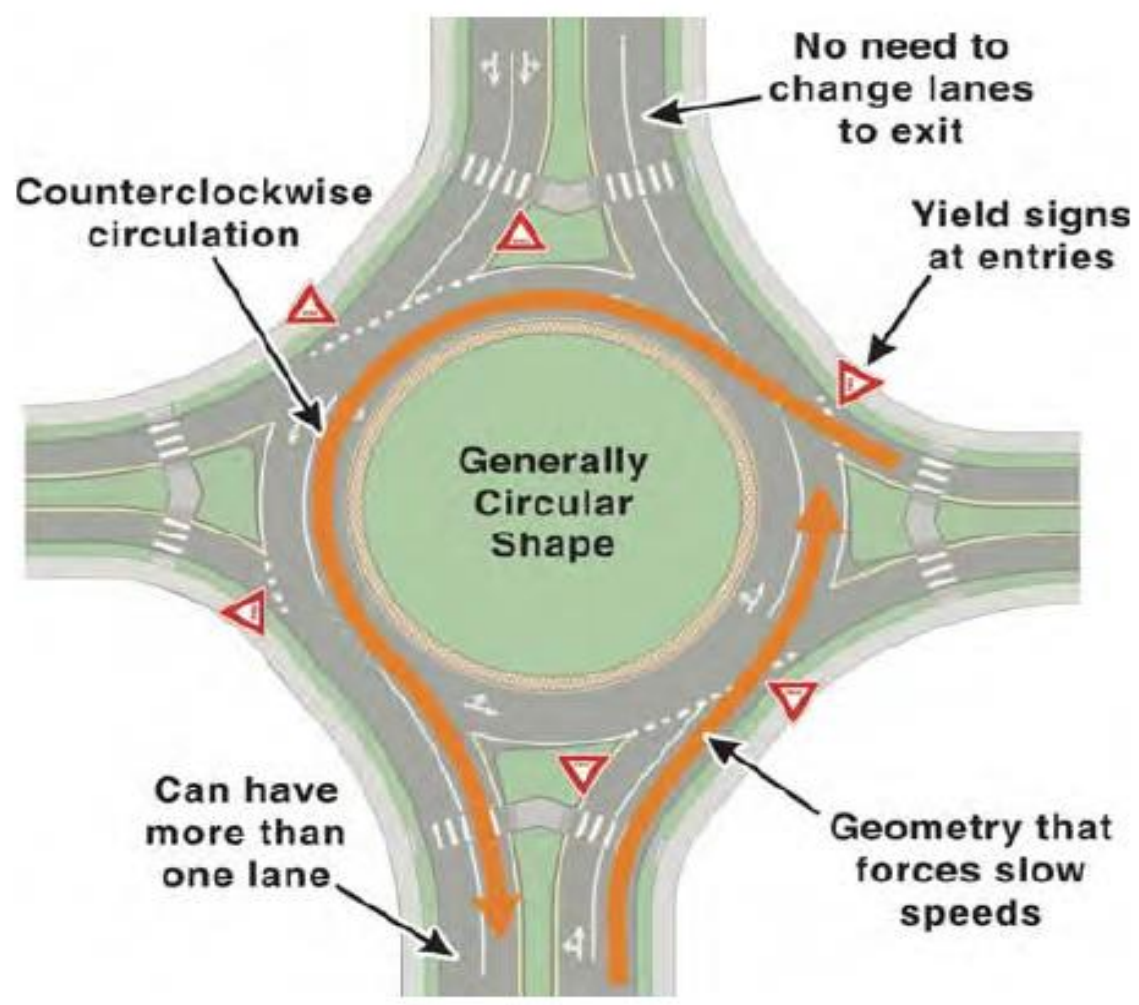

Figure 2-1 Distinguishing Characteristics of single-lane roundabouts

Source: (Rodegerdts et al 2010)

- All approaches are yield controlled to give priority to circulating traffic which ensures the desired speed and reduces conflicts. The slow speed for entering and circulating vehicles 
improves safety and mobility. In signalized roundabouts, traffic signs control some or all approaches.

- The traffic is directed in a counterclockwise direction like other circular intersections in the right-handed traffic system.

- The geometric curvature provided by the central island slows down the circulating speed of vehicles. Appropriate geometric curvatures for approach, entry, and exit curves is required to allow desirable speed for pedestrian crossing.

- Good roundabout design accommodates different design vehicles by adding an apron to the central island if it is needed.

\subsection{Modern Roundabouts Categories}

Roundabouts can be divided into three main categories based on the number of lanes and the size of the roundabout.

1. Mini-roundabout

A mini-roundabout is a small roundabout without a raised central island (the central island is traversable). This kind of roundabout is used on local streets with low speed limits. The features of a typical mini-roundabout are illustrated in Figure 2-2. They are constrained by the right of way and recommended if space cannot accommodate a design vehicle if a regular single-lane roundabout is used. Mini-roundabouts are pedestrian friendly due to their small size. The fully traversable central island is provided to accommodate larger vehicles such as buses. Marking and signs are used to direct drivers into the correct path without running over the central island. 


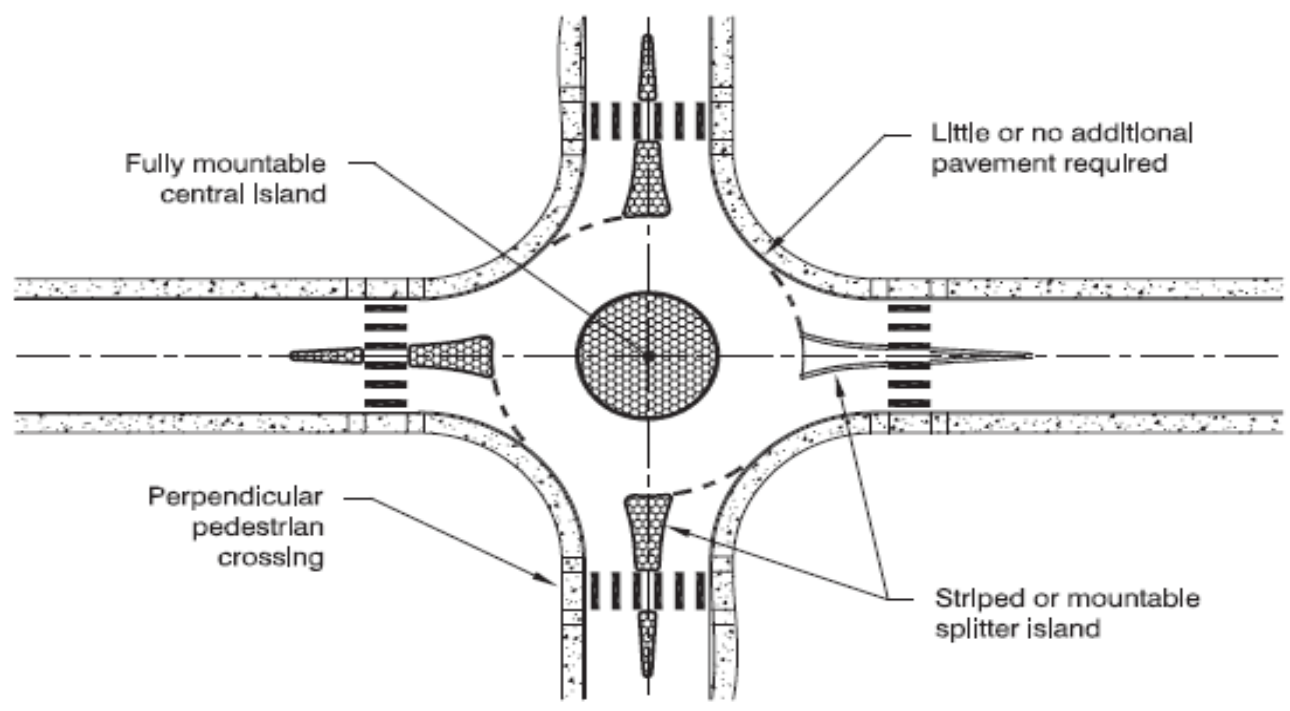

Figure 2-2: Typical mini-roundabout

Source: (Rodegerdts et al 2010)

2. Single-lane roundabout

A single-lane roundabout is distinguished by a single entry lane for all approaches and a single circulating lane. The single-lane roundabout differs from the mini- roundabout in that the central island is raised and is not traversable. The central island may have an apron that is traversable only by large vehicles that might not be accommodated by the circulating lane. The geometric design of single-lane roundabouts allows for a higher entering and exiting speed than the miniroundabout. Raised splitter islands is an aspect of single-lane roundabouts. The size of singlelane roundabouts corresponds to the design vehicles and the right of way. Figure 2-3 shows the typical geometric features of a single-lane roundabout. 


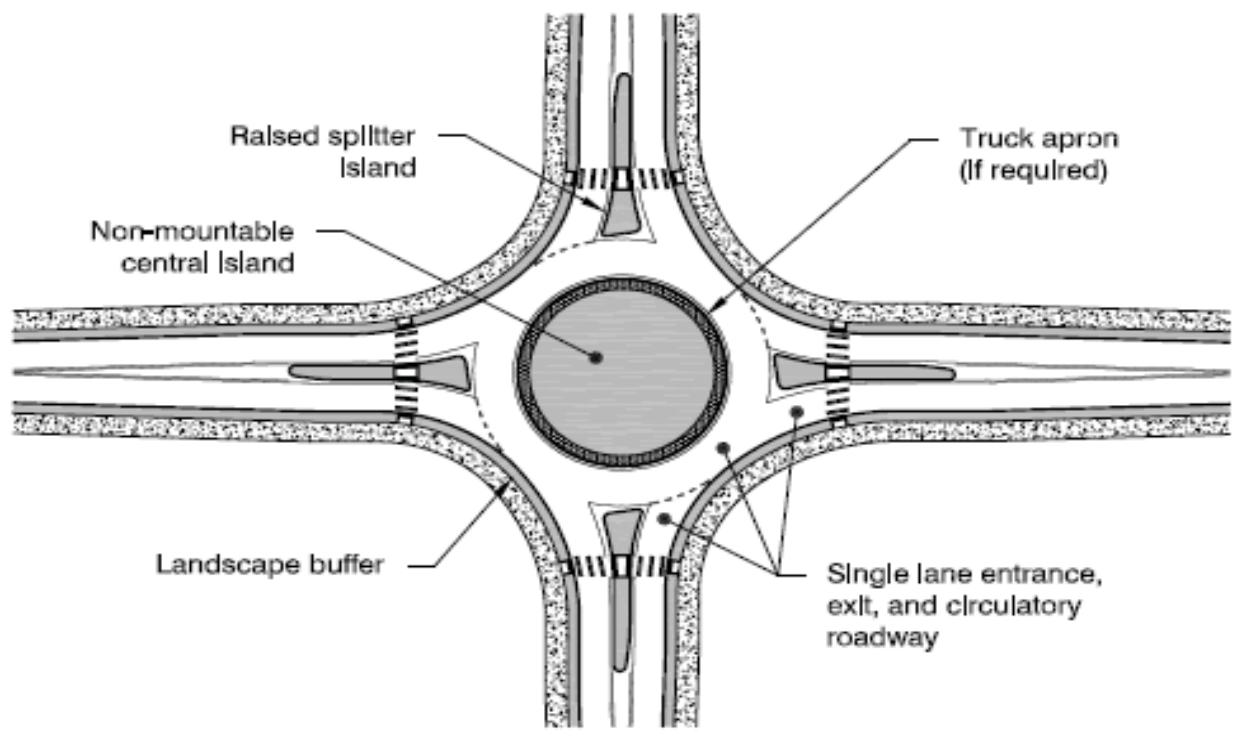

Figure 2-3: Typical single-lane roundabout

Source: (Rodegerdts et al 2010)

3. Multi-lane roundabout

This kind of roundabouts has more than one lane in one or more approaches; the number of lanes can also differ from approach to approach, depending on the traffic demand. For example, the major street might have more lanes than the minor street. A flare could be used to widen the entry of approaches if the approach half width was not enough to accommodate the entering traffic. The entering and exiting speed is approximately the same or slightly higher than singlelane roundabouts. Multi-lane roundabouts have more conflicts than single-lane roundabouts, resulting in safety concerns. Drivers might not be able to enter the appropriate lane, leading them to change lanes within the circulating way. Figure 2-4 shows the geometric aspects of multi-lane roundabouts (two-lanes and three-lanes). There are tradeoffs between safety and operational performance in this type of roundabout. 

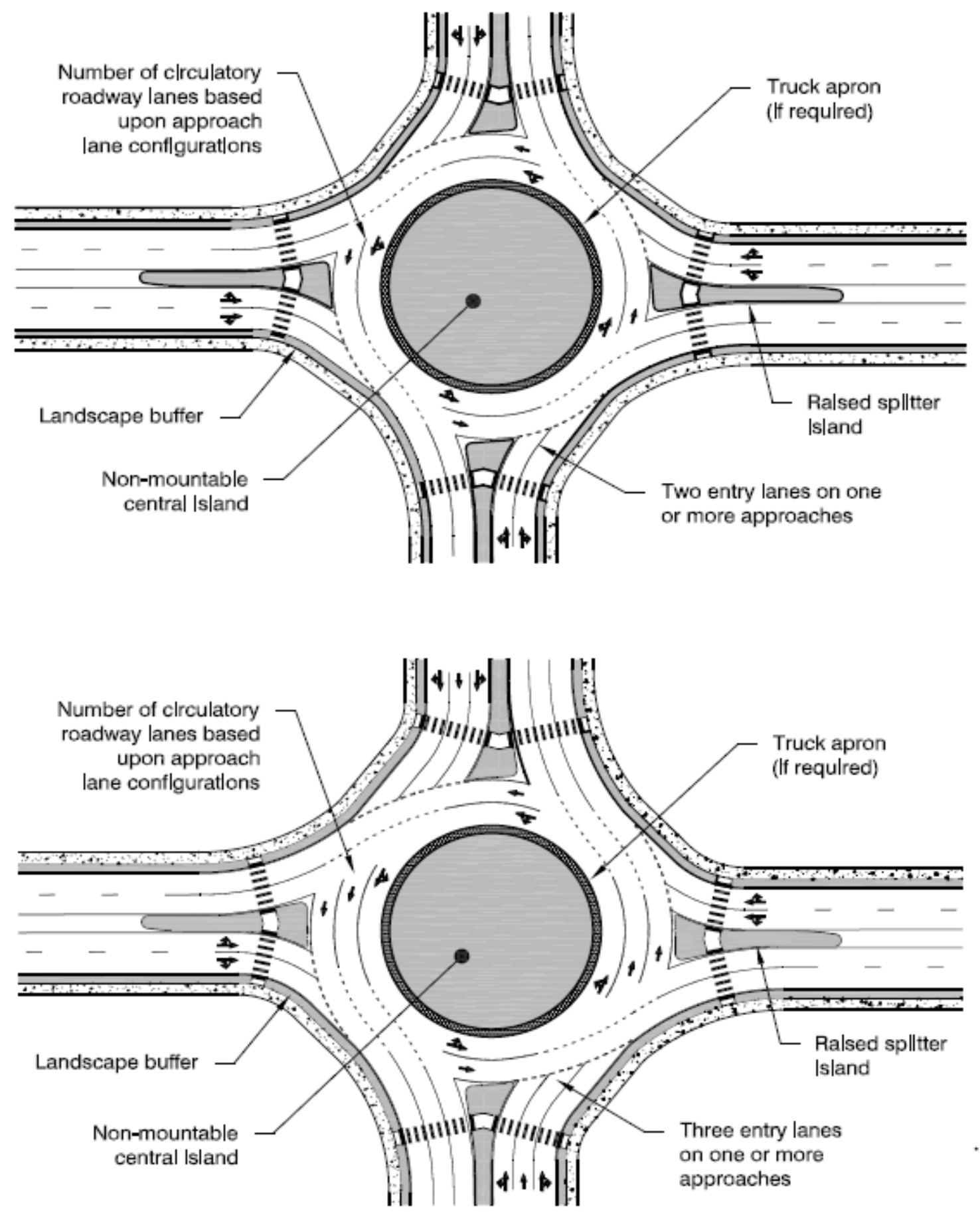

Figure 2-4: Typical multi-lane roundabout

Source: (Rodegerdts et al 2010) 
The characteristics of each type of roundabout are summarized in Table 2-1:

Table 2-1: Design characteristics of the three types of roundabouts

\begin{tabular}{|c|c|c|c|}
\hline Design Element & Mini-Roundabout & $\begin{array}{l}\text { Single-Lane } \\
\text { Roundabout }\end{array}$ & $\begin{array}{l}\text { Multi-lane } \\
\text { Roundabout }\end{array}$ \\
\hline $\begin{array}{l}\text { Desirable maximum entry } \\
\text { design speed }\end{array}$ & ( 25 to $30 \mathrm{~km} / \mathrm{h}$ ) & (30 to $40 \mathrm{~km} / \mathrm{h}$ ) & (40 to $50 \mathrm{~km} / \mathrm{h}$ ) \\
\hline $\begin{array}{l}\text { Maximum number of } \\
\text { entering lanes }\end{array}$ & 1 & 1 & $2+$ \\
\hline Typical inscribed center & (13 to $27 \mathrm{~m})$ & (27 to $55 \mathrm{~m}$ ) & (46 to $91 \mathrm{~m}$ ) \\
\hline Central island treatment & Fully traversable & $\begin{array}{l}\text { Raised (may have } \\
\text { traversable apron) }\end{array}$ & $\begin{array}{l}\text { Raised (may have } \\
\text { traversable apron) }\end{array}$ \\
\hline $\begin{array}{l}\text { Typical daily service } \\
\text { volumes on 4-leg } \\
\text { roundabout (without } \\
\text { detailed capacity analysis) }\end{array}$ & $\begin{array}{l}\text { Up to } \\
\text { approximately } \\
15,000\end{array}$ & $\begin{array}{l}\text { Up to } \\
\text { approximately } \\
25,000\end{array}$ & $\begin{array}{l}\text { Up to approximately } \\
45,000 \text { for two-lane } \\
\text { roundabout }\end{array}$ \\
\hline
\end{tabular}

Source: (Rodegerdts et al 2010)

The size of each roundabout type is determined by considering the design vehicle. The roundabout size is defined by the inscribed circle diameter which is the distance across the inscribed circle from the outer edges. The inscribed circle diameter is defined based on design objectives such as design vehicle, desirable speed, the available right of way, and the visibility of the construction cost.

Table 2-2: Inscribed circle sizes for roundabout categories based on design vehicle

\begin{tabular}{ccc}
\hline Roundabout Configuration & Typical Design Vehicle & Inscribed Circle Diameter \\
\hline Mini-Roundabout & SU-30 (SU-9) & (14 to 27 m) \\
\hline \multirow{2}{*}{ Single-Lane Roundabout } & B-40 (B-12) & (27 to $46 \mathrm{~m})$ \\
& WB-50 (WB-15) & (32 to 46 m) \\
& WB-67 (WB-20) & (40 to 55 m) \\
Multi-lane Roundabout & WB-50 (WB-15) & $(46$ to $67 \mathrm{~m})$ \\
(3 lanes) & WB-67 (WB-20) & (50 to 67 m) \\
\hline
\end{tabular}


Multi-lane Roundabout

(4 lanes)
WB-50 (WB-15)

WB-67 (WB-20)
(61 to $76 \mathrm{~m})$

(67 to $91 \mathrm{~m})$

Source: (Rodegerdts et al 2010)

\subsection{Roundabout Considerations}

Jurisdictions are seeking solutions to safety concerns and congestion issues associated with the different kinds of controlled intersections. Roundabouts appear to be a relief for high crash frequency intersections and low mobility. Roundabouts have become more popular due to several safety, mobility, and environmental advantages. The benefits and tradeoffs of roundabouts are summarized in the next section:

\section{- Non-Motorized Users}

Roundabouts provide many benefits for non-motorized users compared to other un-signalized intersections. Roundabouts provide a refuge for pedestrians through the raised splitter island which allows them to cross the way in two stages. Although the right of way is given to the vehicles, the controlled speed enhances the yield to pedestrians. Cyclists are other non-motorized users that can benefit from the features of roundabouts. They can use the crosswalk in high traffic locations, and can use the roundabout like vehicles in low traffic areas.

\section{- Safety}

Research has shown that the geometric features of roundabouts improve road safety by controlling speed and reducing collisions, especially fatalities. Roundabouts have less conflict between vehicles compared to other types of at-grade intersections. The geometric features of roundabouts provide users with more time, enhancing their decisions and detecting their errors. The safety performance is explained in more detail in chapter 3 .

\section{- Operations}

Gap acceptance is critical in the operation of roundabouts: entering vehicles detect acceptable gaps in the circulating traffic. The low speed of roundabouts assists in this gap acceptance

process. Roundabout capacity is greater at lower circulating speeds because when the circulating traffic is fast, the entering traffic comfortably accepts larger gaps which means fewer acceptable 
gaps and more waiting time for vehicles at the yield line. Roundabout operation and mobility are discussed in more detail in chapter 4.

- Environmental Factors

Intersections are the main source of air pollution due to the congestion and stop and go cycles. Roundabouts enhance mobility and decrease the delay, which leads to environmental benefits. Environmental sustainability is described in more detail in chapter 5.

- Traffic Calming

Roundabouts are an effective traffic calming tool. Geometric design is used to reduce vehicle speeds rather than using traffic control devices. Consequently, speed reduction can be a feature of these locations at all times of day and any traffic conditions.

- Space

Typically, roundabouts require less queue storage space on intersection approaches which helps reduce the right of way between intersection links. Roundabouts have more ability to accommodate wider sidewalks, parking, planter strips, or bicycle lanes on the approaches.

- Operation \& Maintenance

Roundabouts are highly cost-effective compared to signalized intersections since traffic signs are costly in construction and maintenance. Roundabouts require landscaping maintenance.

- Aesthetics

Roundabouts provide attractive entries to communities. Landscaping installed on the central islands and splitter islands is a desirable aesthetic feature. Some roundabouts have mounted art and monuments in a part of the central island. Textures and colors can be added to roundabout elements (such as truck aprons) to enhance the appearance of the intersection.

\subsection{Roundabout Policies}

In mid-1997, Jacquemart (1998) published a study entitled "NCHRP Synthesis of Highway Practice 264: Modern Roundabout Practice in the United States". This study reported the construction of 50 roundabouts. The roundabout practices in the USA were updated by Alek et al. (2016). Alek identified that approximately 3,200 roundabouts were in use throughout the USA 
in 2013. The recent study summarized roundabout policies and practices within the US department of transportation (DOTs), focusing on roundabout selection.

A 2010 study reviewed the statewide roundabout policies of roundabouts using information available online through the department of transportation web pages and other roundabout agencies. The study identified six categories of roundabout policies (Pochowski, 2010). The recent study by Alek et al. (2016) combined two of the six policy categories into one ("Strong" and "Justify" were combined into one category named "Preferred.").

The five roundabout policy categories with an example for each policy are listed below:

1. None

None means there is no policy or mention of roundabouts by the state DOT. Roundabouts are neither encouraged nor discouraged.

2. Allow

The consideration of roundabouts is allowed by the state. For example, Kentucky has an "allow" policy which states "A modern roundabout is an alternative form of intersection control to traffic signals and [multiway] stop control intersections. Therefore, roundabouts may be only considered when these intersection control types are warranted."

3. Encourage

The state encourages the consideration of roundabouts. For example, Connecticut has an "encourage" policy which states "Those locations that meet or nearly meet [signal] warrants should be given consideration for roundabout installation.

Intersections that are, or proposed to be, all-way stop controlled may also be good candidate locations for a roundabout."

4. Evaluate

A roundabout alternative evaluation is required. For example, Georgia has an "evaluate" policy which states "Roundabouts are the preferred safety and operational alternative for a wide range of intersections of public roads. A roundabout shall be considered as an alternative in the following instances: (1) Any intersection in a project that is being designed as new or is being reconstructed. (2) All existing intersections that have been identified as 
needing a major safety or operational improvements. (3) All signal requests at intersections (justify the Traffic Engineering Study if a roundabout is not selected)."

5. Preferred

The state requires a roundabout alternative evaluation and a justification if a roundabout is not the preferred alternative. For example, New York has a "preferred" policy which states "When the analysis shows that a roundabout is a feasible alternative, it should be considered the Department's preferred alternative as a result of the proven substantial safety benefits and other operational benefits."

The Alek et al. (2016) study has surveyed the US country in which state adopt these policies, and they reported the results as shown in Table 2-3.

Table 2-3 Summary of roundabout policies in the USA

\begin{tabular}{ccc}
\hline Policy type & No of states & Percentage \\
\hline None & 7 & 14 \\
\hline Allow & 13 & 25 \\
\hline Encourage & 18 & 35 \\
\hline Evaluate & 8 & 16 \\
\hline Preferred & 5 & 10 \\
\hline
\end{tabular}

Source: (Alek et al 2016)

As shown in Table 2-3, over 50\% of US states allow or encourage the implementation of roundabouts which helps explain the increase in the installation of roundabouts.

\subsection{Roundabout Design}

Roundabout design involves several stages beginning with the planning stage and ending with the final design. The next section summarizes the roundabout design process.

\subsubsection{Planning}

At the planning stage, the planner evaluates whether or not the roundabout is considered as an alternative. As previously stated, more than $50 \%$ of US states have policies that allow or encourage the use of roundabouts. There are several reasons for considering a roundabout as an improvement for a given intersection. At the planning stage, planners usually answer some questions including whether or not a roundabout is an effective choice for this particular 
intersection. If the answer is yes, the next step would be determining the size of the roundabout. These questions are answered based on several criteria.

\subsubsection{Consideration of context}

Planners need to make sure that a roundabout is an appropriate choice for the given location and this decision is made by considering the environment surrounding the location. Planners should consider the context in several ways.

\subsection{Decision environment}

Each specific location has its own unique environment. The three following situations must be taken into account by planners:

1. A new roadway system

A new roadway system has fewer constraints than an existing road. In a new roadway system, the right-of-way is usually not a concern. It is likely that the new road system is faced by private development and the public; in this case, coordination between public and private interest should be addressed.

2. The first roundabout in an area

Usually, the first roundabout in an area gains a high level of public interest. In this case, it is best to have an implementing agency paying attention to operational and design features to keep the public interest. There are some important considerations for this kind of decision environment:

- It is important to gain public support for the decision by communicating the effectiveness of roundabout selection to the public. Public acceptance and understanding are important.

- Convincing the public that a roundabout will benefit the community is an important goal to achieve. Collecting data about steak-holders is the key to addressing their needs and any potential problems. A conservative approach may be appropriate.

- A single-lane roundabout would be easier to understand for a first roundabout.

- The choice of design and analysis procedures can be a reference for roundabout implementation in the future. The planning and design procedures should therefore be done in collaboration with other regional agencies. 
- Following the construction, evaluating and documenting the performance and the impact on the public would help in future implementations.

3. Environment where roundabouts have already gained acceptance

This environment requires a design that fits the specific site problems and addresses the needs of the location. Since there is already public acceptance of roundabouts, the next step involves operational performance.

\subsection{Site-specific conditions}

Each location has its unique specifications, concerns, and design objectives. The optimal alternative is the one that provides a balance between all objectives and needs. The optimal control choice will be the one that best balances those objectives. The following considerations should be made when assessing a roundabout selection decision:

- Physical constraints such as right-of-way limitations, drainage problems, utility conflicts, and geometry may be barriers in roundabout implementation. Different types of traffic may impact the decision. Oversized vehicles might have difficulties negotiating the roundabout. The available space is another important factor in the decision-making process.

- Other surrounding traffic control devices such as railway crossings might conflict with the installation of a roundabout. These devices can create a queue which acts as a barrier to the operational performance of the roundabout.

- The nearby bottlenecks can cause traffic to accumulate in the roundabout, causing a queue in the roundabout approaches. The satisfactory operational performance of a roundabout depends on unsaturated traffic flow in the roundabout circulatory roadway.

- The of two different traffic flows, a major arterial and a minor arterial or local road, could result in a delay for the major street as roundabouts give the two streets the same priority, unlike stop-controlled intersections.

- Heavy pedestrian or bicycle flow affect roundabout operational performance.

- When using a coordinated signal network, signalized intersections perform better than roundabouts, reducing the delay in the through movement delay in the whole artery. 


\subsubsection{Planning -level sizing and space requirements}

At the planning stage, the roundabout size is determined based on the traffic volume that must be accommodated. The different roundabout types were presented in the beginning of chapter 2 . This section explains how to choose the type of roundabout and the number of lanes.

\subsection{Lane requirements}

The four different volume ranges are identified in Figures 2-5. The volume ranges represent volume thresholds that characterize different roundabout types. The figure defines when one-lane or two-lane roundabouts operate acceptably without the need for detailed evaluations. Ranges are presented for roundabouts that still require detailed analysis. This method offers a simple approximate approach with some conditions:

- The ratio of peak-hour to daily traffic $(\mathrm{K})$ of 0.09 to 0.10 ,

- Direction distribution of traffic (D) of 0.52 to 0.58 ,

- The ratio of the minor street to total entering traffic of 0.33 to 0.50 , and

- The acceptable volume-to-capacity ratio of 0.85 to 1.00 .

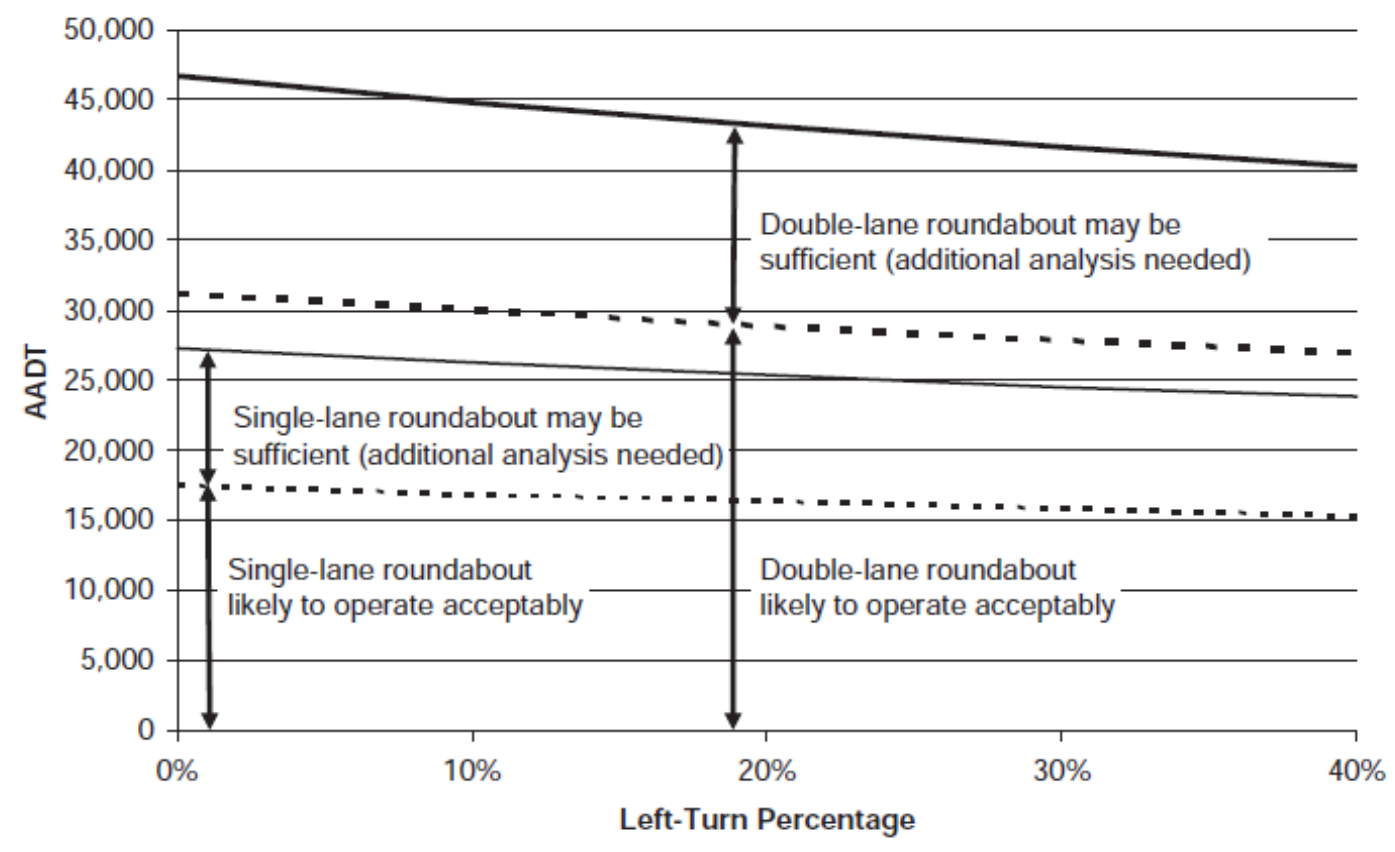

Figure 2-5: Planning -level lane configuration

Source: (Rodegerdts et al 2010) 
Another approximate approach involves using the sum of the entering (ve) and conflicting ( $v c)$ traffic volumes in roundabout lane configurations. As shown in Table 2-4, if the sum of the entering and conflicting traffic is less than $1000 \mathrm{veh} / \mathrm{hr}$., a single-lane roundabout might perform efficiently. If the sum of the entering and conflicting traffic is between 1000 and 1300, the single-lane roundabout may be sufficient, but a more detailed evaluation is required to confirm the performance.

Table 2-4: Traffic flow ranges for roundabout lane configurations

\begin{tabular}{|c|c|}
\hline $\begin{array}{c}\text { Volume Range } \\
\text { (sum of entering and conflicting } \\
\text { volumes) } \\
\end{array}$ & Number of Lanes Required \\
\hline 0 to $1,000 \mathrm{veh} / \mathrm{h}$ & - Single-lane entry likely to be sufficient \\
\hline 1,000 to $1,300 \mathrm{veh} / \mathrm{h}$ & $\begin{array}{l}\text { - Two-lane entry may be needed } \\
\text { - Single-lane may be sufficient based upon more } \\
\text { detailed analysis. }\end{array}$ \\
\hline 1,300 to $1,800 \mathrm{veh} / \mathrm{h}$ & - Two-lane entry likely to be sufficient \\
\hline Above $1,800 \mathrm{veh} / \mathrm{h}$ & $\begin{array}{l}\text { - } \quad \text { More than two entering lanes may be required } \\
\text { A more detailed capacity evaluation should be } \\
\text { conducted to verify lane numbers and } \\
\text { arrangements. }\end{array}$ \\
\hline
\end{tabular}

Source: (Rodegerdts et al 2010)

\subsubsection{Geometric Design}

There are common principles and objectives involved in the design of roundabouts. The general goals are:

- Provide slow entry speeds and maintain speed consistency throughout the roundabout.

- Provide the required number of lanes to accommodate the traffic demand and provide acceptable operational performance.

- Provide smooth channelization that guides drivers into the paths intended by the designer.

- Provide an adequate size to accommodate the design vehicles.

- Design to meet the needs of all users including pedestrians and cyclists. 
- Provide adequate visibility and sight distance to help drivers avoid conflict.

A good roundabout design should provide a balance between the above design objectives because increasing the focus on one objective can cause a trade-off in the other objectives. Each location has specific goals and objectives. Figure 2-6 shows the general geometric features of roundabouts.

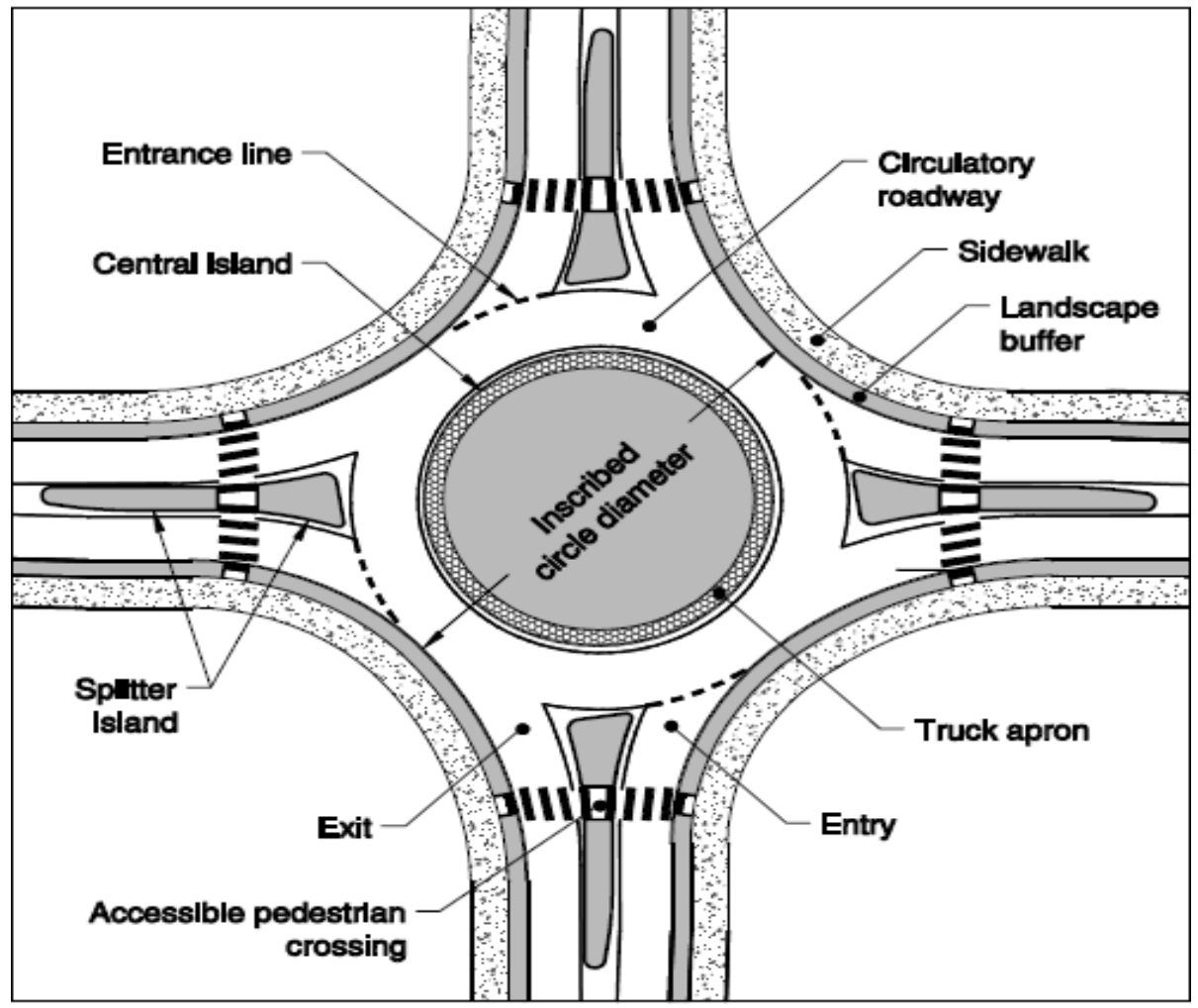

Figure 2-6: General roundabout geometric parameters

Source: (Rodegerdts et al 2010)

\subsubsection{Geometric elements of a single-lane roundabout}

Single-lane roundabouts have the best safety performance since they minimize conflicts between traffic streams. Approximately 71\% of all roundabouts constructed in the US until 2013 were single-lane roundabouts (Pochowski 2016). It is therefore necessary to develop an optimization model for this type of roundabout that can determine the optimal geometric 
parameters that satisfy site-specific conditions. In the planning stage, the designers determine the design objectives based on the unique conditions of each site. Each site has its own issues and specific objectives. If the location is within a sensitive environmental area, more weight will be assigned to vehicle emissions to improve air quality at that location. Sometimes the implementation of roundabouts is required mainly to improve intersection safety due to the increase in annual collisions. In this case, safety performance will be the main design objective. The following section explains the geometric aspects of single-lane roundabouts in more detail. 1. Inscribed circle As explained in the previous section, the inscribed circle is the key aspect of geometric design that significantly affects all of the design measurements including speed, entry capacity, and other geometric parameters. The inscribed circle size is highly dependent on the design vehicle. After determining the inscribed circle diameter, it is necessary to confirm that it accommodates the turning requirements of the design vehicle. As shown in Table 2-2, the inscribed circle diameter of a single-lane roundabout should be a minimum of $32 \mathrm{~m}$ to accommodate the design vehicle WB-50. Smaller inscribed circles can be used on the local streets where the design vehicle is a single unit truck or bus. In a location that needs to accommodate large design vehicles such as WB-76, the inscribed circle should be between 40 and 46m.

\section{Splitter island}

Each single-lane roundabout should have a raised splitter island. The functions of splitter islands include: to protect pedestrians; to add curvature to help reduce speed; to guide traffic in the appropriate path; storage for pedestrians to cross the roundabout in two stages; mounting signs. Figure 2-7 shows the typical minimum splitter island dimensions including crosswalk details. At the initial design stage, an adequate splitter island envelop should be considered before approach entry and exit design to be certain that the minimum requirements of the splitter island are met. As shown in the figure, the crosswalk-sit back should be at least $6 \mathrm{~m}$ which is enough to store a passenger car before the yield line. The splitter island width at the crosswalk should be a minimum of $1.8 \mathrm{~m}$ to provide refuge to pedestrians including those pushing a stroller, walking a bike, or using a wheelchair. A study conducted by the Queensland Department of Main Roads 
found that providing the desirable width of splitter islands improved safety by minimizing entering/circulating vehicle crash rates (Arndt \& Troutbeck, 1998). The tradeoff of increasing splitter island width is the high construction cost as increasing the splitter island width requires an increase in the inscribed circle width (Rodegerdts et al., 2010).
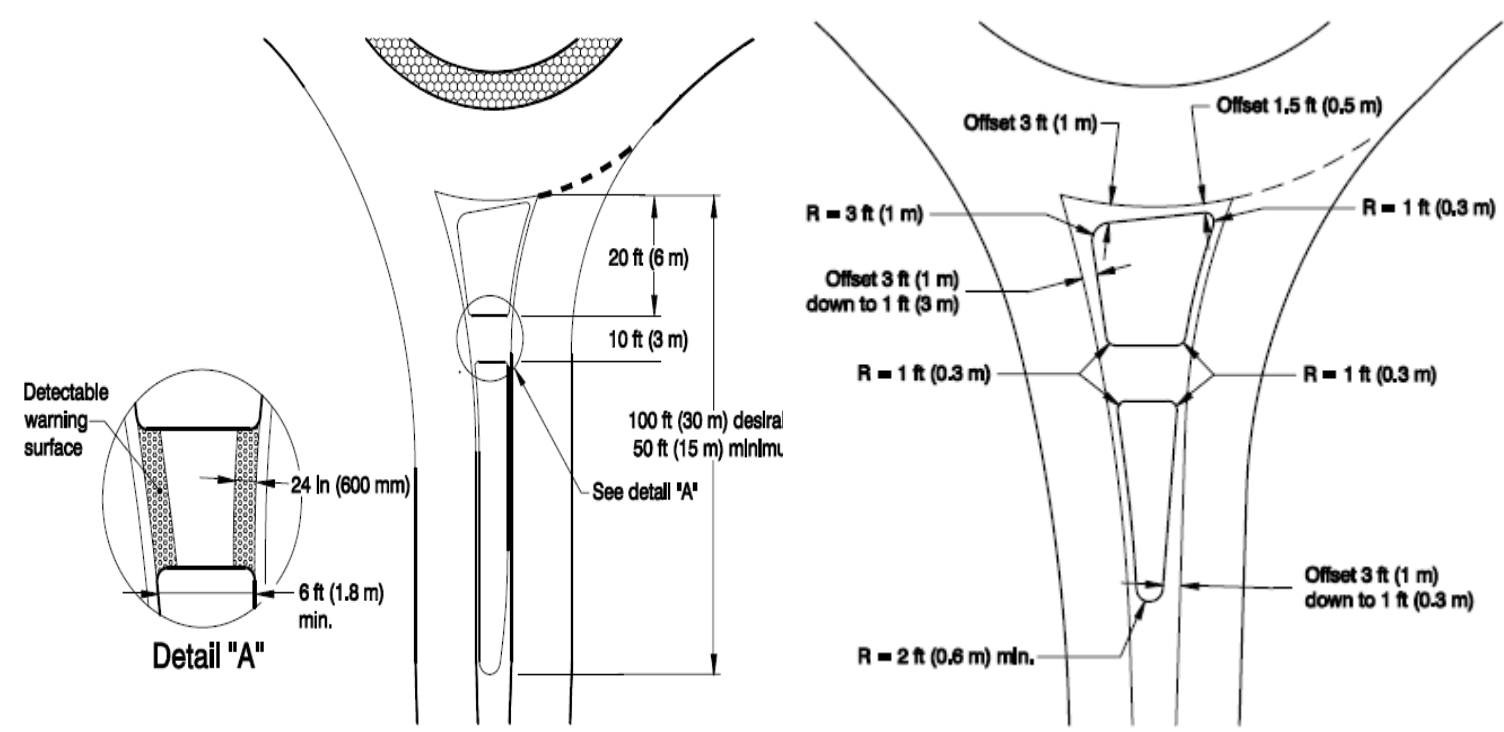

Figure 2-7: Typical minimum splitter island

Source: (Rodegerdts et al 2010)

\section{Entry width}

The entry width is measured from the point of intersection between the outer edge of the inscribed circle and the inner edge of the approach to the outer edge of the approach entry perpendicular to the approach entry, as shown in Figure 2-8. Single-lane entrances typically range from 4.2 to $5.5 \mathrm{~m}$ (Rodegerdts et al., 2010). An entry width that exceeds the circulating width should be avoided as drivers might misinterpret the width and consider it two lanes while the receiving circulating way is only one lane. 


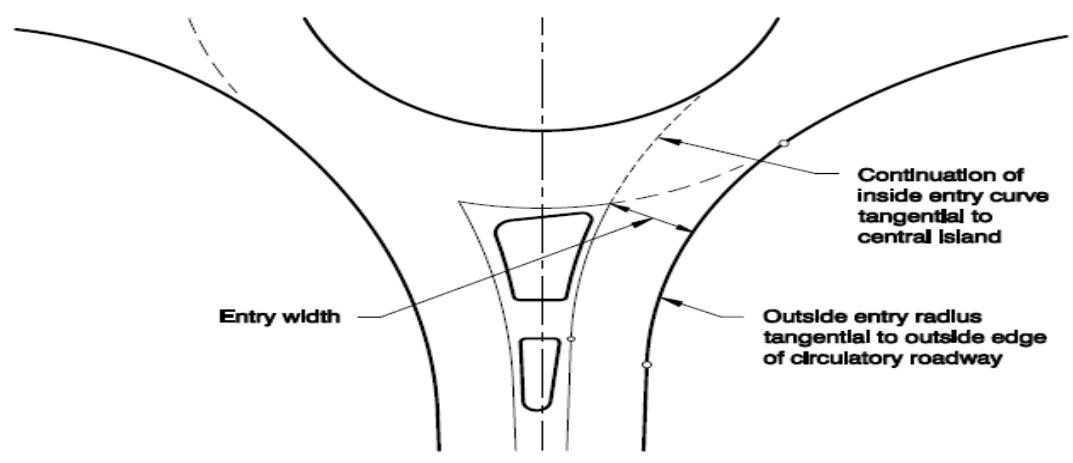

Figure 2-8: Single lane entry design

Source: (Rodegerdts et al 2010)

\section{Exit width}

The exit width is measured from the point of intersection between the outer edge of the inscribed circle and the inner edge of the approach to the outer edge of the approach entry perpendicular to the approach exit, as shown in Figure 2-9. The exit radii should be large enough to avoid congestion, and appropriate to control exit speed for crossing pedestrians. The exit radii should be a minimum of $15 \mathrm{~m}$ (Rodegerdts et al., 2010). The outer exit curve is designed tangential to the outer edge of the circulating way. Likewise, the inner exit edge is designed tangential to the inner edge of the circulating way.

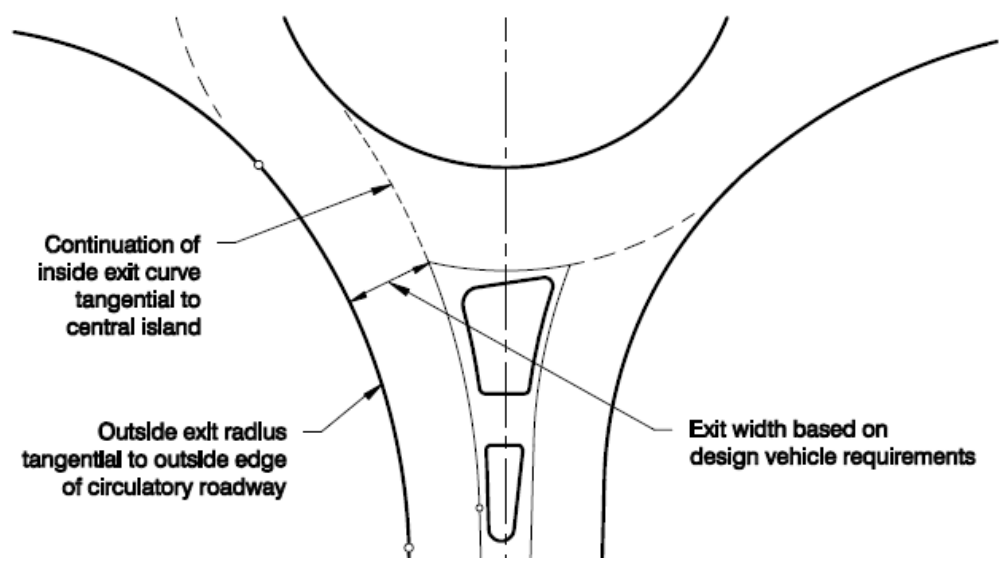

Figure 2-9: Single-lane exit design

Source: (Rodegerdts et al 2010) 


\section{Central island}

The central island of a single-lane roundabout is the non-traversable raised area characterized by the circulatory roadway. Sometimes a part of the central island is traversable if a truck apron is provided. The central island enhances driver recognition of the roundabout and is landscaped for aesthetic purposes. Raised central islands are preferred for single-lane roundabouts, as depressed central islands allow drivers to use it as a traversable area and drainage is a concern. A circular central island is preferred over the oval island as the constant curvature of the circle assists in providing a constant circulating speed throughout the circulated way. In oval islands, the speed is higher in the flatter area.

\section{Circulating width}

Circulating width is measured by the difference between the radius of the inscribed circle and the central island .In a single-lane roundabout, the circulated width is typically constant. It should be more than the maximum entry width of all approaches, and should not exceed the maximum entry by more than $20 \%$. Therefore, drivers interpret the circulated road as one lane.

\section{Truck aprons}

The truck apron is a part of the central island that is traversable by trucks but discourages passenger cars from travelling on it. This part should be constructed using different materials in order for drivers to be able to recognize it easily. Truck aprons assist in maintaining appropriate deflection by keeping a reasonable inscribed circle diameter. They should range between 1 and $4.6 \mathrm{~m}$ wide with a cross slope of $1 \%$ to $2 \%$ down to the circulatory road and a raised outer edge (50 to $75 \mathrm{~mm}$ ) above the circulatory roadway surface (Rodegerdts et al., 2010).

\subsubsection{Speed Management}

Maintaining the desired speed at the roundabout is a critical design objective as many researchers have linked speed to safety. Slow speed at roundabouts provides comfort for all users including drivers negotiating the roundabout, pedestrians, and cyclists.

\subsubsection{Appropriate Path Alignment}

Path alignment issues arise in multi-lane roundabouts as vehicles travel side by side. Drivers have less comfort when driving side by side in curves such as ramps and interchanges. The 
situation is similar in multi-lane roundabouts and overlapping is a critical concern. Good design of multi-lane roundabouts ensures that vehicles entering and exiting the roundabout are on the right path. Vehicle overlap occurs when the natural path of one movement conflicts with another movement path. Path overlapping has a negative effect on roundabout performance in two ways: 1) it reduces the roundabout capacity as drivers may avoid traveling side by side, and 2) it creates safety issues causing crashes. Overlapping most commonly occurs when left lane traffic is cut off by the right lane traffic due to inappropriate entry path or exit path, as shown in Figure 2-10.

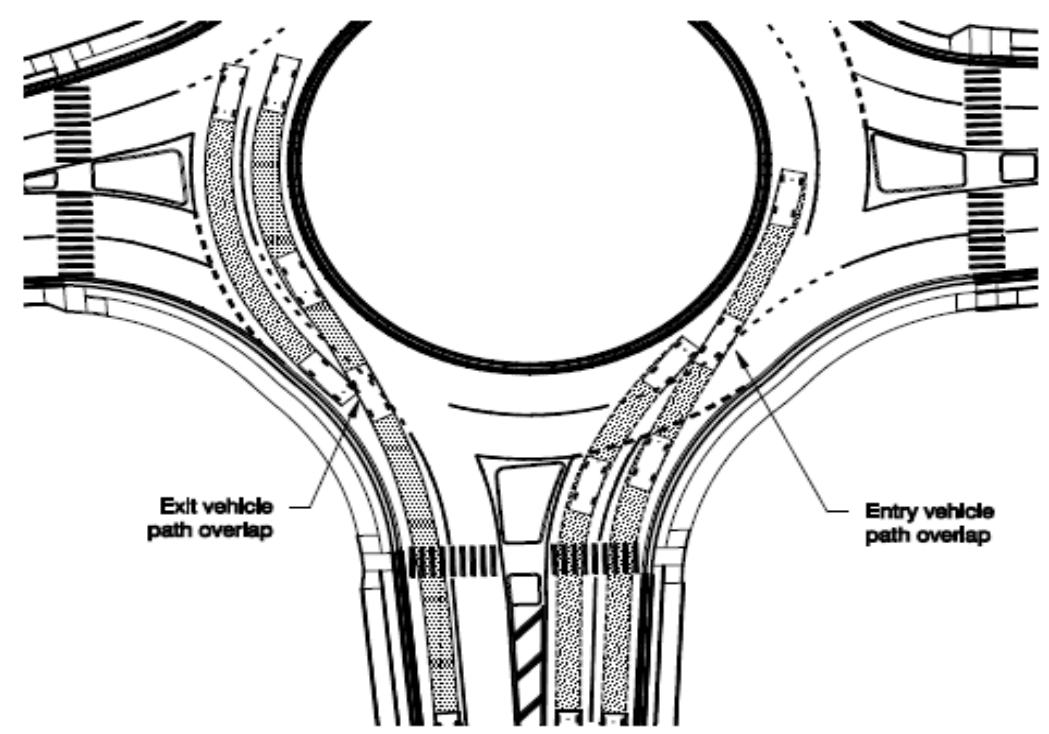

Figure 2-10: Path overlap at a multi-lane roundabout

Source: (Rodegerdts et al 2010)

\subsubsection{Design Vehicle}

Another important concern that should be addressed is the design vehicles that are going to use the intersection. The design vehicle defines the roundabout size. Good roundabout design accommodates the design vehicle well, especially large trucks. There is CAD-based program that assesses the vehicle turning path to make sure that the designed roundabout can accommodate the design vehicles. Failing to consider this factor may cause difficulties for large vehicles using the roundabout. Truck aprons are provided in order to accommodate large vehicles, especially in 
single-lane roundabouts. Without them, the vehicle would encroach the outer curb, causing safety concerns.

\subsubsection{Non-Motorized Design Users}

A well- designed roundabout should consider the non-motorized users to be as important as vehicles. Those users such as cyclists, strollers, pedestrians, skaters, and wheelchair users should be taken into account in the design of the geometric features of roundabouts. Table 2-5 shows different users with their approximate dimensions and the affected geometric parameters.

Table 2-5: Different vehicles dimensions and the effected roundabout feature

\begin{tabular}{ccc}
\hline User & Dimension & Affected Roundabout Features \\
\hline $\begin{array}{c}\text { Bicyclist } \\
\text { Length }\end{array}$ & $5.9 \mathrm{ft}(1.8 \mathrm{~m})$ & $\begin{array}{c}\text { Splitter island width at crosswalk } \\
\text { Bike lane width on approach roadways; } \\
\text { shared use path width }\end{array}$ \\
\hline $\begin{array}{c}\text { Minimum operating width } \\
\text { Pedestrian (walking) }\end{array}$ & $4 \mathrm{ft}(1.2 \mathrm{~m})$ & Sidewalk width, crosswalk width \\
Width & $1.6 \mathrm{ft}(0.5 \mathrm{~m})$ & Sidewalk width, crosswalk width \\
Wheelchair user & & Sidewalk width, crosswalk width \\
Minimum width & $2.5 \mathrm{ft}(0.75 \mathrm{~m})$ & \\
\hline Operating width & $3.0 \mathrm{ft}(0.90 \mathrm{~m})$ & Splitter island width at crosswalk \\
\hline Person pushing stroller & $5.6 \mathrm{ft}(1.70 \mathrm{~m})$ & Sidewalk width \\
\hline Length & $6 \mathrm{ft}(1.8 \mathrm{~m})$ & \\
\hline Typical operating width & & \\
\hline
\end{tabular}

Source: (Rodegerdts et al 2010)

\subsubsection{Sight Distances and Visibility}

Visibility is critical for safety in roundabouts. When designing roundabouts, both the stopping sight distance and intersection sight distance need to be considered. Both sight distances should be provided at any point of the roundabout. 


\subsection{Stopping Sight Distance}

Stopping sight distance is the distance required for a driver to safely stop when they perceive a hazard along the roadway. The stopping sight distance consists of the distance traveled within the perception-reaction time and the braking distance, as given by Equation 2.1

$$
d=1.468 * t * V+1.087 \frac{V^{2}}{a}
$$

Where,

$d=$ stopping sight distance, $\mathrm{ft}$;

$t=$ perception-brake reaction time, assumed to be $2.5 \mathrm{~s}$;

$V=$ initial speed, $\mathrm{mph}$; and

$a=$ driver deceleration, assumed to be $11.2 \mathrm{ft} / \mathrm{s} 2$.

\subsection{Intersection Sight Distance}

Intersection sight distance is the distance required for a driver to perceive and react towards a conflicting vehicle without taking the right of way into consideration. In roundabouts, entries are the only locations that need to check the intersection sight distance. Figure 5.7 shows the triangles of intersection sight distance at a roundabout. The distances $\mathrm{d} 1$ and $\mathrm{d} 2$ are given by Equations 2.2 and 2.3 respectively. 


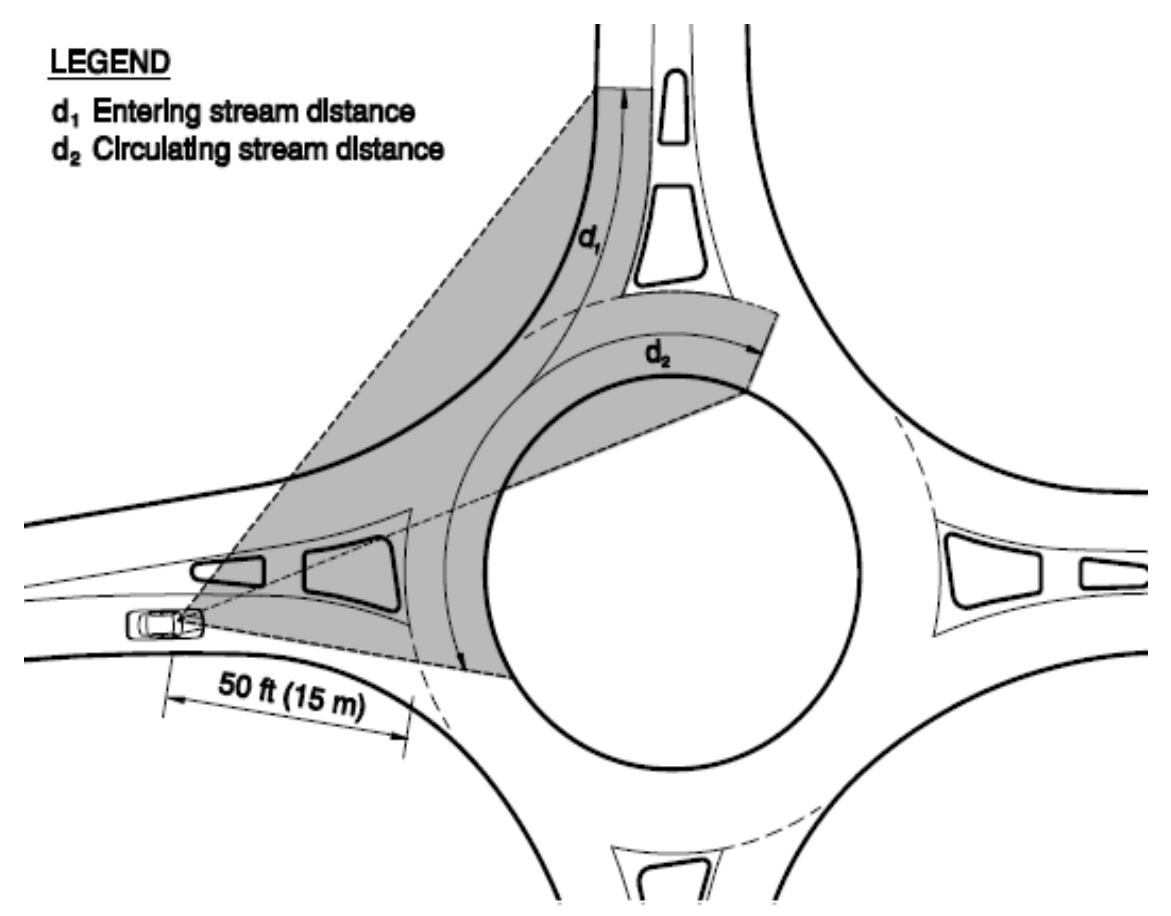

Figure 2-11: Intersection sight distance

Source: (Rodegerdts et al 2010)

$$
\begin{gathered}
d_{1}=1.468 * V_{\text {major,entering }} * t_{c} \\
d_{2}=1.468 * V_{\text {major,circulating }} * t_{c}
\end{gathered}
$$

Where,

$d 1$ = length of entering leg of sight triangle, $\mathrm{ft}$;

$d 2=$ length of circulating leg of sight triangle, $\mathrm{ft}$;

$V \_$major $=$design speed of conflicting movement, $\mathrm{mph}$, and

$t_{c}=$ critical headway for entering the major road, $\mathrm{s}$, equal to $5.0 \mathrm{~s}$.

\subsection{Alignment}

Roundabout approach leg alignment is an important factor in roundabout safety and in controlling speed. The alignment affects the visibility, the deflection that controls speed, and 
design vehicle accommodation. Three alignment options are shown in Figure 2.12: offset alignment to the left of the center, offset alignment to the right of the center, and alignment through the center of the roundabout. Each option has its advantages and trade-offs.

1. Offset alignment to the left of the center

The advantages of this option include the accommodation of large vehicles with a small inscribed circle, the control of speed by providing deflection, and the reduction of the impact on the right side. On the other hand, it is associated with trade-offs such as increasing the exit radius and consequently increasing the exit speed, causing a safety concern for pedestrians at the exit. 2. Offset alignment to the right of the center This option is not common and might be used at larger inscribed diameters in order to improve view angles and reduce impact. This strategy increases the exit curvature which might affect the roundabout capacity and cause delay. Providing speed control in this option is difficult.

3. Alignment with the center of the roundabout

This strategy is the most desired alignment as it keeps the impact centred in the intersection and allows for some curvature at the exit to maintain a slow speed near pedestrians. One of the tradeoffs is that it may require a slightly bigger inscribed circle diameter.
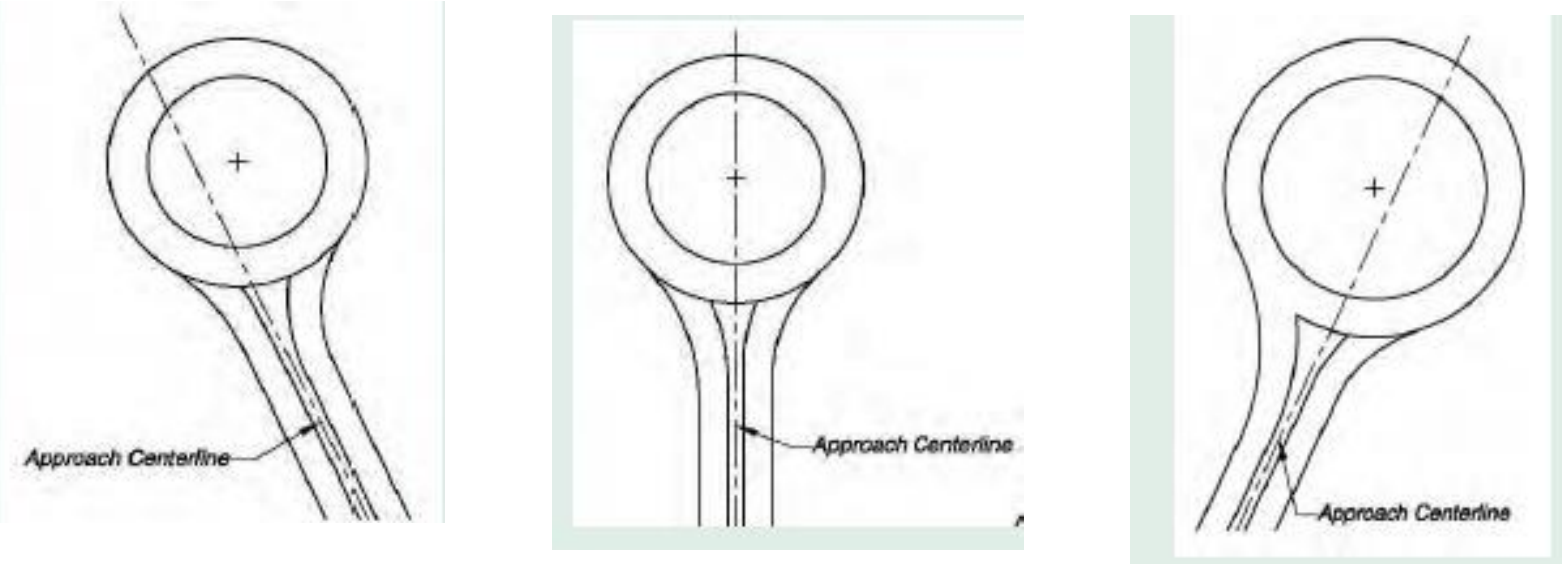

Figure 2-12: Various roundabout alignment options

Source: (Rodegerdts et al 2010) 


\subsection{Angle between approaches}

As with other another kinds of intersections, the angle between roundabout legs is important. It is preferable for legs to intersect at a right angle. There are two situations which designers should avoid: 1), designing two legs intersecting at an angle significantly greater than $90^{\circ}$, or 2) designing two legs intersecting at an angle significantly less than $90^{\circ}$. The first situation results in high speed at one or more of the right turns, and the second approach causes difficulties for large trucks navigating the turn. Figure 5-9 shows the fastest vehicle fastest path in the two
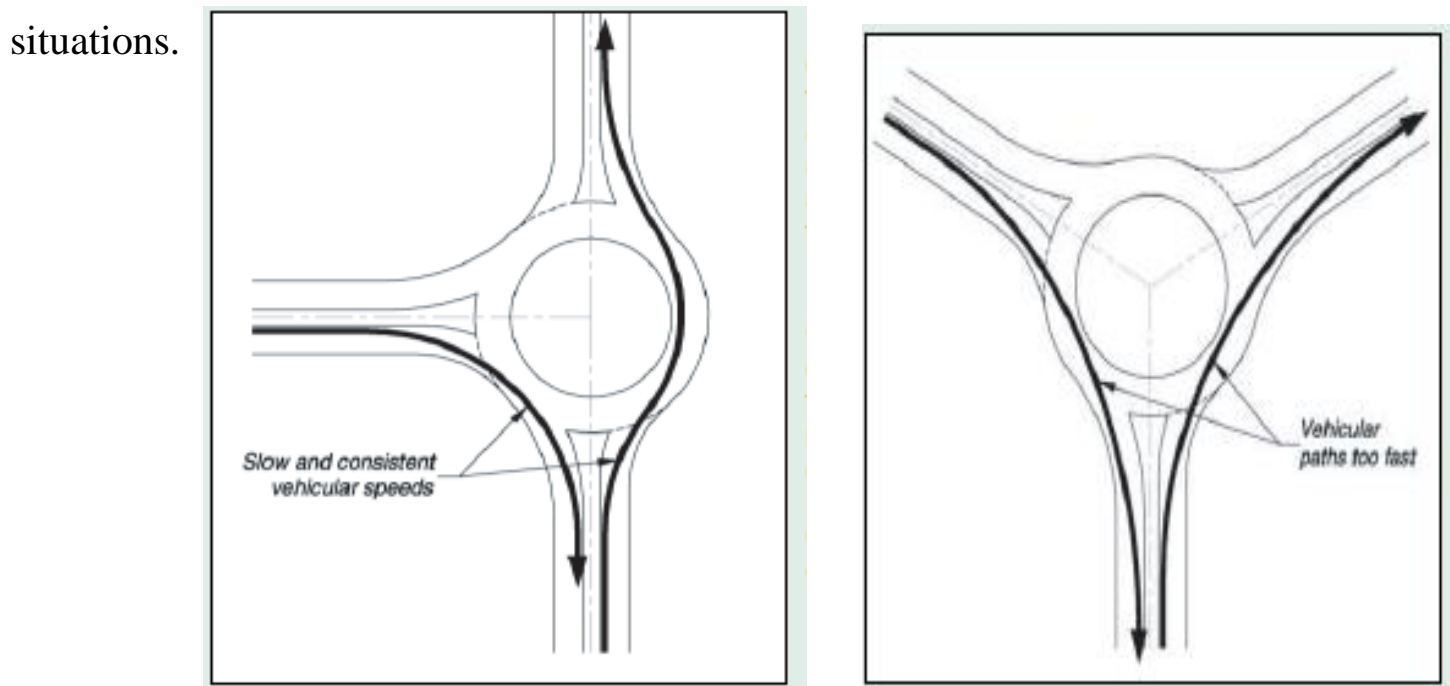

Figure 2-13: Angle between roundabout legs

Source: (Rodegerdts et al 2010) 


\section{Chapter 3 Safety Literature Review}

\subsection{Introduction}

Designers are always looking for new types of controlled intersections in order to improve intersection safety. Roundabouts are one type of controlled intersection which provides significant improvements in intersection safety. One study found that converting a conventional intersection to a roundabout reduced fatal collisions by $50 \%$ to $70 \%$, and injury collisions by $30 \%$ to $50 \%$ (Elvik, 2003). Another study found a significant reduction in vehicle collisions when converting stop sign control and traffic signal intersections into modern roundabouts. The results revealed a 38\% reduction for all collisions, a 76\% reduction for injury collisions, and a 90\% reduction for fatal collisions (Retting et al., 2001).

The reasons for the significant safety improvement at roundabouts are:

- The vehicular conflict points at roundabouts are lower than at conventional intersections. The high-severity conflict points are also reduced.

- The controlled speeds in roundabouts provide drivers with more time to detect potential conflicts and reduce the severity of potential crashes, making fatalities and serious injuries extremely limited at roundabouts.

- The geometry of roundabouts forces a constant low speed and the constant speed results in no relative speed between drivers. Low or no relative speed reduces the severity of crashes.

- Pedestrians receive refuge by crossing only one direction at a time using the splitter island. The two stage pedestrian crossing reduces conflicts between vehicles and pedestrians. In addition, the entering and exiting low speed give drivers more time to react to and yield to pedestrians

\subsection{Vehicular conflicts in roundabouts vs. conventional intersections}

As explained above, one of the main reasons behind the high safety performance of roundabouts is the reduction of conflict points. Figure 3-1 shows the conflict points in a single-lane three leg roundabout compared to a conventional T-intersection. As the figure shows, the vehicular conflict points are reduced from nine to six in a roundabout. 

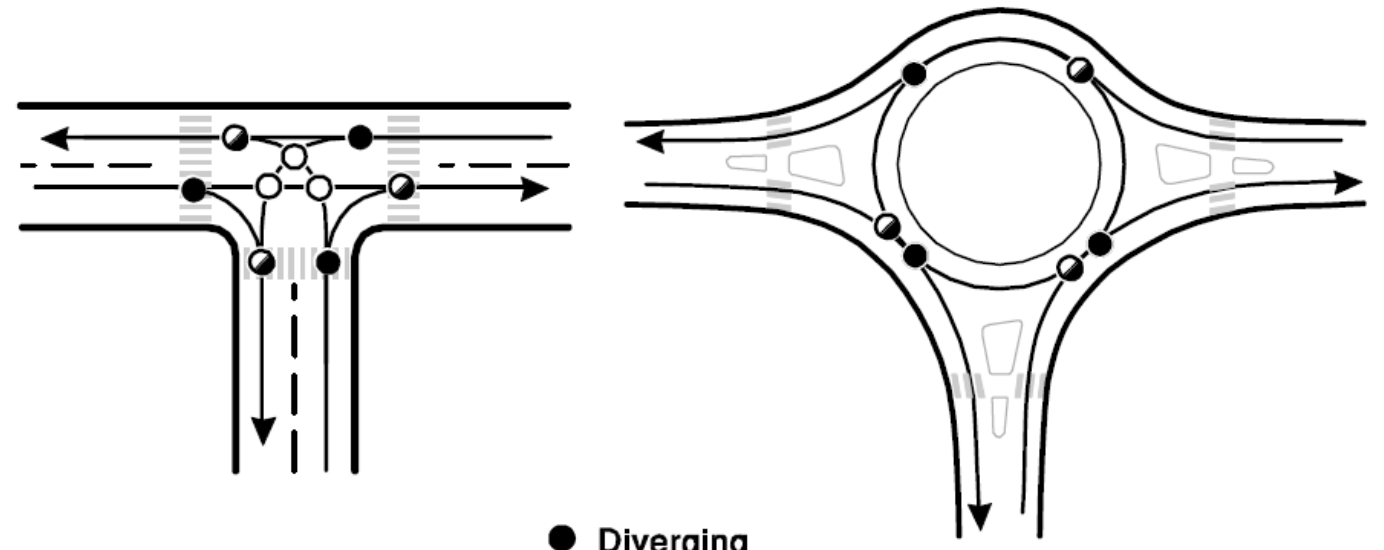

- Diverging

Merging

Crossing

Figure 3-1: Conflict points in single-lane T-intersections

Source: (Rodegerdts et al 2010)

Figure 3-2 illustrates the vehicle-vehicle conflict points in a 4-leg single-lane roundabout. As the figure shows, the conflict points are reduced from thirty-two in the conventional intersection to as low as eight in the roundabout. This is not the case for the multi-lane roundabouts where the number of conflict points is much higher. This is why single-lane roundabouts are preferable over multi-lane roundabouts, and the reason behind the high safety performance of single-lane roundabouts. 

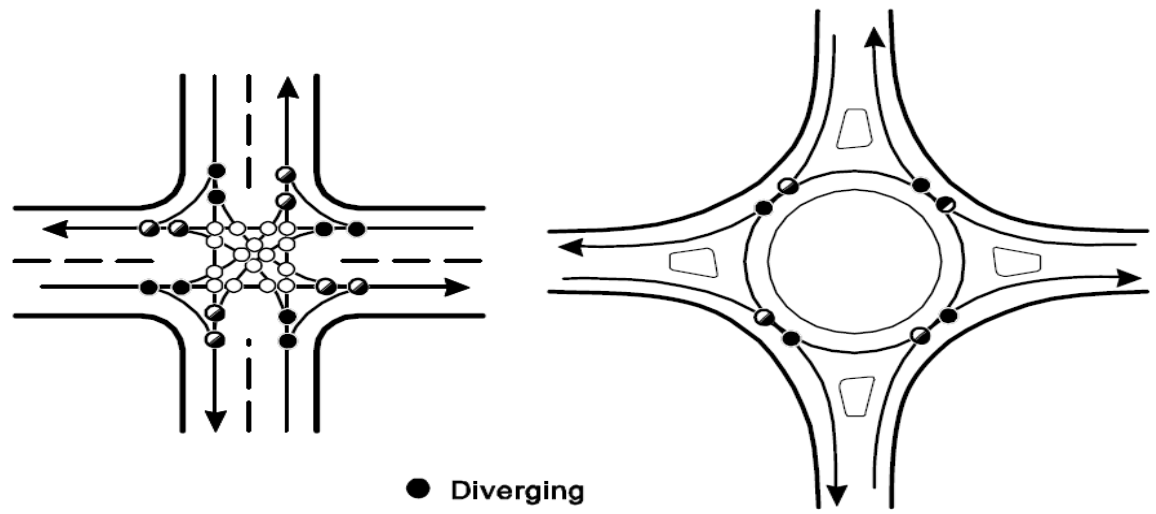

- Diverging

- Merging

Crossing

Figure 3-2: Conflict points in single-lane 4 legs-intersections

Source: (Rodegerdts et al 2010)

The decreased conflict points in single-lane roundabouts enhances the level of safety in this type of roundabouts, unlike multi-lane roundabouts where there are more points of conflict and lane recognition is more complex. Figure 3-3 illustrates the crashes rate of single-lane roundabouts vs. multi-lane roundabouts. As shown in the figure, single-lane roundabouts perform much better from a safety perspective.

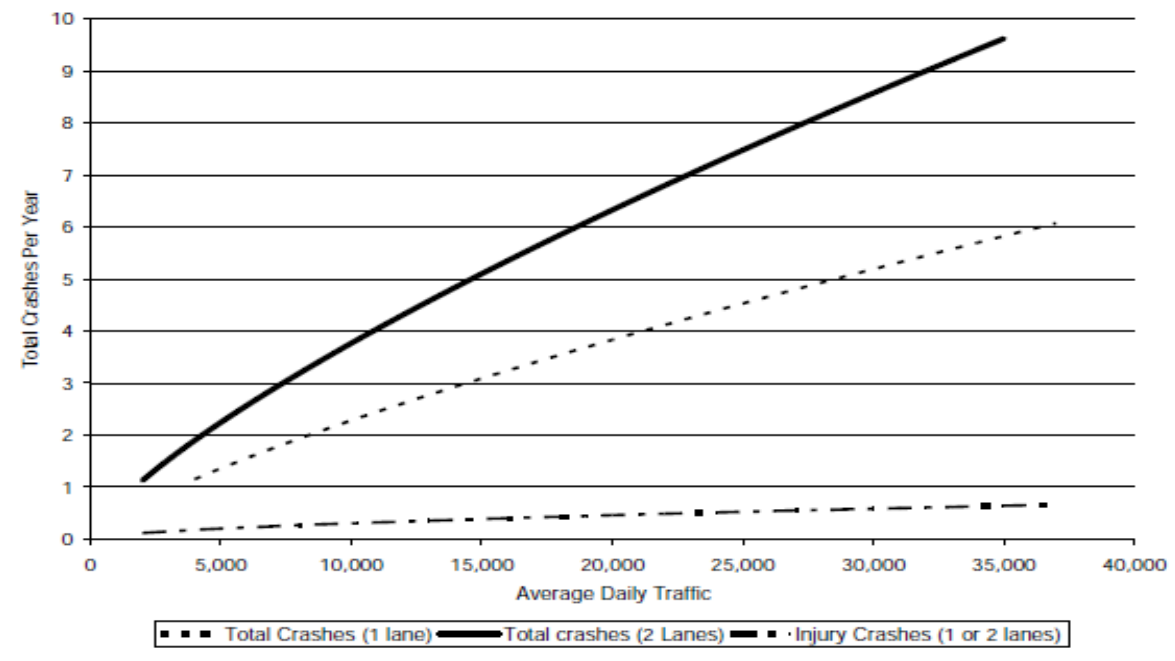

Figure 3-3: Total and Injury Crash Experience for U.S. Roundabouts with Four

Source: (Rodegerdts et al 2010) 
The conflict points are divided into four categories of conflict and each type of conflict is characterized by the severity of contact:

1. Queuing conflicts

These conflicts result when a vehicle runs into another vehicle from behind while queueing on an approach. Queuing conflicts can occur at through-movement, queue back, or near left-turning vehicles.

2. Diverging conflicts

These conflicts are caused when two traffic streams separate. An example of a diverging conflict is right turns diverging from through movements in conventional intersections or exiting vehicles diverging from circulating vehicles in roundabouts. When the relative speed between the two movements is low, the risk of rear-end collisions decreases.

3. Merging conflicts

These conflicts arise when two traffic streams, such as right turns or left turns, join with the upstream through vehicles. This kind of conflict usually causes rear-end and sideswipe crashes. Diverging conflicts might be less severe than merging conflicts because the front and rear of vehicles are more protected than the sides.

\section{Crossing conflicts}

These conflicts occur when the paths of two traffic movements intersect. This is often the case in conventional intersections between minor and major street streams, causing the most severe collisions (fatalities and injuries). The most common types of collision are right-angle and headon crashes. This type of crash is avoided in roundabouts but they occur at signalized intersections when drivers violate traffic signs, or at controlled intersections if drivers ignore the stop sign. Therefore, single-lane roundabouts demonstrate the ability to reduce conflicts through physical and geometric features. 


\subsection{Roundabout crash types}

It is important for designers to study details regarding crash types and where they occur in roundabouts. Table 3-1 shows the main crash types and percentages found in a U.S. study of detailed crash reports of 39 roundabouts. As the table shows, over half of the crashes involved entering or exiting vehicles. In single-lane roundabouts, $80 \%$ of these crashes involved enteringcirculating crashes, while in multi-lane roundabouts, $68 \%$ involved exit-circulating crashes (Rodegerdts et al. 2007).

Table 3-1: Crash types at US roundabouts

\begin{tabular}{cc}
\hline Crash Type & Percentage \\
\hline Entering-Circulating & 23 \\
\hline Exiting-Circulating & 31 \\
\hline Rear-End on Leg & 31 \\
\hline Loss of Control of Leg & 13 \\
\hline Pedestrian & 1 \\
\hline Bicycle & 1 \\
\hline
\end{tabular}

Source: (Rodegerdts et al 2007)

\subsection{Safety Prediction Models}

\subsubsection{United Kingdom Model}

The Transportation Research Group of the University of Southampton conducted a study of the safety performance of 4-leg roundabouts on behalf of the UK government for the Transport and Road Research in the mid-1980s (Maycock \& Hall, 1984). The researchers used 84 four-leg roundabouts on main streets in the UK. They examined accident history over the period of six years (from 1974 to 1979). The geometric parameters and traffic data were collected. The purpose of this study was to link safety to geometric parameters. The researchers categorized the 84 four-leg roundabouts in two main categories divided based on the roundabout speed (from 30 to $40 \mathrm{mph}$ and from 50 to $70 \mathrm{mph}$ ) and the geometric parameters (size, small roundabout, normal single-lane, and normal dual-lane).

They also categorized crashes into different types:

- Entering-circulating accidents 
The accidents between an entering vehicle and a circulating vehicle.

- Approaching accidents

Mostly rear-end accidents and accidents resulting from lane changes.

- Single-vehicle accidents

A single vehicle hitting some part of the intersection or roadside construction.

- Other accidents

- Pedestrian accidents

Any accident involving a pedestrian.

The models were created in two stages. The first stage involved linking the predicted accidents to the geometry through the size categories, as shown in Table 3-2.

Table 3-2: UK Safety Predicted Models

\begin{tabular}{cccc}
\hline Speed limit & Small & $\begin{array}{c}\text { Normal-Single } \\
\text { Carriageway arms }\end{array}$ & $\begin{array}{c}\text { Normal-One pair of } \\
\text { Dual- Carriageway } \\
\text { arms }\end{array}$ \\
\hline 30-40mph & $\begin{array}{c}A=0.101 Q^{0.68} \\
(25 \text { sites })\end{array}$ & $\begin{array}{c}A=0.057 Q^{0.68} \\
(11 \text { sites })\end{array}$ & $\begin{array}{c}A=0.057 Q^{0.68} \\
(14 \text { sites })\end{array}$ \\
\hline $50-70 \mathrm{mph}$ & $A=0.181 Q^{0.68}$ & $A=0.080 Q^{0.68}$ & $A=0.061 Q^{0.68}$ \\
$(11$ sites $)$ & $(11$ sites $)$ & $(12$ sites $)$
\end{tabular}

Source: (Maycock \& Hall, 1984)

Where,

$Q=$ cross-product flow function

$Q=($ major $\mathrm{AADT}) / 1000 *($ minor $\mathrm{AADT}) / 1000$,

$\mathrm{A}=$ injury accidents per year.

In the second stage of the analysis, the researchers tried to link the specific geometric parameters for each arm to the predicted accidents. Full geometric data for the 78 roundabouts was collected to form 312 data units. The model conducted in stage two is given by Equation

$$
A=Q a \alpha Q b \beta \exp \left(\sum \gamma i j+\sum \varepsilon i G i\right)
$$

Where $A=$ accident frequency, in accidents per year; 
$Q a, Q b=$ functions of the vehicle and pedestrian flow movements;

$D_{j, i}(j=2, n)=$ dummy variables representing the 2 nd to $n$th level of each discrete factor;

$G i=$ continuous variables (e.g., flow proportions, geometric variables); and

$k, \alpha, \beta, \gamma_{i j}, \varepsilon i=$ model parameters estimated from the data.

The geometric variables and other factors were added to the models in a step by step procedure. At each step, the most effective variable or factor was selected from all variables. These choices are based on the variable sensitivity and statistical validity.

The full models are presented in the ARCADY software.

\subsubsection{Australian Model}

Two studies were conducted by Arndt (1994 and 1998). Arndt modeled the $85^{\text {th }}$ percentile speed for vehicle paths, as shown in Figure 3-4.

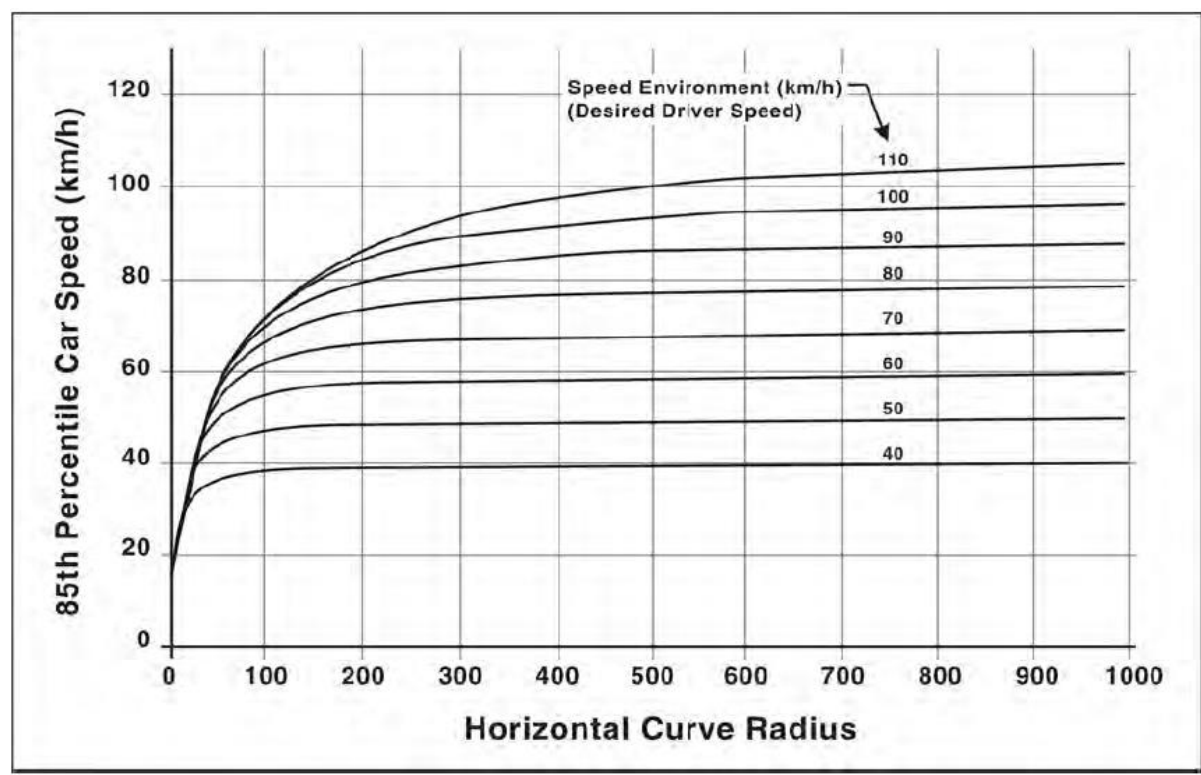

Figure 3-4: Australian Speed Model

Source: (Arndt, 1998) 
Arndt used the speed model to predict different types of accidents:

- Accident Model for Single Vehicles:

$$
A s p=\frac{1}{R^{1.91}} *\left[1.64 * 10^{-12} Q^{1.17} L(S+\Delta S)\right]
$$

Where,

$A_{s p}=$ number of single vehicle accidents per year per leg for vehicle path segments before the give way line;

$A_{s a}=$ number of single vehicle accidents per year per leg for vehicle path segments after the give way line;

$Q=$ AADT in direction considered;

$L=$ length of vehicle path on the horizontal geometric element (m);

$\mathrm{S}=85$ th-percentile speed on the horizontal geometric element $(\mathrm{km} / \mathrm{h})$;

$\Delta S=$ decrease in 85th-percentile speed at the start of the horizontal geometric element $(\mathrm{km} / \mathrm{h})$;

and

$R=$ vehicle path radius on the horizontal geometric element $(\mathrm{m})$.

- Accident Model for Approaching Rear-End Vehicles:

$$
A r=1.81 * 10^{-18} Q a^{1.39}\left(\sum Q c i\right)^{0.65} \mathrm{Sa}^{4.77} \mathrm{Na}^{2.31}
$$

Where,

$A r$ = number of approaching rear-end vehicle accidents per year per approach leg;

$Q_{a}=\mathrm{AADT}$ on the approach;

$Q c i=$ circulating vehicle AADTs from the other approaches;

$S_{a}=85$ th-percentile speed on the approach curve $(\mathrm{km} / \mathrm{h})$; and

$N a=$ number of lanes on the approach. 
- Accident Model for Entering-Circulating Vehicles:

$$
A_{e}=\frac{1}{t_{G a}^{0.21}} *\left(7.31 * 10^{-7} Q_{a}^{0.47} N_{c}^{0.9}\left(\sum Q_{c i}\right)^{0.41} S_{r a}^{0.21}\right)
$$

Where,

$A_{e}=$ number of entering-circulating vehicle accidents per year per approach leg;

$Q_{a}=\mathrm{AADT}$ on the approach;

$N_{c}=$ number of circulating lanes;

$\sum Q_{c i}=$ sum of the circulating vehicle AADTs from the other approaches;

$\operatorname{Sra}=\frac{\sum Q_{c i} S_{r i}}{\sum Q_{c i}}$

$T_{G a}=\frac{\sum Q_{c i} t_{G i}}{\sum Q_{c i}}$

$S r i=$ the various relative 85 th-percentile speeds between vehicles on the approach curve and circulating vehicles from each direction $(\mathrm{km} / \mathrm{h})$;

$t_{G i}=$ the various travel times are taken from the give way line of the approach to the intersection point between the entering and circulating vehicles;

$t_{G i}=3.6 d_{g i} / S_{c i}$

$d_{G i}=$ distance from the give way line of the approach to the intersecting point between entering and circulating vehicles $(\mathrm{m})$; and

$S_{c i}=$ the various 85 th-percentile speeds of the circulating vehicles adjacent to the approach $(\mathrm{km} / \mathrm{h})$.

- Accident Model for Sideswipe Vehicles:

$$
A_{s S}=6.49 * 10^{-8}\left(Q Q_{t}\right)^{0.72} \Delta f_{l}^{0.59}
$$

Where,

Ass $=$ number of sideswipe vehicle accidents per leg per vehicle path segment;

$Q=$ AADT for the particular movement on the particular geometric element; 
$Q_{t}=$ total AADT on the particular geometric element; and $\Delta_{f l}=$ difference in potential side friction $(\mathrm{km} / \mathrm{h} 2 / \mathrm{m})$.

- Accident Model for Other Vehicles:

$$
A_{o}=4.29 * 10^{-6} \sum Q_{a}
$$

Where,

$A_{O}=$ number of "other" accidents per year; and

$Q_{a}=$ AADT on approach $a$.

\subsubsection{France Model}

The French model does not consider geometric parameters as variables for predicting the total number of injury accidents in roundabouts. The model applies to roundabouts with entering traffic between 3,200 and 40,000 veh/day (SETRA, 1998). The model is given in Equation 3.7

$$
A=0.15 * 10^{-5} Q_{T E} F_{C}
$$

Where,

$\mathrm{A}=$ the accident rate,

$Q_{T E}=$ total daily incoming traffic; and

$F_{c}=$ adjustment coefficient for the period under consideration.

\subsubsection{Sweden Model}

A study in Sweden (Brüde and Larsson, 2000) surveyed about 650 roundabouts in 1997 and categorized them based on speed, geometric parameters, and other variables. Accident and traffic volumes of vehicles, bicycles, and pedestrians were available from 1994 to 1997. An analysis of accidents involving cyclists and pedestrians was conducted for 72 and 182 roundabouts, respectively, and another analysis of vehicle accidents was conducted. The researchers conducted a speed analysis for 536 roundabouts.

$$
A_{1}=0.1353 * 0.86^{3 \text { leg }} * 1.88^{\text {speed } 70} * 1.2^{\text {2lanes }}
$$


Where,

$\mathrm{A}=$ accident rate;

3 leg $=1$ if 3-legged, 0 if 4-legged;

speed $70=1$ if speed limit is $70 \mathrm{~km} / \mathrm{h}, 0$ if $50 \mathrm{~km} / \mathrm{h}$; and

2lanes $=1$ if there are 2 lanes in the roundabout, 0 if there is one.

$$
A_{2}=0.1130 * 0.92^{3 \text { leg }} * 1.84^{\text {speed } 70} * 1.17^{\text {2lanes }} * 1.4^{\text {loclow }}
$$

Where,

3 leg = 1 if 3-legged, 0 if 4-legged;

peed70 = 1 if speed limit is $70 \mathrm{~km} / \mathrm{h}, 0$ if $50 \mathrm{~km} / \mathrm{h}$;

loclow $=1$ if the speed limit within $600 \mathrm{~m}$ of the roundabout is higher than the local limit; and 2lanes $=1$ if there are 2 lanes in the roundabout, 0 if there is one.

Because the number of injury accidents is low, injury accident were modeled by relating injury accident rates to the total accident rate, as given by Equations 3.10 and 3.11 .

$$
\begin{gathered}
P I_{1}=0.8178 A_{1}^{1.6871} \\
P I_{2}=0.8178 A_{2}^{1.6871}
\end{gathered}
$$

Where,

$\mathrm{PI}=$ the predicted injury rate, and

$\mathrm{A}=$ the total accidents.

\subsubsection{Italian operation speed model}

Operating speeds were evaluated empirically through an experimental investigation conducted at urban roundabouts in Italy. Operating speed can be used to examine speed consistency or to determine vehicle specific power. The Italian model is given by Equation 3.12:

$$
V_{85}=0.4433 D_{I N T}+0.8367 W_{C R}+3.2272 W_{E n}
$$

Where,

$\mathrm{V} 85=$ the 85 -percentile operating speed at circulating roadway $(\mathrm{km} / \mathrm{h})$, 
$\mathrm{D}_{\mathrm{INT}}=$ the central island diameter $(\mathrm{m})$,

$\mathrm{W}_{\mathrm{CR}}=$ circulatory roadway width $(\mathrm{m})$, and

$\mathrm{W}_{\mathrm{En}}=$ the entry lane width $(\mathrm{m})$.

\subsubsection{United States Models}

\subsubsection{Intersection level crash prediction}

The models are functions of AADT. The roundabouts are categorized based on the number of legs (3-leg, 4-leg, and 5-leg) and the AADT is divided into ranges. The models are for total crashes and KAB injury, as shown in Tables 3-3 and 3-4.

Table 3-3: Models for predicted total crashes frequency per year

\begin{tabular}{|c|c|c|c|}
\hline Cir. lane & 3-leg & 4-leg & 5-leg \\
\hline \multirow{2}{*}{1} & $0.001(\mathrm{AADT})^{0.749}$ & $0.0023(\mathrm{AADT})^{0.749}$ & $0.0049(\mathrm{AADT})^{0.749}$ \\
\hline & 4000 to 31,00 AADT & 4000 to $37,00 \mathrm{AADT}$ & 4000 to 18,00 AADT \\
\hline \multirow{2}{*}{2} & $0.0018(\mathrm{AADT})^{0.749}$ & $0.0038(\mathrm{AADT})^{0.749}$ & $0.0073(\mathrm{AADT})^{0.749}$ \\
\hline & 3000 to $20,00 \mathrm{AADT}$ & 2000 to $35,00 \mathrm{AADT}$ & 2000 to $52,000 \mathrm{AADT}$ \\
\hline 3 or 4 & Not Available & $\begin{array}{c}0.00126(\mathrm{AADT})^{0.749} \\
25000 \text { to } 59.000 \text { AADT }\end{array}$ & Not available \\
\hline
\end{tabular}

Dispersion parameter $\mathrm{K}=0.90$

Source: (Rodegerdts et al 2010)

Table 3-4: Models for predicted KAB injury crashes frequency per year

\begin{tabular}{|c|c|c|c|}
\hline Cir. lane & 3-leg & 4-leg & 5-leg \\
\hline \multirow[t]{2}{*}{1 or 2} & $0.008(\mathrm{AADT})^{0.5923}$ & $0.0013(\mathrm{AADT})^{0.5923}$ & $0.0029(\mathrm{AADT})^{0.5923}$ \\
\hline & 3000 to $31,00 \mathrm{AADT}$ & 2000 to 37,00 AADT & 2000 to 52,000 AADT \\
\hline 3 or4 & Not Available & $\begin{array}{c}0.00119 \text { (AADT) } \\
25000 \text { to } 59,000 \text { AADT }\end{array}$ & Not available \\
\hline
\end{tabular}

\section{Dispersion parameter $\mathrm{K}=0.946$}

Source: (Rodegerdts et al 2010) 
Using the corresponding model from Tables 3-3 and 3-4 to estimate the crash type $\mathrm{P}$, the annual predicted crashes can be calculated using Equation 3.12:

$$
\begin{aligned}
& m=w_{1} x+w_{2} P \\
& w_{1}=\frac{p}{\left(\frac{1}{k}\right)+n p} \\
& w_{2}=\frac{\left(\frac{1}{k}\right)}{\left(\frac{1}{k}\right)+n p}
\end{aligned}
$$

Where,

$m=$ expected annual crash frequency;

$x=$ total crashes observed;

$P=$ predicted annual number of crashes;

$n=$ years of observed data; and

$k=$ dispersion parameter for a given model in Tables 3-3 and 3-4

\subsubsection{Approach level crash prediction}

Approach level models are used to predict three separate crash types: entering-circulating, exiting-circulating, and approach crashes. The models are functions of AADT and geometric design parameters.

- Entering-circulating predicted crashes $\left(\mathrm{PC}_{1}\right)$

The main geometric parameters that affect this type of crash are the entry width and the angle between legs. The model is given by Equation 3.15.

$$
P C_{1}=1.76 * 10^{-6}\left(A A D T_{e n}\right)^{0.7018}\left(A A D T_{c i r}\right)^{0.1321} e^{(0.0511 E-.0276 \theta)}
$$

- Exiting-circulating predicted crashes $\left(\mathrm{PC}_{2}\right)$ 
The main geometric parameters that affect this type of crash are the inscribed diameter and circulated width as given by Equation 3.16.

$$
P C_{2}=8.96 * 10^{-6}\left(A A D T_{e x}\right)^{0.2801}\left(A A D T_{c i r}\right)^{0.2530} e^{(0.0222 D+0.1107 C)}
$$

- Approach predicted crashes

This type of crash is affected by the approach half width as given by Equation 3.17.

$$
P C_{3}=0.0057838\left(A A D T_{e n}\right)^{0.4613} e^{(0.0301 v)}
$$

Where,

$\mathrm{AADT}_{\mathrm{en}}, \mathrm{AADT}_{\mathrm{ex}}, \mathrm{AADT}_{\mathrm{cir}}=$ the entering, exiting, and circulating traffic, respectively,

$\mathrm{E}=$ the entry width in $\mathrm{m}$,

$\mathrm{D}=$ the inscribed circle diameter in $\mathrm{ft}$.,

$\mathrm{C}=$ the circulated width in $\mathrm{ft}$.,

$\mathrm{v}=$ the approach half width in $\mathrm{ft}$., and

$\theta=$ the angle between legs in degrees.

The HSM identifies an accident prediction algorithm that can be used in calculating the total intersection accidents per year using Equation 3.18

$$
N_{\text {int }}=N_{b} * A M F_{1} * A M F_{2} * A M F_{n}
$$

Where,

$N_{\text {int }}=$ predicted number of total intersection-related crashes per year after applying accident modification factors;

$N_{b}=$ predicted number of total intersection-related crashes per year for; and $A M F i=$ base conditions accident modification factors (AMF), $(i=1$ to $n)$ for design intersection features different from base conditions.

$$
A M F_{i}=A F M_{\text {base }}^{x-x_{\text {base }}}
$$

Where,

$A M F_{\text {base }}=\mathrm{AMF}$ calculated for the base condition value as provided given in Table 3-5 $x=$ existing value for the variable, and 
$x_{\text {base }}=$ base condition value for the variable provided in Table 3-5

Table 3-5: Base Conditions for Design Variables and AMFs

\begin{tabular}{ccccc}
\hline Variable & $\begin{array}{c}\text { Base Condition } \\
\text { Value }\end{array}$ & $\begin{array}{c}\text { Entering-Circulating } \\
\text { AMF }\end{array}$ & $\begin{array}{c}\text { Exiting-Circulating } \\
\text { AMF }\end{array}$ & $\begin{array}{c}\text { Approach } \\
\text { AMF }\end{array}$ \\
\hline Entry Radius & $76 \mathrm{ft}$ & 1.010 & & \\
\hline Entry Width & $20 \mathrm{ft}$ & 1.052 & & 1.031 \\
\hline Approach Half Width & $18 \mathrm{ft}$ & & & \\
\hline Inscribed Circle Diameter & $134 \mathrm{ft}$ & & 1.022 & \\
\hline Central Island Diameter & $69 \mathrm{ft}$ & 0.992 & 1.117 & \\
\hline Circulating Width & $23 \mathrm{ft}$ & & & \\
\hline Angle To Next Leg & $93 \mathrm{deg}$ & 0.973 & & \\
\hline
\end{tabular}

Source: (Rodegerdts et al 2010)

\subsubsection{Speed-based crash predicted models}

NCHRP Report 572 presented research by Rodegerdts et al. (2007) which aimed to develop a speed-based approach-level safety performance function (SPF) for roundabouts in the US, as provided in Equation 3.20:

$$
\operatorname{Exp}^{(\text {intercept })} * A A D T^{b} * \operatorname{Exp}^{c x}
$$

Where,

$\mathrm{AADT}=$ the average annual daily traffic,

$\mathrm{X}=\mathrm{a}$ speed-related variable, and

$\mathrm{B}, \mathrm{c}=$ the parameters determined using the data.

The model was considered inadequate because the speed variables were weak (Rodegerdts et al., 2007).

The Federal Highway Administration Roundabout Guide (Federal Highway Administration, 2000) documented a speed prediction model that was tested and included in NCHRP Report 572 (Rodegerdts et al., 2007). The model is given by Equations 3.21 and 3.22:

$$
V=8.7602 R^{0.386}
$$

For $\mathrm{e}=+0.02$ 


$$
\begin{gathered}
V=8.616 R^{0.3673} \\
\text { For e }=-0.02
\end{gathered}
$$

Where,

$\mathrm{V}=$ the predicted speed for each movement (left-turn circulating, through circulating, exit or entry movements in $(\mathrm{km} / \mathrm{h})$,

$\mathrm{R}=$ the radius of the vehicle path $(\mathrm{m})$ for the corresponding movement, and $\mathrm{e}=$ the super-elevation $(\mathrm{m} / \mathrm{m})$.

\subsubsection{Recent speed-based crash prediction model}

A recent study (Chen et al. 2013) used the US and Italian approach-level data for roundabouts to investigate models linking safety to predicted speed. This study is considered an indirect approach to relate geometric design features to roundabout safety performance. The researchers developed a predicted speed model as a function of some geometric parameters that they then used to develop a safety performance function. The investigated speed is the average approach, entering, circulating and exiting speeds (Chen et al., 2013).

The speed prediction model is given by Equation 3.23:

$$
A A S=13.015958-3.088964 C n t r y+0.034074 D_{a v}+0.142936 W_{a v}
$$

Where,

$\mathrm{AAS}=$ the average speed of the roundabout approach $(\mathrm{mph})$,

Cntry $=1$ for U.S. and 0 for Italy,

$D_{a v}=$ the average of the inscribed and central island diameters ( $\mathrm{ft}$ ), and

Wav $=$ the average of the entry width, circulated width, and exit width (ft).

The researchers used the speed model given in Equation 2.23 to investigate a safety performance function as given in Equation 3.24:

$$
P C=\operatorname{Exp}^{-16.3755}(A A D T)^{0.5094}(A A S)^{4.3314}
$$

Where,

$\mathrm{PC}=$ the predicted crashes rate (crash/year), AADT $=$ the average annual daily traffic, and $\mathrm{AAS}=$ the average approach speed $(\mathrm{mph})$ determined by Equation 3.24 


\section{Chapter 4 Mobility Literature Review}

\subsection{Introduction}

The most important function of transportation is to provide mobility for people or goods. Mobility defines the traffic quality of road facilities based on mobility measures. Capacity, delay, and level of service are mobility measurements that need to be addressed (McLeod et al., 2016). Researchers have modeled these mobility measurements in different ways, taking different variables into consideration. The next section explains the three measurements of mobility in more detail, including the modeling of each measurement and the different international models.

\subsection{Capacity}

The Highway Capacity Manual (HCM, 2010) defines the capacity of a facility as "the maximum hourly rate at which persons or vehicles can reasonably be expected to traverse a point or uniform section of a lane or roadway during a given period under prevailing roadway, traffic, and control conditions." Capacity is a specific measurement that can be estimated and used to calculate delay which defines the level of service. LOS is a qualitative measurement that examines the operational conditions of traffic streams at road facilities. To assess the LOS of intersections, the capacity should be identified and the control delay should be calculated. Based on the control delay value, the LOS (as perceived by users) is identified. In addition to the control delay, drivers experience a geometric delay due to the geometric features of the intersection that force drivers to reduce their speed while turning.

Roundabout traffic rules give the circulating traffic priority and force entering vehicles to yield to circulating vehicles. The entering vehicles wait for an acceptable gap in the circulating traffic and this gap facilitates roundabout capacity. Therefore, capacity is highly dependent on gap acceptance. The other main factor that affects roundabout capacity is geometric design. The following section provides more detail about the factors that affect capacity.

\subsubsection{Factors that affect capacity}

\subsubsection{Effect of driver behaviour and traffic flow}

- Effect of exiting vehicles. 
Just as the circulating traffic directly affects the entry traffic, the exiting traffic sometimes affects a driver's decision to accept a gap and enter the roundabout. This case is similar to the situation in a two-way stop-controlled intersection when drivers attempt to do a right turn from the left side of the road. The other drivers experience uncertainty until the turning or exiting drivers complete their maneuvers.

- Changes in effective priority.

When entering and circulating traffic change the ruled priority as in the case of high traffic entering that forces the circulating traffic to yield for them, or high circulating traffic that makes the entering traffic accept any available gap. This change in priority and driver behavior can affect gap acceptance and capacity.

- Capacity constraint.

Approaches can affect each other. When one approach is over saturated, fewer vehicles from this approach can enter the roundabout. This reduction in entry demand will affect the downstream approach. Because the circulating traffic downstream is lower, the entering traffic in the affected approach will be above its capacity. This condition is called capacity constraint.

- Origin-destination patterns.

Origin-destination patterns may impact capacity due to multiple factors including the familiarity of drivers with using roundabouts. This is why the local conditions need to be calibrated.

\subsubsection{Geometric effect}

Geometry plays a key role in the operational performance of roundabouts in a number of ways:

- Geometric features define the speed of vehicles travelling through roundabouts which affects travel time.

- The number of lanes is one aspect of geometry which affects the number of vehicles entering the roundabout at the same time.

- The geometry of each lane is the main factor that facilitates the flow of traffic or constrains it. For example, the entry or exit curve defines the entry or exit speed. Capacity is also 
affected by user comfort level in a multi-lane roundabout. Some drivers avoid circulating side by side which might reduce capacity.

- Geometric features may also alter driver perception regarding proper lane allocation.

Improper lane allocation creates friction between adjacent lanes, which results in a reduction of capacity.

\subsubsection{Data requirements}

Estimating roundabout capacity for any given approach requires two kinds of data: 1) geometric data (including geometric features), and 2) traffic data (including movement flow rates, entering traffic, circulating traffic). The following section explains how to calculate roundabout traffic rates for any given approach.

\subsubsection{Determining roundabout flow rates}

The primary data required to estimate roundabout capacity is the traffic flow rate for entering, exiting and circulating vehicles for each approach. This section illustrates the methodology used to determine roundabout flow rates.

- Calculating the circulating flow rate

The circulating flow rate at a specific approach involves the traffic facing this approach entry or the flow conflicting with this approach entry. Figure 4-1 illustrates the northbound circulating traffic which consists of the other flow passing in front of the NB entry. The flow movements that pass in front of NB include: westbound U-turn (WBU) movements; southbound left-turn (SBL) movements; southbound U-turn (SBU) movements; the eastbound through (EBT) movements; eastbound left-turn (EBL) movements; and eastbound U-turn (EBU) movements. 


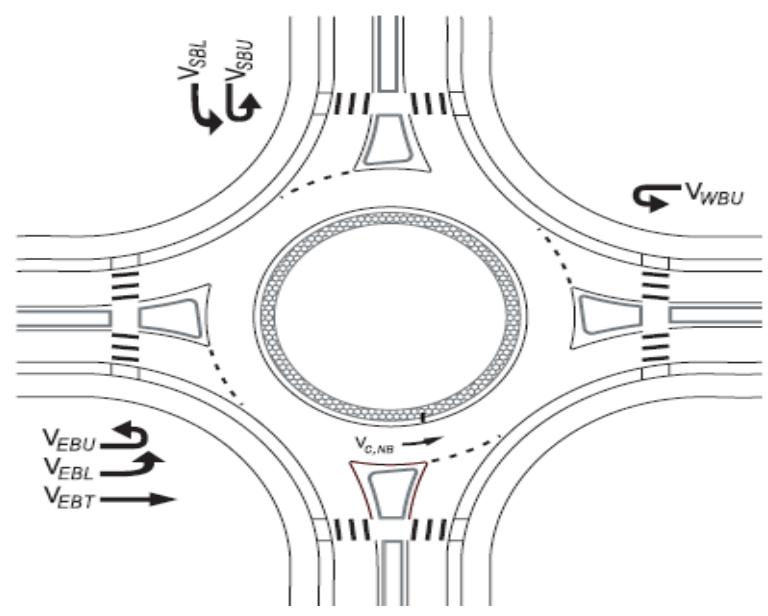

Figure 4-1: Roundabout traffic calculation

Source: (Rodegerdts et al 2010)

For any approach, the circulating flow rate can be estimated using Equation 4.1.

$$
Q_{c j}=Q_{U T j+1}+Q_{L T j+2}+Q_{U T j+2}+Q_{T H j+3}+Q_{L T j+3}+Q_{U T j+3}
$$

Where,

$Q_{c i}=$ the circulating flow for approach $\mathrm{j}$,

$\mathrm{Q}_{\mathrm{LT}}, \mathrm{Q}_{\mathrm{UT}}, \mathrm{Q}_{\mathrm{TH}}=$ the left turn, U-turn, and through traffic movements, respectively, and $\mathrm{j}=$ the approach number $(1,2,3$, or 4$)$

- Calculating the exiting flow

The exiting flow rate for an approach is typically used to calculate right-turn bypass lane conflicting flows. The exiting flow rate for the southbound exit is shown in Figure 4-2. The exiting flow rate for the southbound (SB) exit is the sum of the flow of the southbound through (SBT) movements, the eastbound right-turn (EBR) movements, the northbound U-turn (NBU) movements, and the westbound left (WBL) movements. 


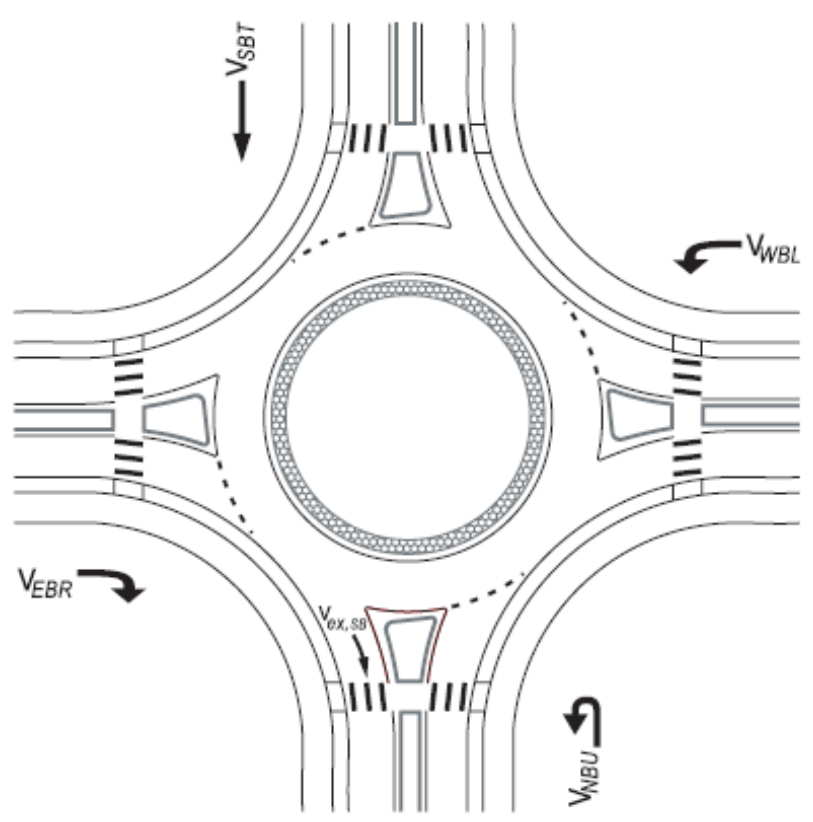

Figure 4-2 Calculating approach exiting flow rate

Source: (Rodegerdts et al 2010)

For any approach, the exiting flow rate can be calculated using Equation 4.2.

$$
Q_{e x j}=Q_{U T j}+Q_{L T j+1}+Q_{T H j+2}+Q_{R T j+3}
$$

Where,

$Q_{e x, j}=$ the exiting flow for approach $\mathrm{j}$,

$\mathrm{Q}_{\mathrm{RT}}=$ the right turn traffic movements,

$\mathrm{j}=$ the approach number $(1,2,3$, or 4$)$

4.2.2.2 Adjustment for vehicle fleet mix

Since the traffic volume includes different vehicle sizes, the flow should be adjusted to a standard size (passenger car). The traffic flows used to calculate capacity take this adjustment into consideration. The flow rates that are given in vehicle per hour should be adjusted to be in 
passenger car per hour. Factors that express the relativeness of different vehicles to passenger cars are called passenger car equivalent factors. These factors are provided in Table 4-1.

Table 4-1: Passenger car equivalent factors

\begin{tabular}{cc}
\hline Vehicle Type & Passenger Car Equivalent, $\mathrm{E}_{\mathrm{T}}$ \\
\hline Passenger Car & 1.0 \\
\hline Heavy Vehicle & 2.0 \\
\hline Bicycle & 0.5 \\
\hline
\end{tabular}

Source: (Rodegerdts et al 2010)

$$
\begin{gathered}
Q_{p c e}=Q_{v e h} / f_{H V} \\
f_{H V}=\frac{1}{1+P_{T}\left(E_{T}-1\right)}
\end{gathered}
$$

Where

$Q_{p c e}=$ demand flow rate for movement $\mathrm{pc} / \mathrm{h}$;

$Q_{v e h}=$ demand volume for movement, veh $/ \mathrm{h}$;

$f_{H V}=$ heavy vehicle adjustment factor;

$P_{T}=$ proportion of demand volume that consists of heavy vehicles; and

$E_{T}=$ passenger car equivalent for heavy vehicles given in Table 3-1

\subsubsection{Entry capacity models}

There are two ways to estimate roundabout capacity: gap-acceptance and empirical regression analysis based on geometric aspects, and linear or exponential empirical regression.

- Gap acceptance methodology

Gap acceptance means that the driver at the yield line is looking for an acceptable gap in the circulating stream in order to perform the appropriate maneuver. The "gap" is defined as the headway between two successive vehicles in the circulating stream. The minimum gap that a driver who is entering the roundabout can accept is his critical gap, $t c$. The critical headway changes from driver to driver and from situation to situation; it is not a constant. The follow-up 
time, $t f$, is the time headway between two flowingly entering vehicles, using the same gap in the conflicting stream. The follow-up time can be measured directly in the field without complex equations.

\subsubsection{US Model}

There are two major methods that can be found in the United States literature:

The operational method quoted in the FHWA Roundabout Guide (Robinson et al., 2000), and the Highway Capacity Manual gap acceptance model (HCM, 2000).

- FHWA Method

The models for single-lane roundabouts are given by Equations 4.5, 4.6 and 4.7.

$$
q_{\text {emax }}=1218-0.74 q_{c} \quad \text { for } 0 \leq q_{c} \leq 1646
$$

The minimum of Equations 3.6 and Equation 4.7.

$$
\begin{gathered}
q_{\text {emax }}=1212-0.5447 q_{c} \quad \text { for } 0 \leq q_{c} \leq 1800 \\
q_{\text {emax }}=1800-q_{c} \quad \text { for } 0 \leq q_{c} \leq 1800
\end{gathered}
$$

The model for multi-lane roundabouts is given by equation 4.8 .

$$
q_{e, \max }=2424-0.7159 q_{c} \quad \text { for } 0 \leq q_{c}
$$

Where,

$q_{e, \max }=$ maximum entry flow $(\mathrm{veh} / \mathrm{h})$

$q_{c}=$ traffic flow on the circulatory roadway $(\mathrm{veh} / \mathrm{h})$

- HCM 2000 Method

The HCM 2000 method for one-lane roundabouts is given by Equation 4.9.

$$
q_{e, \max }=\frac{q_{c} e_{c}^{-\frac{q_{c} t_{c}}{3600}}}{1-e^{-\frac{q_{c} t_{f}}{3600}}}
$$

Where,

$q_{e, \max }=$ maximum entry flow $(\mathrm{veh} / \mathrm{h})$, 
$q_{c}=$ conflicting flow $(\mathrm{veh} / \mathrm{h})$,

$t_{c}=$ critical headway $(\mathrm{s}), 4.1 \leq t_{c} \leq 4.6 \mathrm{sec}$, and

$t_{f}=$ follow-up time $(\mathrm{s}), 2.6 \leq t_{f} \leq 3.1 \mathrm{sec}$

\subsubsection{UK Capacity Model}

Kimber developed a regression model linking six geometric parameters to capacity. This method is associated with the ARCADY and RODEL software. The capacity formula used in the UK for estimating entry capacity in roundabouts is as follows:

$$
\begin{gathered}
Q e=k\left(F-f_{c} Q_{c}\right) \\
k=1-0.00347(\phi-30)-0.978\left(\frac{1}{r}-0.05\right) \\
F=303 x 2 \\
f_{c}=0.210 T_{D}\left(1+0.2 x_{2}\right) \\
T_{D}=1+\frac{0.5}{1+\exp ^{(D-60) / 10}} \\
x 2=v+\frac{e-v}{1+2 S} \\
S=1.6(e-v) l^{\prime}
\end{gathered}
$$

Where,

$Q e=$ maximum entry flow $(\mathrm{veh} / \mathrm{h})$,

$Q_{c}=$ circulating flow $(\mathrm{veh} / \mathrm{h})$,

$e=$ entry width $(\mathrm{m})$,

$v=$ approach half-width $(\mathrm{m})$,

$l^{\prime}=$ effective flare length $(\mathrm{m})$,

$r=$ entry radius $(\mathrm{m})$,

$\varphi=$ entry angle $\left(^{\circ}\right)$, 
$S=$ measurement of the degree of the flaring, and

$D=$ inscribed circle diameter $(\mathrm{m})$

\subsubsection{Australian Capacity Model}

Detailed capacity models have been published in Australia. These models are most recently found in Akçelik et al. (1999). These expressions are found in the aaSIDRA software (Akçelik, 2004). The capacity for single-lane entry is calculated as follows:

$$
\begin{gathered}
q_{e, \max }=\max \left(f_{o d} q_{g}, q_{m}\right) \\
q_{g}=\frac{3600}{\beta}\left(1-\Delta \frac{q_{c}}{3600}+0.5 \beta \phi_{c} \frac{q_{c}}{3600}\right) \exp ^{-\lambda\left(\alpha-\Delta_{c}\right)} \\
q_{m}=\min \left(q_{e}, 60 n_{m}\right) \\
f_{o d}=1-f_{q c}\left(P_{g d} P_{c d}\right)
\end{gathered}
$$

Where,

$q_{e, \max }=$ maximum entry flow for an entry lane $(\mathrm{veh} / \mathrm{h})$,

$q_{g}=$ minimum entry flow $(\mathrm{veh} / \mathrm{h})$,

$q_{c}=$ conflicting flow $(\mathrm{veh} / \mathrm{h})$,

$q_{e}=$ entry arrival flow $(\mathrm{veh} / \mathrm{h})$,

$f_{\text {od }}=\mathrm{o}-\mathrm{d}$ adjustment factor,

$P_{g d} P_{c d} \approx 0.5$ to 0.8 ( 0.6 used),

$n_{m}=$ minimum entry flow (veh/min),

$n_{c}=$ number of lanes in the conflicting flow,

$\Delta_{c}=$ minimum headway in the circulating traffic (s), and

$$
=2.0 \text { for } n_{c}=1
$$$$
=1.2 \text { for } n_{c}=2
$$

$\lambda=$ arrival headway distribution factor $(\mathrm{veh} / \mathrm{s})$. 


$$
\begin{gathered}
\lambda=\frac{\frac{\phi_{c} q_{c}}{3600}}{1-\frac{\Delta_{c} q_{c}}{300}} \quad \text { for } q_{c} / 3600 \leq 0.98 / \Delta_{c} \\
\text {, and } \lambda=\frac{49 \phi_{c}}{\Delta_{c}} \quad \text { else }
\end{gathered}
$$

$\phi_{c}=$ proportion of $\mathrm{UN}$ bunched conflicting vehicles, and

$$
\begin{aligned}
& =\exp (-5.0 q c / 3600) \text { for } n_{c}=1 \\
& =\exp (-3.0 q c / 3600) \text { for } n_{c}=2
\end{aligned}
$$

$\beta=$ follow-up headway (s).

If there is a dominant entry lane in multi-lane roundabouts, the capacity of this dominant lane can be computed using the following expressions:

$$
\begin{gathered}
\beta=\beta_{d}=\beta_{o}^{\prime}-3.94 * 10^{-4} q_{c} \text { for } \beta_{\min } \leq \beta^{\prime} \leq \beta_{\max } \\
\beta_{o}^{\prime}=3.37-0.0208 D_{i}+0,889 * 10^{-4} D_{i}^{2}-0.395 n_{e} \text { for } 20 \leq D_{i} \leq 80
\end{gathered}
$$

Where:

$D i=$ inscribed diameter $(\mathrm{m})$,

$n_{c}=$ number of entry lanes,

$\beta_{\min }=1.2(\mathrm{~s})$,

$\beta_{\max }=4.0(\mathrm{~s})$,

For a subdominant lane, the lane that has less flow than the other lanes in a multi-lane roundabout, the capacity can be computed using Equation 4.25.

$$
\beta=\beta_{s}=2.149+\left(0.5135 \beta_{d}-0.8735\right) r_{d s} \text { for } \beta_{d} \leq \beta_{s} \leq \beta_{\max }
$$

Where:

$r_{d s}=$ ratio of dominant and subdominant flow in the entry $=q d / q s$, $\alpha=$ critical headway (s), 


$$
\begin{gathered}
\left.\alpha=3.6135-3,137 * 10^{-4} q_{c}-0339 w_{L}-0.277 n_{c}\right) \beta \text { for } q_{c} \leq 1200 \\
\left.\alpha=3.2371-0.339 w_{L}-0.2775 n_{c}\right) \beta \quad \text { else }
\end{gathered}
$$

$$
\text { subjected to: } 3.0 \geq \frac{\alpha}{\beta} \geq 1 \text { and } \alpha_{\min } \leq \alpha \leq \alpha_{\max }
$$

$\alpha_{\min }=2.2(\mathrm{~s})$

$\alpha_{\max }=8.0(\mathrm{~s})$

$w_{L}=$ average entry width $(\mathrm{m})$

For $n_{c}=1$ :

$$
\begin{gathered}
f_{q c}=0.04+0.00015 q_{c} \text { for } q_{c}<600 \\
f_{q c}=0.0007 q_{c}-0.29 \text { for } 600 \leq q_{c} \leq 1200 \\
f_{q c}=0.55 \text { for } q_{c} \geq 1200
\end{gathered}
$$

For $n_{c}=2$ :

$$
\begin{gathered}
f_{q c}=0.04+0.00015 q_{c} \text { for } q_{c}<600 \\
f_{q c}=0.0035 q_{c}-0.29 \text { for } 600 \leq q_{c} \leq 1800 \\
f_{q c}=0.55 \text { for } q_{c} \geq 1800
\end{gathered}
$$

\subsubsection{German Capacity Models}

The Tanner-Wu capacity model has been officially introduced into the German Highway Capacity Manual (2001). The German capacity model for roundabout entries provided by Wu (2001) is given by Equation 3.35: 


$$
q_{\text {emax }}=n_{e} * \frac{3600}{t_{f}} *\left[1-\Delta * \frac{\frac{q_{c}}{3600}}{n_{c}}\right]^{n_{c}} * \exp \left[-\frac{q_{c}}{3600} *\left(t_{c}-\frac{t_{f}}{2}-\Delta\right)\right]
$$

Where,

$q_{\text {emax }}=$ maximum entry flow $(\mathrm{pcu} / \mathrm{h})$,

$q_{c}=$ conflicting flow $(\mathrm{pcu} / \mathrm{h})$,

$n_{c}=$ number of conflicting lanes ( 1 or 2 with $\left.n c \leq n e\right)$,

$n_{e}=$ number of lanes in the entry,

$t_{c}=$ critical headway $=4.1 \mathrm{~s}$,

$t_{f}=$ follow-up time $=2.9 \mathrm{~s}$, and

$\Delta=$ minimum headway of circulating traffic $=2.1 \mathrm{~s}$

More recently, Rodegerdts (2007) re-calibrated The Tanner-Wu capacity model and the equation showed some bias when used for two-lane entries. Thus, the researcher attempted to approximate it to the German data set and presented new parameters, as shown in Equation 4.36.

$$
q_{\text {emax }}=n_{e} * \frac{n_{F} /\left(n_{F}+1\right)}{t_{f}} *\left[1-\Delta * \frac{\frac{q_{c}}{3600}}{n_{c}}\right]^{n_{c}} * \exp \left[-q_{c} *\left(t_{c}-\frac{t_{f}}{2}-\Delta\right)\right]
$$

Where,

$t_{c}=$ critical headway $=3.3 \mathrm{~s}$,

$t_{f}=$ follow-up time $=3.1 \mathrm{~s}$,

$\Delta=$ minimum headway of circulating traffic $=1.8 \mathrm{~s}$, and

$n_{f}=$ short lane length $=1.4 \mathrm{veh}$

\subsubsection{French Capacity Models}

Louah (1997) adopted a three parallel modeling strategy and this model was incorporated into the Girabase software. The Gigabase model is considered the most current exponential regression model based on geometric parameters and takes into consideration the effect of 
exiting flow (Louah, 1993). The form of the Girabase model is given by Equations 4.37, 4.38, and 4.39.

$$
q_{e, \max }=A * \exp \left(-C_{B} * q_{g}\right)
$$

Where,

$$
\begin{gathered}
q_{g}=q_{a} * k_{a} *\left[1-\frac{q_{a}}{q_{c}+q_{a}}\right]+q_{c i} * k_{t i}+q_{c e} * k_{t e} \\
A=\frac{3600}{t_{f}}\left[\frac{L_{e}}{3.5}\right]^{0.8}
\end{gathered}
$$

$q_{e, \max }=$ maximum entry flow $(\mathrm{pcu} / \mathrm{h})$,

$q_{c}=$ total conflicting flow $(\mathrm{pcu} / \mathrm{h})$,

$q_{c i}=$ conflicting flow on inner lane (default $\left.0.4 * q k\right)(\mathrm{pcu} / \mathrm{h})$,

$q_{c e}=$ conflicting flow on outer lane (default $\left.0.6^{*} q k\right)(\mathrm{pcu} / \mathrm{h})$,

$q_{g}=$ exiting flow $(\mathrm{pcu} / \mathrm{h})$,

$C_{B}=3.525$ for urban area,

$$
=3.625 \text { for rural area, }
$$

$t_{f}=$ follow-up time $=2.05 \mathrm{~s}$,

$R=$ radius of the central island (m),

$L e=$ entry width $(\mathrm{m})$,

$L a=$ circulating width (m), and

$L i=$ width of the splitter island (m)

$$
\begin{gathered}
L_{i, \max }=4.55 * \sqrt{R+\frac{L_{a}}{2}} \\
k_{a}=\left\{\begin{array}{cc}
\frac{R}{R+L A}-\frac{L_{i}}{L_{\text {imax }}} & \text { for } L_{i}<L_{\text {imax }} \\
0 & \text { els }
\end{array}\right\}
\end{gathered}
$$




$$
\begin{aligned}
& k_{t, i}=\min \left\{\begin{array}{c}
\frac{160}{L A *(R+L A)} \\
1
\end{array}\right\} \\
& k_{t, i}=\min \left\{1-\frac{(L A-8)}{L A} *\left[\frac{R}{R+L A}\right]^{2}\right\}
\end{aligned}
$$

\subsubsection{Swiss Capacity Models}

Bovy (1991) created a model that considers the effect of exiting flow and one geometric

parameter which is the width of the splitter island. This capacity model is given by Equation 4.44 .

$$
q_{e, \max }=\left[1500-\frac{8}{9} * q_{b}\right] * \beta
$$

Where,

$q_{b}=k a \gamma \cdot q+\alpha \cdot q(\mathrm{pcu} / \mathrm{h})$,

$q_{e, \max }=$ maximum entry flow $(\mathrm{pcu} / \mathrm{h})$,

$q_{k}=$ circulating flow $(\mathrm{pcu} / \mathrm{h})$,

$q_{a}=$ exiting flow $(\mathrm{pcu} / \mathrm{h})$,

$\gamma=0.9$ to 1.0 for single circulating lane (taken= 1.00$)$,

$=0.6$ to 0.8 for double circulating lane $($ taken $=0.66)$,

$=0.5$ to 0.6 for triple circulating lane (taken $=0.55$ ),

$\beta=0.9$ to 1.1 for single entry lane (taken $=1.00)$,

$=1.4$ to 1.6 for double entry lane $($ taken $=1.50)$,

$=1.9$ to 2.1 for triple entry lane $($ taken $=2.00)$, and

$b=$ taken from Figure 3.3 in $(\mathrm{m})$

$$
\alpha=\left\{\begin{array}{cr}
0.6 & \text { for } 0<b \leq 21 \\
0.6-\frac{0.5}{12} *(b-9) & \text { for } 9<b \leq 21 \\
0.1 & \text { for } 21<b \leq 27 \\
0.1-0.1 *(b-27) & \text { for } 27<b \leq 28 \\
0 & \text { for } b .28
\end{array}\right\}
$$




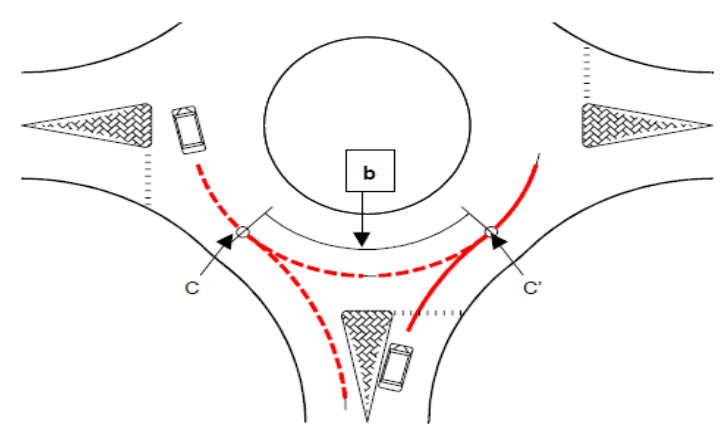

Figure 4-3 Swiss Measure of the Parameter ' $b$ '

Source: (Rodegerdts et al 2007)

\subsection{Operational Performance Measures}

The operational performance of roundabouts can be defined by key mobility variables including the degree of saturation (volume/capacity), the average delay, the distribution of delays, the average queue length, the distribution of queue lengths, the number of stopped vehicles, and the acceleration or deceleration between the stop and normal velocity. The following section covers each mobility measurement in more detail.

\subsubsection{Delay}

Traffic delay is the extra travel time that users experience due to traffic conditions that impede free-speed movement. The roundabout delay model is a function of the volume-capacity ratio through a period $\mathrm{T}$. A number of researchers have adopted models based on the queuing theory. These equations can only be applied under saturation conditions and assume that traffic is constant over time (Brilon, 1988; Kremser, 1964; Yeo, 1962).

The more considerable delay models are the models that take into account the effect of traffic changes over time. Time-dependent models were presented by Kimber and Hollis (1979). These models are quite complicated because they take the period after and before analysis into consideration. Akçelik and Troutbeck (1991) simplified these models by only considering the time analysis. 


\subsubsection{Kimber's Equation}

This formula is suitable for oversaturation traffic conditions. The formulas developed by Kimber and Hollis (1979) are given by the expressions below:

$$
d=0.5\left(\sqrt{j^{2}+k}-k\right.
$$

Where,

$$
\begin{gathered}
j=t_{i} \frac{(1-p)}{2}-\frac{L_{a}+1}{\mu} \\
k=2 \frac{t_{i}}{\mu} \\
\rho=\frac{q}{\mu}
\end{gathered}
$$

The average queue length is expressed by Equation 4.49.

$$
\begin{gathered}
L=0.5 \sqrt{A^{2}+B}-A \\
A=(1-\rho) \mu t_{i}+1-L_{o} \\
B=4\left(L_{o}+\rho \mu t_{i}\right)
\end{gathered}
$$

Where,

$\mathrm{d}=$ average delay in $\mathrm{sec} / \mathrm{h}$,

$\mathrm{L}=$ the queue length in veh,

$\mathrm{L}_{0}=$ the initial queue length in veh,

$t_{i}=$ the time interval in sec,

$\mathrm{q}=$ the flow rate in $\mathrm{veh} / \mathrm{sec}$, and

$\mu=$ the capacity rate in veh/sec. 


\subsubsection{HCM Formula}

The formula adopted in the HCM is for stop-controlled intersections and is given by Equation 4.52 .

$$
d=\frac{3600}{c}+900 * T *\left[\frac{v}{c}-\sqrt{\left(\frac{v}{c}-1\right)^{2}+\frac{\left(\frac{3600}{c}\right) *\left(\frac{v}{c}\right)}{450 * T}}\right]+5
$$

Where,

$d=$ control delay $(\mathrm{s} / \mathrm{veh})$,

$T=$ analysis time period $(T=0.25$ for a 15 -min period $)(\mathrm{h})$,

$c=$ capacity $(\mathrm{veh} / \mathrm{h})$, and

$v=$ flow rate $(\mathrm{veh} / \mathrm{h})$.

The last term in the equation " +5 " is the additional time added that reflects the deceleration before stopping at the stop-sign and the acceleration needed to move forward after stopping. This term is excluded when calculating the delay for roundabouts to suit the yield sign. The equation for roundabouts is as follows:

$$
d=\frac{3600}{c}+900 * T *\left[\frac{v}{c}-\sqrt{\left(\frac{v}{c}-1\right)^{2}+\frac{\left(\frac{3600}{c}\right) *\left(\frac{v}{c}\right)}{450 * T}}\right]
$$

\subsubsection{Queue Length}

The maximum queue length or 95th-percentile queue length is a more useful design measurement than the average queue length. The relationships have been adopted by Wu (1994) and formed as graphs included in the HCM 2000. The graph shown in Figure 4-4 is valid only when the volume-to-capacity ratio is a maximum of 0.85 immediately before and after the analysis time when the queue length is not considerable. 


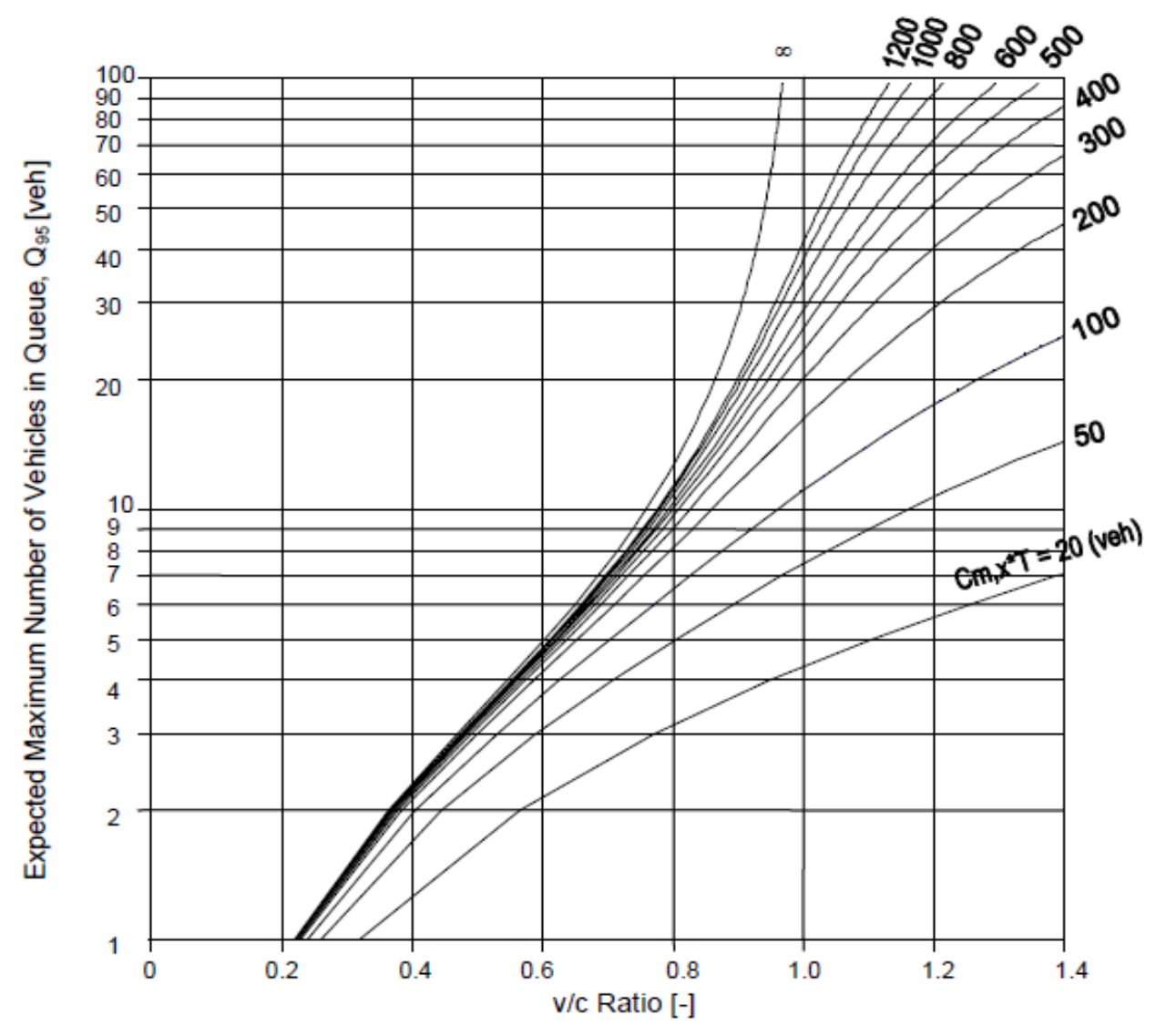

Figure 4-4 Maximum queue length

Source: (HCM, 2000)

\subsubsection{Effect of Pedestrians on Entry Capacity}

The effect of pedestrian density on entry capacity was not previously considered. In 1992, Stuwe observed; three roundabouts with heavy pedestrian flow and developed an empirical equation to estimate the entry capacity for one and two-lane roundabouts. The models are presented in the FHWA Roundabout Guide (Robinson et al., 2000). Another study was conducted by Marlow and Maycock (1982) also created a capacity model which considers pedestrian impact based on queue theory. 
There are no standard traffic priority rules around the world. In Germany, vehicles exiting roundabouts should yield for pedestrians, however, vehicles entering the roundabout have priority over pedestrians. The priority given to pedestrians has a considerable effect on entry capacity. These calculations are valid when pedestrians have the unrestricted right of way. The capacity is calculated using the regular formulas and then a pedestrian reduction is applied to account for the pedestrian effect. The formulas developed by Stuwe (1992) are given by Equations 3.55 for one-lane entry and 4.56 for two-lane entry, then applied to Equation 3.54.

- Stuwe Formula:

$$
\begin{gathered}
q_{e, \max , F g}=q_{e, \max } * M \\
M=\frac{1119.5-0.715 * q_{k}-0.644 * q_{F g}+0.00073 * q_{k} q_{F g}}{1069-0.65 * q_{k}} \\
M=\frac{1260.6-0.715 * q_{k}-0.329 * q_{F g}+0.381 * q_{F g}}{1380-0.5 * q_{k}}
\end{gathered}
$$

Where,

$M=$ entry capacity reduction factor,

$q_{k}=$ volume of circulating vehicles in front of the subject entry (pcu/h), and $q_{F g}=$ volume of pedestrians $(\mathrm{ped} / \mathrm{h})$.

- Griffiths Formulas:

A study by Griffiths (1981) adopted the pedestrian effect model below:

$$
C_{F G U}=\frac{\mu}{\mu * \beta+\left(e^{\mu \alpha}-1\right) *\left(1-e^{-\mu \beta}\right)} * 3600
$$

Where, 
$C_{F G U}=$ capacity of the crosswalk for vehicles $(\mathrm{veh} / \mathrm{h})$,

$\mu=$ volume of pedestrians $=q_{F g} / 3600(\mathrm{ped} / \mathrm{s})$,

$\boldsymbol{\beta}=$ minimum time gap between two vehicles (s) when driving across the crosswalk $=1 / \mathrm{C}_{0}$,

$C_{o}=$ capacity of one lane of the entry, at an otherwise empty roundabout (veh/s),

$\boldsymbol{\alpha}=$ time needed to cross the crosswalk by the pedestrians $(\mathrm{s})=\mathrm{B} / v_{F g}$,

$B=$ width of road at crosswalk (m), and

$v_{F g}=$ walking speed of pedestrians at the crosswalk $(\mathrm{m} / \mathrm{s})$

The speed $v_{F g}$ is approximately 0.5 to $2.0 \mathrm{~m} / \mathrm{s}$. If there is no information given, $1.4 \mathrm{~m} / \mathrm{s}$ can be used.

- Marlow and Maycock formula:

The formulas given by Marlow and Maycock (1982) are given by Equations 4.58 and 4.59:

$$
q_{e, \max , F g}=q_{e, \max } * M
$$

$$
M=\frac{R^{N+2}-R}{R^{N+2}-1}
$$

Where,

$q_{e, \max }=$ Capacity of the entry neglecting pedestrian traffic $(\mathrm{veh} / \mathrm{h})$,

$N=$ Number of vehicles that can queue between the crosswalk and entry, and

$\mathrm{R}=$ Pedestrian flow (ped/hr.)

The parameter $N$ is to be determined for every single entry. $\mathrm{N}$ represents the number of queue spaces for cars that can be stored within the area between the crosswalk and the yield line of the roundabout. $\mathrm{N}$ is the total number of all lanes.

\subsubsection{Quality of service and level of service}

Quality of service represents user opinions regarding the operational performance of the facility. Traveler perspective is highly dependent on travel time. Level of service is a quantitative 
measurement of the operational performance of a given facility. For roundabouts, LOS is defined based on the control delay criteria provided in Table 4-2.

Table 4-2: Level of service based on control delay

\begin{tabular}{cc}
\hline Level of Service (LOS) & Average Control Delay \\
\hline A & $0-10$ \\
\hline B & $>10-15$ \\
\hline C & $>15-25$ \\
\hline D & $>25-35$ \\
\hline E & $>35-50$ \\
\hline F & $>50$ \\
\hline
\end{tabular}

Source: (Rodegerdts et al 2010) 


\section{Chapter 5 Environmental Sustainability Literature Review}

\subsection{Introduction}

Air pollution is a critical problem that affects the quality of our lives as well as the environment. In 2012, the World Health Organization estimated that 3 million deaths were caused by ambient (outdoor air pollution) in urban and rural areas (WHO, 2011). Environment Canada reported that transportation were the largest contributor to Canada's GHG emissions in the year 2011 (24\% of overall GHGs) (Canada, 2017). The problem remains significant as traffic numbers continue to climb each day, especially in urban areas. Because of this, reduction of vehicle emissions has become a major objective in road design. The next section presents vehicle emission modeling techniques and methodologies.

\subsection{Vehicle emissions modeling}

Many approaches have been used to model vehicle emissions and energy consumption. These models can be divided d into five categories: scale of the input variables modeling, formulation modeling, explanatory variable modeling, state variables modeling and number of dimensions modeling. The next section explains vehicle emission modeling in more detail.

\subsubsection{Scale of the input variables modeling}

Three basic approaches are used when modeling vehicle emissions and fuel consumption. These three modeling categories are based on data input level for three different data scales: microscopic, mesoscopic, and macroscopic. Each scale measures the vehicle emissions or energy consumption at different levels of the transportation network.

\subsubsection{Microscopic modeling}

Microscopic models are used to compute instantaneous vehicle fuel consumption and emission rates for individual vehicles and then aggregate information to estimate the emission and energy consumption rates of the entire network. Instantaneous vehicle emissions are estimated using the relationship between the vehicle's power and the emission rates that correspond to this power. Calculations of vehicle power require second by second information about vehicle speed and road conditions. A number of models have been incorporated into microscopic simulation software tools used to estimate vehicles energy consumption and 
emissions. These include the comprehensive modal emission model (CMEM), the VTmicroscopic model, the vehicle transient emissions simulation software (VeTESS), the NetSim software, the VERSIT tool, the passenger car and heavy-duty emissions model (PHEM), and the motor vehicle emission simulator MOVES.

\subsection{Comprehensive Modal Emission Model (CMEM)}

The College of Engineering-Center for Environmental Research and Technology (CECERT) was involved in a collaborative research project to develop a Comprehensive Modal Emission Model (CMEM). The model estimates the emissions of light-duty Vehicles such as passenger cars and single unit trucks and is linked to the vehicle operating mode. The model is comprehensive as it can predict emissions in several conditions for various types of LDVs. The CMEM model is capable of estimating second by second vehicle tailpipe emissions (Barth \& Norbeck, 1997).

The model is based on an empirical approach which consists of six modules: engine power prediction module, engine speed module, air/fuel ratio module, fuel use module, engine-out emissions estimation module, and catalyst pass fraction module. This model was developed using 300 vehicles that were tested using an odynometer. The input for this model includes three dynamic features: vehicle acceleration, fuel rate, and air/fuel equivalence ratio. The outputs for this model include three components: fuel rates, the mass of emissions out of the engine, and the ratio of tailpipe emissions to engine emissions, as given by Equation 5.1.

$$
\text { tailpipe emissions }=F R *\left(\frac{g_{\text {emissions }}}{g_{\text {fuel }}}\right) * C P F
$$

Where,

$F R=$ Fuel-use rate in grams/s,

$\frac{g_{\text {emissions }}}{g_{\text {fuel }}}=$ Grams of engine-out emissions per grams of fuel consumed, and

$C P F=$ ratio of tailpipe to engine-out emission.

The first module of CMEM is the engine power prediction module which estimates the engine power using Equation 5.2. 


$$
\begin{gathered}
P_{\text {tract }}=A * v+B * v^{2}+C * v^{3}+M * a+M * g * v * \sin \theta \\
P=\frac{P_{t r a c t}}{\eta_{t f}}+P_{a c c}
\end{gathered}
$$

Where,

$P_{\text {tract }}=$ total tractive power $(\mathrm{kW})$,

$A=$ coefficient of rolling resistance,

$B=$ coefficient of speed-correction to rolling resistance,

$C=$ coefficient of air-drag factor,

$v=$ instantaneous speed $(\mathrm{m} / \mathrm{s})$,

$a=$ instantaneous acceleration $(\mathrm{m} / \mathrm{s} 2)$,

$g=$ gravitational constant $(9.81 \mathrm{~m} / \mathrm{s} 2)$,

$\theta=$ road grade angle,

$P=$ engine power output,

$\eta_{t f}=$ combined efficiency of the transmission and final drive, and

$P_{a c c}=$ engine power demand associated with the operation of vehicle accessories.

Engine speed is the second CMEM module which presents the vehicle speed using the shift schedule and gear ratios.

The typical air/fuel ratio is evaluated using Equation 5.4:

$$
F R \approx \phi\left(K N V+\frac{P}{\eta}\right) \frac{1}{44}
$$

Where,

$K=$ engine friction factor,

$N=$ engine speed (rps),

$V=$ engine displacement (L), and

$\eta=$ efficiency measure $(\approx 0.4)$. 
The engine-out emissions are computed using Equation 5.5, 5.6, 5.7 and 5.8.

$$
\begin{gathered}
E_{C O} \approx\left[C_{o}\left(1-\phi^{-1}\right)+a_{C O}\right] F R \\
E_{H C} \approx a_{H C} F R+r_{H C} \\
E_{N O x}=a_{1 N O x}\left(F R-F R_{N O x}\right) \text { for } \phi<1.05 \\
E_{N O x}=a_{2 N O x}\left(F R-F R_{N O x} \text { for } \phi \leq 1.05\right)
\end{gathered}
$$

The sixth CMEM module estimates the catalyst fraction using Equation 5.9.

$$
C P F_{e i}=1-\varepsilon_{e i} * \exp \left[F R *\left(-b_{e i}-c_{e i} *\left(1-\phi^{-1}\right)\right)\right.
$$

Where,

$\Phi=$ air/fuel equivalence ratio,

$a_{C O}=$ emission of $\mathrm{CO}$ index coefficient,

$r_{H C}=$ emission of $\mathrm{HC}$ residual coefficient,

$\varepsilon_{e i}=$ maximum catalyst $\mathrm{CO}$ or $\mathrm{HC}$ efficiency,

$F R=$ fuel rate $(\mathrm{g} / \mathrm{s})$,

$b_{e i}=$ stoichiometric CPF coefficients, and

$c_{e i}=$ enrichment $\mathrm{CPF}$ coefficient.

Although the CMEM can estimate second-by-second emissions and total vehicular emissions based on network conditions, the model contains some limitations. First, data is collected using a dynamometer which does not reflect real world driving conditions. Second, the model only estimates four emission components $(\mathrm{CO}, \mathrm{CO} 2, \mathrm{HC}$, and $\mathrm{NOx})$ without measuring particular emissions. Lastly, the model only estimates emissions for light-duty vehicles; bus or truck emissions cannot be examined using this model.

\subsection{VT-microscopic model}

Researchers developed a microscopic model called CT-Micro to estimate vehicle fuel consumption and emissions. This model computes vehicle emissions of $\mathrm{HC}, \mathrm{CO}, \mathrm{NOx}$, and CO2 for dynamic variables such as speed and acceleration (Ahn et al., 2002). 
The general mathematical formulation is given by Equations 5.10 and 5.11.

$$
\begin{gathered}
M O E_{e}=\sum_{i=0}^{3} \sum_{j=0}^{3} \exp \left(* v_{V T}^{i} * a^{j}\right) \text { for } a \geq 0 \\
\operatorname{MOE}_{e}=\sum_{i=0}^{3} \sum_{j=0}^{3} \exp \left(l_{i, j}^{e} * v_{V T}^{i} * a^{j}\right) \text { for } a \geq 0
\end{gathered}
$$

Where,

$M O E_{e}=$ instantaneous fuel consumption or emission rate $(\mathrm{L} / \mathrm{s}$ or $\mathrm{mg} / \mathrm{s})$,

$v_{V T}^{i}=$ instantaneous speed of vehicle $(\mathrm{km} / \mathrm{h})$,

$K_{i, j}^{e}=$ vehicle-specific acceleration regression coefficients, and

$l_{i, j}^{e}=$ vehicle-specific deceleration regression coefficients.

- VeTESS model

VeTESS is another microscopic model that estimates vehicle emissions components (NOx, $\mathrm{COx}, \mathrm{HC}$, and $\mathrm{PM}$ ) while taking driving patterns, vehicle specification, and road conditions into consideration. The model computes vehicle emissions from the total force acting on the vehicle, as expressed in Equation 5.12.

$$
F_{\text {total }}=F_{\text {accel }}+F_{\text {grad }}+F_{\text {roll }}+F_{\text {aero }}
$$

Where,

$F_{\text {total }}=$ total force acting on the vehicle

$F_{\text {accel }}=$ the force required in order to cause an acceleration of the mass of the vehicle

$F_{\text {grad }}=$ the component of the weight force of the vehicle acting parallel to the slope

$F_{\text {roll }}=$ the rolling resistance

$F_{\text {aero }}=$ the aerodynamic resistance

VeTESS has been adopted into the CORSIM software developed by the Federal

Highway Administration (FHWA). CORSIM is a software tool that enables improved simulation logic for several facilities and a wide range of vehicle types. 


\subsection{VERSIT microscopic model}

This model was developed in the Netherlands to simulate traffic emissions ( $\mathrm{CO} 2$, NOx, and PM10) based on the instantaneous speed and acceleration of vehicles. The output of this model is the emission factor (EMFACs) which varies according to vehicle type and traffic conditions. This model simulates real-world driving conditions (Smit et al., 2007). The Advanced Interactive Microscopic Simulator for Urban and Non-urban Networks (AIMSUN) adopted the VERSIT model and has become popular because of its friendly user interface (Boxill $\& Y u, 2000)$

\subsection{PHEM model}

The PHEM model estimates emissions microscopically using an emissions map which works as a look-up table. The emissions map is developed based on engine operating features such as engine speed and torque instead of vehicle speed and power. The PHEM model has been extended to include heavy-duty vehicles in addition to light-duty vehicles. The model estimates the $\mathrm{CO}, \mathrm{CO} 2, \mathrm{HC}$, and NOx emissions (Zallinger et al., 2005).

The PHEM model was incorporated into the VISSIM software. VISSIM is another realistic microscopic simulator that can simulate more driving logic.

\subsection{EMIT model}

EMIT is another vehicle emissions model that takes vehicle speed and acceleration into account while estimating vehicle emissions. This model only computes only one emission component (CO2). This model was validated for the measurement of the environmental impact of inter-vehicle communication (IVC) technologies (Sommer et al., 2011).

\subsection{MOVES model}

The Motor Vehicle Emission Simulator (MOVES) is the official microscopic model and simulator of the United States Environmental Protection Agency (EPA) which is used in the USA to evaluate vehicle fuel consumption and emissions. MOVES evaluates vehicle emission components such as NOx, $\mathrm{PM}, \mathrm{CO}, \mathrm{CO} 2, \mathrm{SO} 2$, and $\mathrm{NH} 3$ based on the speed and acceleration of vehicles and other variables. 


\subsubsection{Macroscopic models}

This type of model uses the average size of network aggregate parameters to estimate the emissions of inventories for large regional areas using input data such as speed, flow, and density. This kind of modeling uses the relationship between the three parameters. MOBILE, EMFAC, CORFLO, the Watson model, and COPERT are examples of macroscopic models.

\subsection{MOBILE macroscopic model}

The MOBILE model is a transportation macro-simulation software developed by the US EPA and used in transportation planning in the US. The MOBILE model evaluates eight emission components including $\mathrm{HC}, \mathrm{CO}, \mathrm{NOx}, \mathrm{CO} 2, \mathrm{PM}, \mathrm{SO} 2, \mathrm{NH} 3$, and HAP. In this model, $\mathrm{CO} 2$ emissions are estimated based only on vehicle type.

\subsection{EMFACs model}

This model was developed by the California Air Resources Board (CARB) and is used to estimate $\mathrm{HC}, \mathrm{CO}, \mathrm{NOx}, \mathrm{CO} 2, \mathrm{PM}, \mathrm{SOx}$, and pb emissions in California

\subsection{MOVES model}

MOVES is a simulation tool used in transportation analysis that was incorporated in the TRANSIMS software adopted by the Los Alamos National Laboratory in New Mexico. TRANSIMS is based on simple logic such as car following, lane changing, and cellular automaton techniques. It simulates the second by second traffic movement between networks and estimates vehicle emission for the whole network.

\subsection{CORFLO model}

CORFLO is a macroscopic simulation software developed by the Federal Highway Administration. It is designed to evaluate integrated traffic networks and is calibrated and documented as a macroscopic tool. The model is associated with the conservation and dynamic

speed density equations. One of the limitations of CORFLO is that it cannot simulate most ITS applications (Boxill \&Yu, 2000).

\subsubsection{Mesoscopic models}

The input variable aggregate for the mesoscopic model is somewhere between the macroscopic and microscopic models. Examples of mesoscopic models include the Elemental 
model, CONTRAM, and the mobile emission assessment system for urban and regional evaluation (MEASURE) model (Yue, 2008).

\subsection{Elemental Model:}

The elemental model was developed based on average speed in two different studies.

The model is based on a theoretical expression of fuel consumption in urban conditions as a linear function regarding the average trip time (Chang \& Evans, 1981; Evans \& Herman, 1978). The model formula is expressed by Equation 5.13.

$$
\phi_{E}=K_{1}+K_{2} T \text { for } v<55 \mathrm{~km} / \mathrm{hr}
$$

Where,

$\phi_{E}=$ fuel consumption per unit distance,

$T=$ average travel time per unit distance,

$V=$ average speed,

$K 1=$ model parameter representing the vehicle mass (in $\mathrm{mL} / \mathrm{km}$ ), and

$K 2=$ model parameter that is a function of the average vehicle speed (in $\mathrm{mL} / \mathrm{s}$ ).

As Equation 5.13 shows, the model is only valid for average speeds under $55 \mathrm{~km} / \mathrm{hr}$. The model is not applicable for high speeds because it does not take aerodynamic resistance into account. The elemental model was incorporated into the SIDRA INTERSECTION software developed by Akcelik (Akcelik, 1985; Richardson and Akcelik, 1981). The model is widely used in Australia to estimate vehicle emissions in all driving trajectories (cruising, deceleration, acceleration and idle).

\subsection{CONTRAM model}

The continuous traffic assignment model (CONTRAM) estimates emissions based on heavy traffic flow dynamics using aggregated speed-density relationships (Sommer et al., 2011). TRL and Mott McDonald developed CONTRAM to model complex travel behavior links with the ability to simulate ITS applications. 


\subsection{MEASURE model}

Researchers at the Georgia Institute of Technology developed this model based on a geographic information system (GIS) to estimate $\mathrm{HC}, \mathrm{CO}$, and NOx emissions as a function of vehicle specifications, road characteristics, and travel trajectories (Bachman and Sarasua, 1996).

\subsubsection{Formulation modeling}

This technique is based on formulas developed analytically, statistically, or empirically. The analytical formulas are usually derived from physical relationships. The statistical formulas only use data obtained through statistical analysis. The empirical formulas use analytical expressions along with additional parameters determined using observational data.

\subsubsection{Main input variables}

This process of modeling is based on using the main inputs as variables. There are three different models that consider three different main variables. The three different variables that are considered as main variables are average speed, instantaneous speed and specific power.

\subsubsection{Average speed based model}

Many researchers have adopted emissions models based on average speed as a main independent variable (Ding \& Rakha, 2004; Evans \& Herman, 1978; Guensler et al. 1993; Kent \& Mudford, 1979; Taylor, 2003).

\subsubsection{Instantaneous speed based model}

Several researchers have used instantaneous speed as the primary variable when modelling vehicle emissions. Rakha and Ahn (2004) concluded that the average speed based model is not accurately used in some situations, especially for ITS applications. They observed that there is some variation in the instantaneous speed and acceleration/deceleration profiles in some cases with the same average speed. Another study conducted by Ahn et al. (2002) adopted a statistical model for the evaluation of vehicle emissions as a function of instantaneous speed and other variables.

\subsubsection{Specific power}

A number of papers consider vehicle specific power as the main independent variable in vehicle emission modeling. Frey et al. (2007) adopted a vehicle specific power (VSP) model 
that can be used to model fuel consumption for diesel and hydrogen fuel cell buses. A comparison of the actual fuel consumption with the estimated fuel consumption revealed less than $10 \%$ variation for all of their observations. Ran et al. (2007), Wang et al. (2008), Song et al. (2009) and Feng (2007) also adopted vehicle emission estimation models based on specific power.

Jiménez (1999) developed a vehicle specific power model which includes variables such as rolling resistance, kinetic and potential energy, aerodynamic drag, and acceleration as expressed by Equation 5.14.

$$
V S P=\frac{\text { power }}{\text { mass }}=\frac{d}{d t} \frac{\left.\left(E_{\text {kinetic }}+E_{\text {potential }}\right)+F_{\text {rolling }} * v+F_{\text {aerodynamic }} * v\right)}{m}
$$

Where, $v=$ speed,

$E_{\text {kinetic }}=$ kinetic energy,

$E_{\text {potential }}=$ potential energy,

$F_{\text {rolling }}=$ rolling resistance,

$F_{\text {aerodynamic }}=$ aerodynamic drag, and

$\mathrm{m}=$ vehicle mass.

The equation can be simplified to be expressed as shown in Equation 4.15 if the grade is zero (horizontal segment).

$$
V S P=v *(1.14 \mathrm{a}+0.132)+0.000302 * v^{3}
$$

Where,

$\mathrm{VSP}=$ Vehicle specific power $(\mathrm{kW} / \mathrm{ton})$;

$v=$ Speed $(\mathrm{m} / \mathrm{s}) ;$ and

$a=$ Acceleration $\left(\mathrm{m} / \mathrm{s}^{2}\right)$. 


\section{Chapter 6 Proposed Model}

\subsection{Introduction}

The geometric features of a roundabout are linked to several design measurements such as speed, safety, and capacity and significantly affect safety performance and environmental impact. The design of roundabouts involves an iterative method that begins by assuming the initial values of basic geometric parameters and then checks the performance of the roundabout using suitable software tools. Researchers have found that the optimization technique is an effective way to find the optimal design parameters instead of a trial and error process.

\subsection{Proposed Methodology}

The methodology described in Figure 6-1 is based on modeling three design objectives (safety performance, mobility and environmental impact) using a multi-objective optimization methodology. The model was developed using a spreadsheet and solved using a solver tool in the Excel software with significant saving time. The necessary input data included the traffic data, site conditions, and guidelines. The methodology is explained in more detail in the following section. 


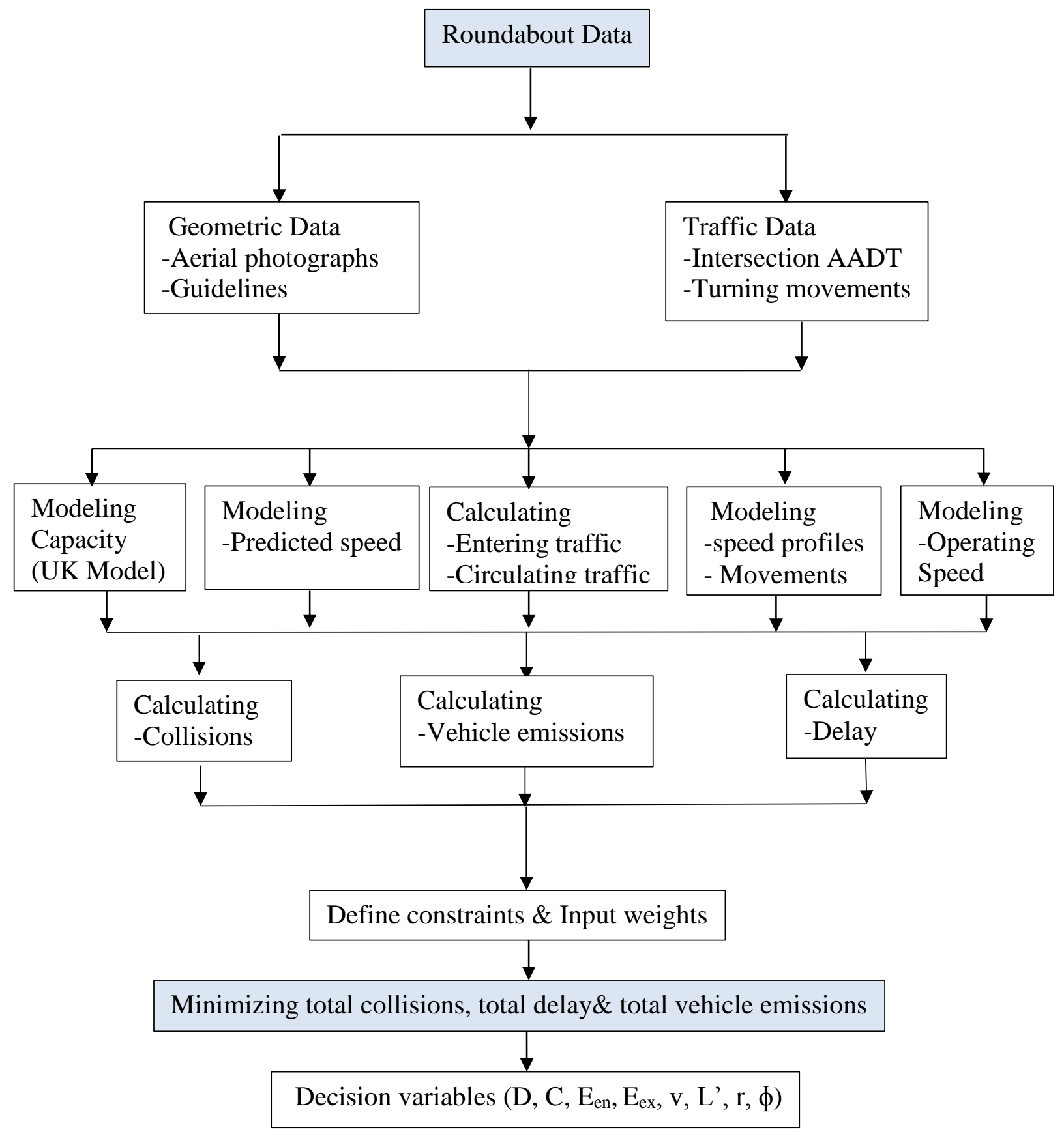

Figure 6-1: Model development proposed methodology 


\subsection{Roundabout Data}

The required roundabout data consists of geometric data and traffic data. The geometric data include ranges for the inscribed circle diameter, the entry width, the exit width, and the circulated width. The maximum values of the geometric parameters depend on the site conditions and physical constraints such as the available right of way, drainage and utility constraints. The aerial photography of the proposed site provides the maximum ranges of the geometric diameters and should be verified through the site survey. The minimum ranges of the geometric parameters were retrieved from the guidelines based on the design vehicle: Roundabouts - An Informational Guide (Rodegerdts et al., 2010).

Traffic data involves the volume of vehicles entering the intersection. Actual traffic data are used if the module is used to evaluate an existing roundabout or transform an existing intersection into a roundabout to improve any of the design objectives. Predicted traffic data can be used if the module is used to design a new roundabout. The traffic data should first be prepared and converted from vehicle per hour to the passenger car equivalent by considering the peak hour factor and heavy vehicle factor given by Equations 6.1 and 6.2.

$$
\begin{gathered}
\mathrm{Q}_{\mathrm{pce}}=\frac{Q_{v e h}}{\mathrm{HVF} * \mathrm{PHF}} \\
H V F=\frac{1}{1+P_{t} *\left(E_{t}-1\right)}
\end{gathered}
$$

Where,

$\mathrm{HVF}=$ heavy vehicle factor,

$\mathrm{Pt}=$ the percentage of tracks,

$E_{t}=$ the truck equivalent factor of the passenger car, and

$\mathrm{PHF}=$ the peak hour factor.

The intersection traffic is converted to roundabout traffic by calculating the total approach entering traffic which is the sum of all movements at this approach, as given in Equation 6.3.

$$
Q_{e n, j}=Q_{T H, j}+Q_{R T, j}+Q_{L T, j}+Q_{U T, j}
$$


Where,

$Q_{e n, j}=$ the entering traffic at approach $\mathrm{j}$,

$Q_{T H, j}=$ the through movement traffic at approach $\mathrm{j}$,

$Q_{R T, j}=$ the right-turn movement traffic at approach $\mathrm{j}$,

$Q_{L T, j}=$ the left-turn movement traffic at approach $\mathrm{j}$,

$Q_{U T, j}=$ the U-turn movement traffic at approach $\mathrm{j}$, and

$\mathrm{J}=$ approach number $(1,2,3$, or 4$)$

The conflicting traffic or circulating traffic of a roundabout is the sum of all the traffic that passes in front of this entering approach and is obtained using Equation 6.4

$$
\begin{gathered}
Q_{c o n f, j}=Q_{U T,(j+1)}+Q_{U T,(j+2)}+Q_{L T,(j+2)}+Q_{U T,(j+3)}+Q_{L T,(j+3)} \\
+Q_{T H,(j+3)}
\end{gathered}
$$

Where,

$Q_{\text {conf }, j}=$ the conflicting traffic for approach $\mathrm{j}$, and the rest are defined previously in Equation 6.3.

\subsection{Modeling the First Objective: Safety Performance}

The predicted speed model obtained using equation 6.5 is used when modeling safety performance. There is evidence that modern roundabouts provide a significant improvement in the safety performance of intersections. The major factor behind this improvement is speed control. The safety performance of roundabouts can therefore be linked to the operating or predicted speed (Rodegerdts et al., 2010). Chen et al (2013) developed a predicted speed model expressed in terms of the geometric features of the roundabout using data from 139 U.S and 34 Italian roundabout approaches. This model provided superior safety performance measurement and is given by Equation 6.5.

$$
\begin{gathered}
\mathrm{AAS}_{\mathrm{j}}=13.015958-3.088964 * \text { Cntry }+0.034074 * \mathrm{D}_{\mathrm{av}, \mathrm{j}}+0.142936 \\
* W_{a v, j}
\end{gathered}
$$


Where,

$\mathrm{AAS}_{\mathrm{j}}=$ average speed at approach $\mathrm{j}(\mathrm{mph})$,

Cntry $=1$ for U.S. and 0 for Italy,

$\mathrm{D}_{\mathrm{av}}=$ the average of the inscribed and central island diameters $(\mathrm{ft})$, and

$W_{a v, j}=$ the average of the entry width, circulated width, and exit width of approach $\mathrm{j}(\mathrm{ft})$.

The approach average speed is the average of the entry speed, circulating speed and exit speed.

The average speed is determined by the geometric parameters of the roundabout including inscribed circle diameter (D), central island diameter $\left(2 \mathrm{R}_{\mathrm{c}}\right)$, circulated width $(C)$, entry width $\left(E_{e n}\right)$, and exit width $\left(E_{e x}\right)$. The predicted speed is modeled for each approach as each approach might have different exit and entry widths. A safety performance function (SPF) function is then used to evaluate the safety performance of the roundabout. Chen et al (2013) also developed a safety performance function based on the predicted speed model given by equation 6.5 . The safety performance function is given by Equation 6.6.

$$
C F_{j}=\exp (-16.3755) *\left(A A D T_{j}\right)^{0.5094} *\left(A A S_{j}\right)^{4.3314}
$$

Where,

$C F_{\mathrm{j}}=$ collision frequency (collision/yr.),

$A A D T_{\mathrm{j}}=$ the entering traffic $(\mathrm{pcu} / \mathrm{h})$, and

$A A S_{\mathrm{j}}=$ the average speed of approach $\mathrm{j}(\mathrm{mph})$.

The approach collisions are modeled based on the predicted speed given by Equation 6.5 and the speed based safety performance function given by Equation 6.6. For each approach, the collision frequencies are modeled using Equation 6.7.

$$
\begin{aligned}
C F_{j}=\exp (-16.3755) *\left(A A D T_{j}\right)^{0.5094} & \\
& *\left(13.015958-3.088964 * \text { Cntry }+0.034074 * \mathrm{D}_{\mathrm{av}}\right. \\
& \left.+0.142936 * W_{a v, j}\right)^{4.3314}
\end{aligned}
$$

The dispersion parameter is obtained using Equation 6.8 


$$
K=\frac{3}{\exp (0.0618 A A S)}
$$

The dispersion parameter and observed crashes are used to calculate the predicted crashes, as given by Equations 6.9, 6.10 and 6.11.

$$
\begin{gathered}
m=w_{1} x+w_{2}(C F) \\
w_{1}=\frac{C F}{\frac{1}{k}+n(C F)} \\
w_{2}=\frac{\frac{1}{K}}{\frac{1}{K}+n(C F)}
\end{gathered}
$$

Where,

$\mathrm{CF}=$ the crash frequency calculated using Equation 6.7

$\mathrm{K}=$ the dispersion parameter

$w_{1}=\mathrm{T}$ the observed crashes weight

$w_{2}=$ the predicted crashes weight

$\mathrm{x}=$ the observed crashes

$\mathrm{n}=$ the number of years

$\mathrm{m}=$ the predicted number of crashes

\subsection{Modeling the Second Objective: Mobility}

As previously explained in chapter 4, mobility is defined by delay and level of service. Several capacity models were presented in chapter 4 . The capacity models were categorized into two groups. One group are functions in traffic flow while the geometric parameters are taken into consideration by roundabout size or lane configuration and the other group are functions in the geometric parameters. Recent research conducted by Johnson (2018) discovered that the absence of geometric parameters in the HCM gap acceptance model leads to a wide range of data. This was confirmed using the empirical geometric model of the UK to test the same set of data that 
was used to develop the HCM6 model. The results revealed that the inclusion of variation in geometric features improves the accuracy of predicted capacity.

\subsubsection{Modeling roundabout capacity}

The United Kingdom model was used to model roundabout capacity in this study. The model is given by Equations 6.12 to 6.18 .

$$
\begin{gathered}
Q e=k\left(F-f_{c} Q_{c}\right) \\
Q e=k\left(F-f_{c} Q_{c}\right) \\
k=1-0.00347(\phi-30)-0.978\left(\frac{1}{r}-0.05\right) \\
F=303 x 2 \\
f_{c}=0.210 T_{D}\left(1+0.2 x_{2}\right) \\
x 2=v+\frac{e-v}{1+2 S} \\
S=1.6(e-v) l^{\prime}
\end{gathered}
$$

Where,

$Q e=$ maximum entry flow $(\mathrm{veh} / \mathrm{h})$,

$\left.Q_{c}\right)=$ circulating flow $(\mathrm{veh} / \mathrm{h})$,

$e=$ entry width $(\mathrm{m})$,

$v=$ approach half-width $(\mathrm{m})$,

$l^{\prime}=$ effective flare length $(\mathrm{m})$,

$r=$ entry radius $(\mathrm{m})$,

$\varphi=$ entry angle $\left({ }^{\circ}\right)$,

$S=$ measure of the degree of the flaring, and

$D=$ inscribed circle diameter $(\mathrm{m})$.

Using the UK empirical model, the roundabout capacity is modeled as a function of six geometric parameters (defined above) for each approach. 


\subsubsection{Modeling roundabout delay}

In this study, the HCM delay model was used to model roundabout delay. The model is given by Equation 6.19.

$$
d=\frac{3600}{c}+900 * T *\left[\frac{v}{c}-\sqrt{\left(\frac{v}{c}-1\right)^{2}+\frac{\left(\frac{3600}{c}\right) *\left(\frac{v}{c}\right)}{450 * T}}\right]
$$

Where,

$d=$ control delay $(\mathrm{s} / \mathrm{veh})$,

$T=$ analysis time period $(T=0.25$ for a 15 -min period $)(\mathrm{h})$,

$c=$ capacity $(\mathrm{veh} / \mathrm{h})$, and

$v=$ flow rate $(\mathrm{veh} / \mathrm{h})$.

The approach delay is modeled using Equation 6.20.

$$
d_{j}=\frac{3600}{c_{j}}+900 * T *\left[\frac{v_{j}}{c}-\sqrt{\left(\frac{v_{j}}{c_{j}}-1\right)^{2}+\frac{\left(\frac{3600}{c_{j}}\right) *\left(\frac{v_{j}}{c_{j}}\right)}{450 * T}}\right]
$$

\subsection{Modeling the Third Objective: Vehicle Emissions}

\subsubsection{Vehicle Specific-Power Model}

Numerous researchers have used models based on vehicle specific power to measure vehicle emissions (Coelho 2006; Federal Highway Administration 2010; Salamati at al. 2013; Song 2015; and Zhai 2008). Vehicle specific power (VSP) is the engine power needed to move a vehicle unit mass. Researchers simplified the VSP equation to be expressed in terms of the instantaneous speed and acceleration of the vehicle as well as the road grade. In roundabouts, road grade is considered as horizontal, as given by Equation 6.21.

$$
\mathrm{VSP}=\mathrm{v} *(1.1 \mathrm{a}+0.132)+0.000302 * \mathrm{v}^{3}
$$

Where,

$\mathrm{VSP}=$ the vehicle specific power,

$\mathrm{v}=$ the vehicle instantaneous speed or second by second speed $(\mathrm{m} / \mathrm{s})$, and 
$\mathrm{a}=$ the vehicle acceleration or deceleration $\left(\mathrm{m} / \mathrm{s}^{2}\right)$.

In this study, the acceleration and deceleration values were $2.1 \mathrm{~m} / \mathrm{s}^{2}$ and $1.3 \mathrm{~m} / \mathrm{s}^{2}$, respectively, as recommended by Rodegerdts (2010). The acceleration and deceleration are considered constant for simplicity and due to the unavailability of acceleration/ deceleration models for roundabouts.

The speed is the operating speed modeled by Bassani and Sacchi (2011) and given by Equation 6.22 .

$$
\mathrm{V}_{85}=0.4433 * \mathrm{D}_{\mathrm{INT}}+0.8367 * \mathrm{C}+3.2272 * \mathrm{E}
$$

Where,

$v=85$ th percentile speed $(\mathrm{km} / \mathrm{hr})$,

$C=$ the width of the circulatory roadway $(\mathrm{m})$,

$E=$ the width of the entry lane (m), and

$\mathrm{D}_{\mathrm{INT}}=$ the central island diameter $(\mathrm{m})$.

\subsubsection{Speed Profiles}

The speed profile of roundabouts, based on vehicle trajectories, is divided into three cases with three different speed profiles modeled by Coelho et al. (2006) and illustrated in Figure 6-2. Using extensive empirical measurements, the researchers identified three representative speed profiles for vehicles navigating a single-lane roundabout. They related the frequency of each speed profile to the congestion level. The researchers divided the vehicles approaching a singlelane roundabout into three scenarios:

1. Unstopped vehicles that approach the roundabout. These vehicles decelerate from the upstream approach speed to reach the roundabout operating speed then accelerate to reach the downstream speed.

2. Vehicles experiencing one-stop. These vehicles decelerate to a full stop at the yield line. The vehicles remain idle waiting for an acceptable gap in the conflicting traffic. When they accept a gap, they enter the roundabout, accelerating until they reach the operating speed of the roundabout. The vehicles travel a specific distance in the roundabout based on their movement, then accelerate to the downstream speed. 
3. Vehicles that experience more than one-stop on the approach because they line up in a queue. When the vehicles reach the yield line, they remain idle waiting to accept a gap. The vehicles travel a specific distance at the roundabout operating speed, then accelerate when exiting the roundabout.

The study developed regression models based on the sum of the entering and conflicting traffic to express the number of vehicles that experience each trajectory.

Regression models that best described the relative occurrence of the three speed profiles were developed. The stop and go cycles experienced in the third-speed profile was expressed according to the queue length (Coelho et al., 2006). The speed profiles are explained in the following section and shown in Figure 6-2. The stop and go cycles were either long or short. 


\section{Speed}

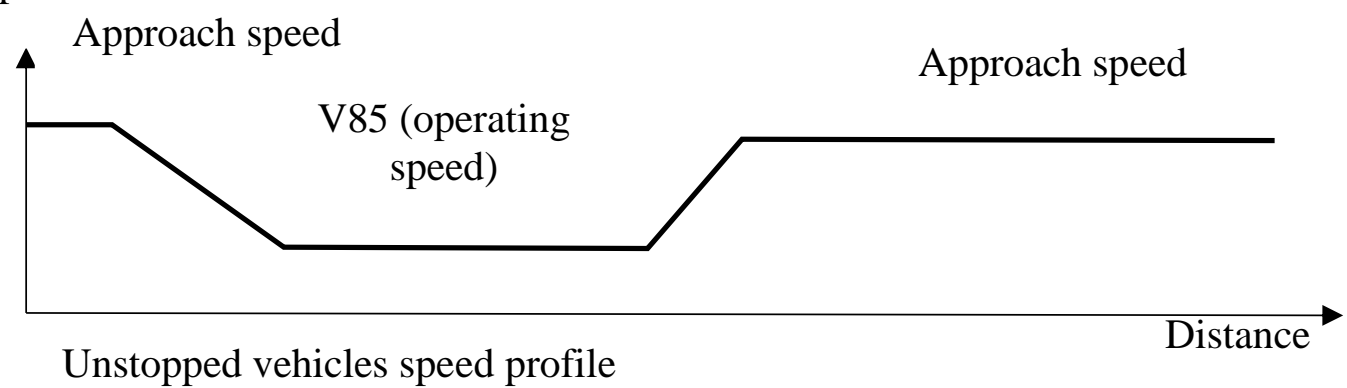
Speed

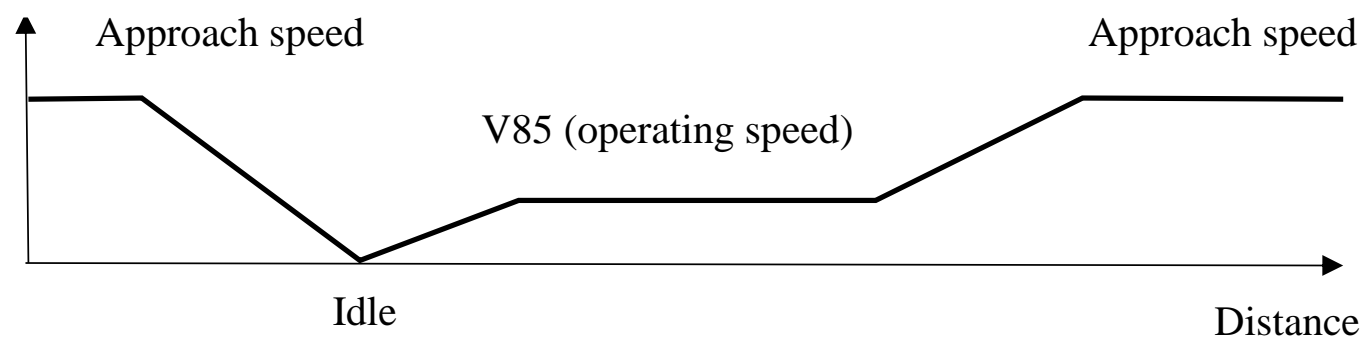

One-stop vehicles speed profile

Speed

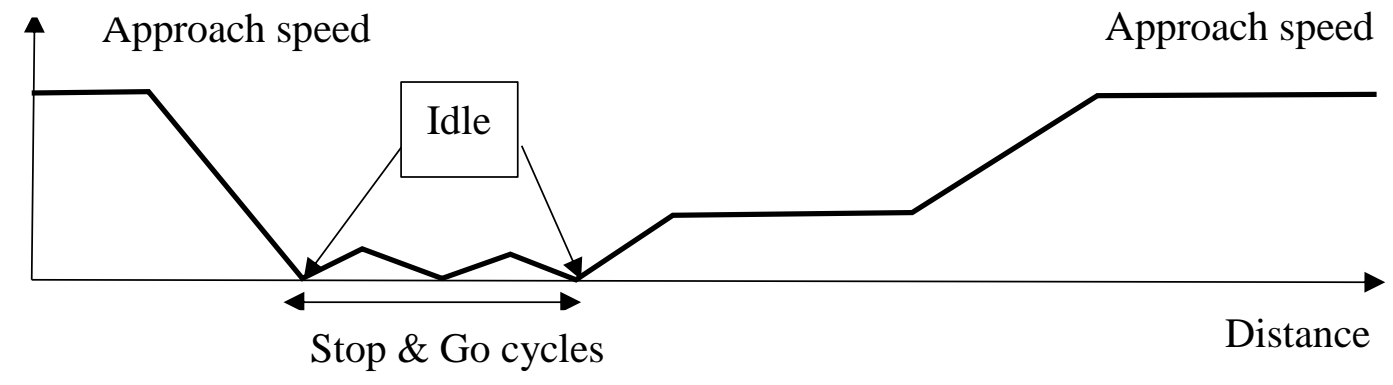

More than one-stop vehicles speed profile

Figure 6-2: A single-lane roundabout typical speed profiles

1. The percentage of vehicles that cross the roundabout without stopping is given by Equation 6.23.

$$
\%(\text { Unstopped vehicles })=100-0.0000611\left(Q_{\text {conf }}+Q_{e n}\right)
$$


2. The percentage of vehicles that stop only once at the yield line of the roundabout is given by Equation 6.20.

$$
\begin{aligned}
& \%(\text { one }- \text { stop vehicles }) \\
& \qquad \begin{array}{l}
=100-\%(\text { Unstopped vehicles })-\%(\text { more than one } \\
- \text { stop vehicles })
\end{array}
\end{aligned}
$$

3. The percentage of vehicles that experience more than one stop through go and stop cycles before crossing the roundabout is given by Equation 6.25 .

$$
\begin{aligned}
& \%(\text { more than one }- \text { stop vehicles }) \\
& \qquad=\exp \left[0.00123\left(Q_{\text {conf }}+Q_{\text {en }}-300\right)^{1.2}-1\right.
\end{aligned}
$$

Where,

$Q_{\text {conf }}=$ the conflicting traffic of the calculated approach, and $Q_{e n}=$ the total approach entering traffic of the approach.

The stop and go cycles experienced by vehicles were characterized into short and long cycles based on the queue length. The numbers are given by Equations 6.26 and 6.27.

$$
\begin{gathered}
S S G=1.834 * \exp (0.0759 Q L)-1 \\
\mathrm{LSG}=1.997 * \exp (0.1124 Q L)-[1.834 * \exp (0.0759 Q L)-1]
\end{gathered}
$$

Where,

$\mathrm{SSG}=$ short stop and go cycle number,

$\mathrm{LSG}=$ long stop and go cycle number, and

$\mathrm{QL}=$ the queue length (veh.).

The researchers identified the typical characteristics of short and long cycles. The typical maximum speed of a short cycle is $3.8 \mathrm{~km} / \mathrm{h}$, the typical distance is $5.2 \mathrm{~m}$, and the typical idle 
time before each cycle is $4.5 \mathrm{sec}$. The typical maximum speed of a long cycle is $6.6 \mathrm{~km} / \mathrm{h}$, the typical distance is $15.1 \mathrm{~m}$, and the typical idle time before each cycle is $5.2 \mathrm{sec}$.

The idle time at the yield line was modeled theoretically based on the probability of accepting a gap between the circulating traffic. The average headway of the circulating traffic is given by Equation 6.28.

$$
A H W=\frac{3600}{Q_{\text {conf }}}
$$

Where,

$\mathrm{AHW}=$ the average headway time (sec), and

$\mathrm{Q}_{\text {conf }}=$ the circulating traffic in $\mathrm{pce} / \mathrm{hr}$

The probability of waiting for 0 gaps is given by Equation 6.29.

$$
P=\exp \left(-\frac{t_{c}}{A H W}\right)
$$

Where,

$\mathrm{P}=$ the probability of waiting for 0 gaps, and

$t_{c}=$ the critical gap specified in HCM6 to be $4.99 \mathrm{sec}$

The expected number of gaps is given by Equation 6.30, and the idle time is given by Equation 6.31 .

$$
\begin{gathered}
\mathrm{E}_{\mathrm{n}}=(1-\mathrm{P}) / \mathrm{P} \\
\text { Idle time }=E_{n} * A H W
\end{gathered}
$$

Where,

$\mathrm{E}_{\mathrm{n}}=$ the expected number of gaps.

Using a small optimizing model, the stop and go cycles of speed profile 3 are modeled based on the information provided by Coelho et al. (2006) and kinematic equations that consider acceleration and deceleration as the same value. The model determines the acceleration/deceleration of SSG and LSG to be 0.327 and $1.902 \mathrm{~m} / \mathrm{s}^{2}$, respectively. 
Each speed profile includes three basic movements: through movement, right turn movement, and left turn movement. The vehicles for each movement travel different distances through the roundabout. The three basic movements and three speed profiles provide nine different speed profiles. The vehicles decelerate from approach downstream speed to reach the roundabout operation speed then cross the roundabout at the operation speed for a different distance based on each movement. The vehicles exiting the roundabout accelerate from the roundabout operation speed to the upstream approach speed. In this study, the through movement, right turn movement and left turn movement was modeled for each speed profile specified in the previous section. The three movements are characterized by the distance or time traveled in the roundabout until exit. Easa and Mehmood (2004) calculated the fastest path of vehicles in single-lane roundabouts with different inscribed circle diameters. They found that the through movement vehicles enter and exit the roundabout at around a $60^{\circ}$ angle, right turn movement vehicles enter and exit at $30^{\circ}$ and $60^{\circ}$ (respectively), and left turn movement vehicles enter and exit at around a $45^{\circ}$ angle. The fastest vehicle path is $1.5 \mathrm{~m}$ from the concrete curb (Rodegerdts et al., 2010), as shown in Figure 6-3.

1. Through movement vehicle path.

Figure 6.3 shows the through movement vehicle path.

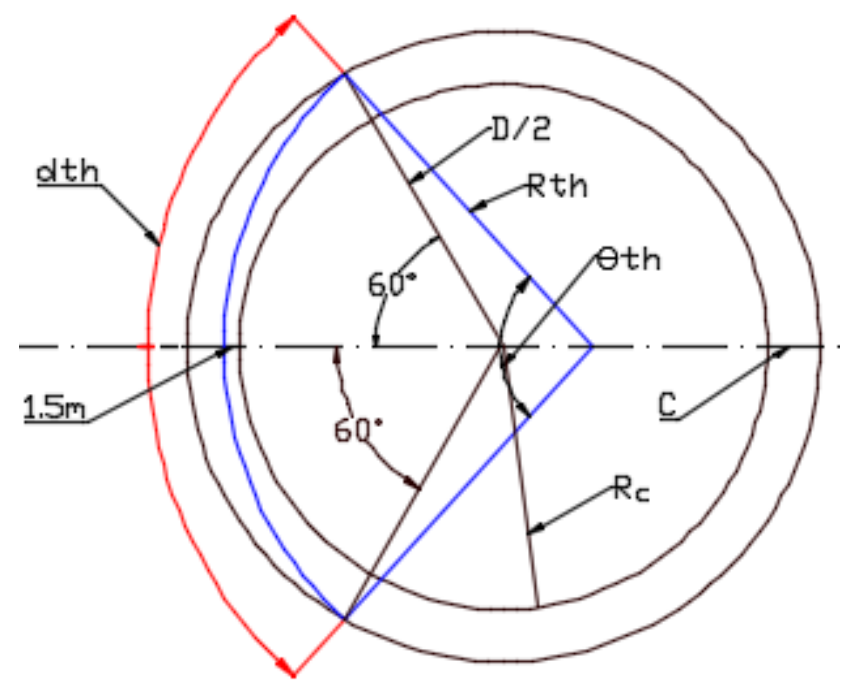

Figure 6-3: Through movement vehicle path at single-lane 
The distances $d_{\text {the }}, d_{r}$ and $d_{L}$ can be derived from the geometric parameters of Figure 6-3 as follows:

$$
\begin{gathered}
\frac{D}{2} \cos 30=R_{t h} \sin \left(\frac{\theta_{t h}}{2}\right) \\
\mathrm{R}_{\mathrm{th}}=\mathrm{R}_{\mathrm{th}} \cos \left(\frac{\theta_{t h}}{2}\right)+1.5+R_{c}-\frac{D}{2} \sin 30
\end{gathered}
$$

Equation 6.33 can be simplified by Equation 6.34 .

$$
R_{t h}\left(1-\cos \left(\frac{\theta_{t h}}{2}\right)\right)=R_{c}-\frac{D}{2} \sin 30+1.5
$$

By dividing Equation 6.34 by Equation 6.32, Equation 6.35 can be expressed as:

$$
\frac{\left(1-\cos \left(\frac{\theta_{t h}}{2}\right)\right)}{\sin \left(\frac{\theta_{t h}}{2}\right)}=\frac{\left(R_{c}-\frac{D}{2} \sin 30+1.5\right)}{\frac{D}{2} \cos 30}
$$

Equation 6.36 is a geometry rule that relates the three measures of any angle: sin, cos and tan.

$$
\frac{1-\cos x}{\sin x}=\tan \left(\frac{x}{2}\right)
$$

Therefore,

$$
\tan \left(\frac{\theta_{t h}}{4}\right)=\frac{\left(R_{c}-\frac{D}{2} \sin 30+1.5\right)}{\frac{D}{2} \cos 30}
$$

Equation 6.37 can be simplified to express $\theta_{t h}$ as:

$$
\theta_{t h}=4 \tan ^{-1}\left[\frac{R_{c}+1.5}{0.433}-0.57735\right]
$$

The radius of the through movement vehicle path can be determined by Equation 6.35 . 


$$
\mathrm{R}_{\mathrm{th}}=\frac{0.433 \mathrm{D}}{\sin \left(\frac{\theta_{t h}}{2}\right)}
$$

From Equations 6.39 and 6.38, the radius of the through movement vehicle path can be expressed in terms of $\mathrm{D}$ and $R_{c}$ as given by Equation 6.40 .

$$
R_{t h}=\frac{0.433 \mathrm{D}}{\sin \left[\left(4 \tan _{1}\left(\frac{R_{c}+1.5}{0.433}-0.57735\right) / 2\right]\right.}
$$

The distance traveled by a vehicle navigating through the roundabout can be determined by Equation 6.41.

$$
d_{t h}=R_{t h} * \theta_{t h} * \pi / 180
$$

Where,

$\mathrm{D}=$ the inscribed circle diameter $(\mathrm{m})$,

$R_{c}=$ the central island radius $(\mathrm{m})$,

$\mathrm{R}_{\mathrm{th}}=$ the through path radius $(\mathrm{m})$, and

$\theta_{\text {th }}=$ the through path angle (degrees).

2. Right turn movement vehicle path.

The right turn movement vehicle path is shown in Figure 6.4. 


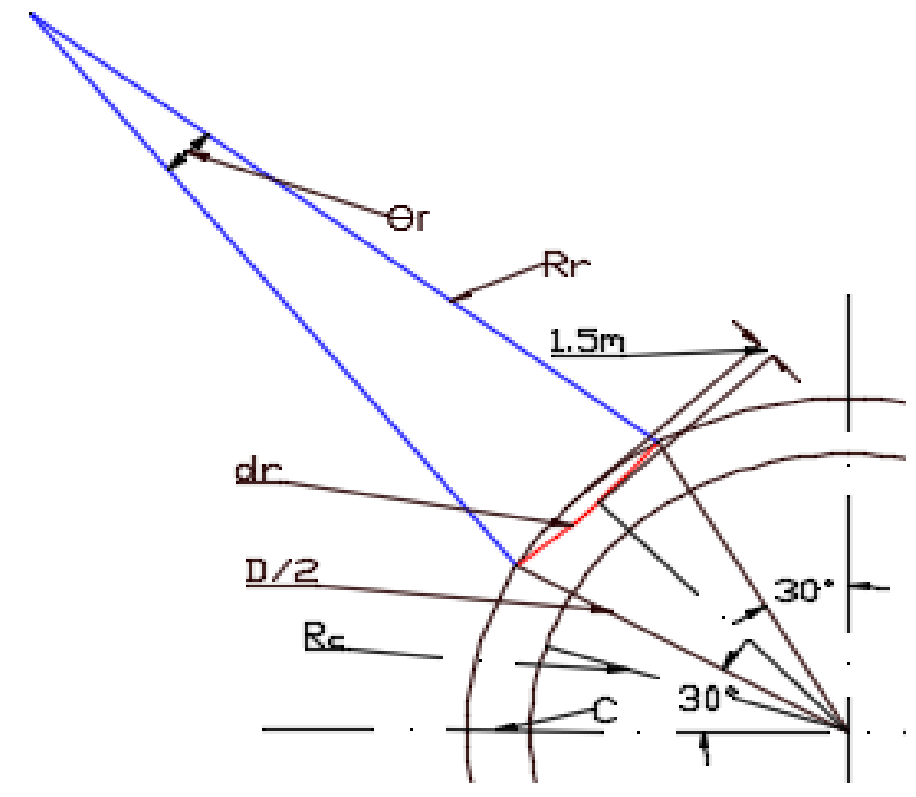

Figure 6-4: Right-turn movement vehicle path

From the geometry of Figure 6.4, the right path radius and angle can be derived as follows:

$$
\begin{gathered}
\mathrm{R}_{\mathrm{r}} \sin \left(\frac{\theta_{r}}{2}\right)=\frac{D}{2} \sin 15 \\
\frac{D}{2}(1-\cos 15)+R_{r}\left(1-\cos \left(\frac{\theta_{r}}{2}\right)\right)=1.5
\end{gathered}
$$

Equation 6.43 can be simplified to:

$$
R_{r}\left(1-\cos \left(\frac{\theta_{r}}{2}\right)\right)=1.5-\frac{D}{2}(1-\cos 15)
$$

By dividing Equation 6.44 by Equation 6.42, Equation 6.45 can be expressed as: 


$$
\frac{\left(1-\cos \left(\frac{\theta_{r}}{2}\right)\right)}{\sin \left(\frac{\theta_{r}}{2}\right)}=\frac{1.5-\frac{D}{2}(1-\cos 15)}{\frac{D}{2} \sin 15}
$$

Using the geometry rule shown previously in Equation 6-36 that was given by the expresion:

$\frac{1-\cos x}{\sin x}=\tan \left(\frac{x}{2}\right)$

$\theta_{r}$ can be expressed as:

$$
\tan \left(\frac{\theta_{r}}{4}\right)=\left(\frac{1.5-0.017037 D}{0.12941 D}\right)
$$

Therefore,

$$
\theta_{\mathrm{r}}=4 \tan ^{-1}\left(\frac{11.59111}{D}-0.131651\right)
$$

Then, the right-turn movement vehicle path radius is determined by Equation 6.48 .

$$
\mathrm{R}_{\mathrm{r}}=\frac{0.1294 D}{\sin \left(\frac{\theta_{r}}{2}\right)}
$$

From Equations 6.45 and 6.48, the radius of the right-turn movement vehicle path can be expressed in terms of $\mathrm{D}$, as given by Equation 6.49 .

$$
R_{r}=\frac{0.1294 D}{\sin \left[\frac{\left(4 \tan ^{-1}\left(\frac{11.59111}{D}-0.131651\right)\right)}{2}\right]}
$$

The distance traveled in the roundabout by a vehicle making a right-turn is given by Equation 6.50 . 


$$
\mathrm{d}_{\mathrm{r}}=\mathrm{R}_{\mathrm{r}} * \theta_{\mathrm{r}} * \pi / 180
$$

Where,

$\mathrm{D}=$ the inscribed circle diameter $(\mathrm{m})$,

$\mathrm{R}_{\mathrm{r}}=$ the right turn path radius $(\mathrm{m})$, and

$\theta_{\mathrm{r}}=$ the right turn path angle (degrees).

1. Left- turn movement vehicle path.

The left- turn movement vehicle path is shown in Figure 6-5.

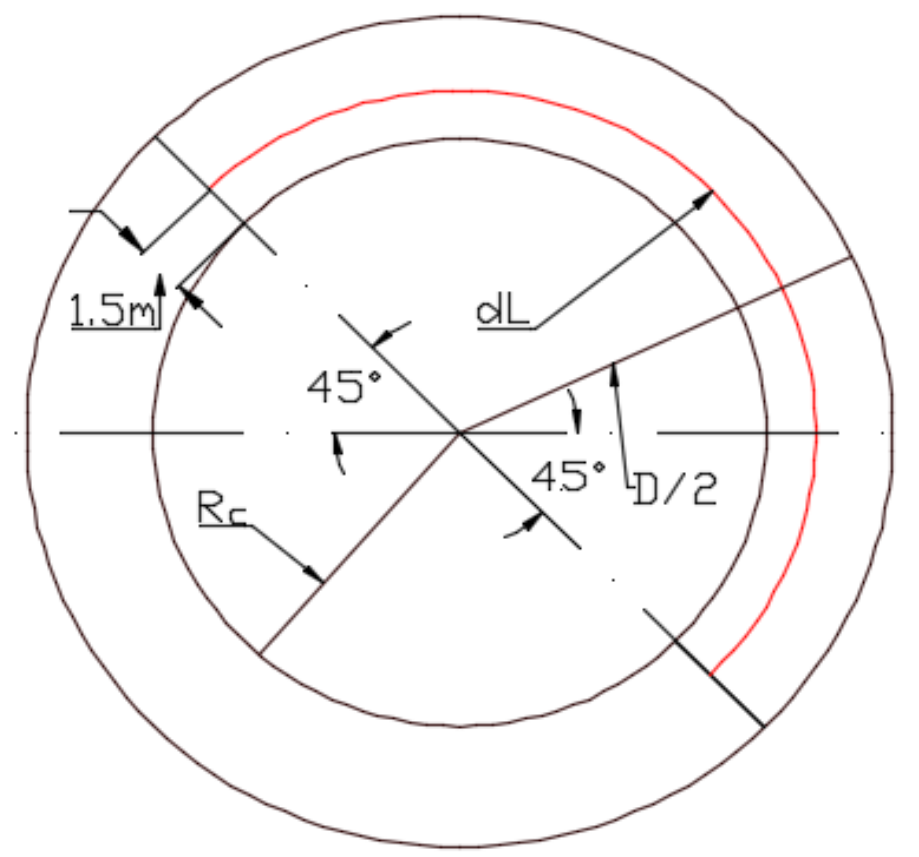

Figure 6-5: left-turn movement vehicle path

From the geometry of Figure 6.5, the left-turn path radius and distance can be derived as follows:

$$
\begin{gathered}
R_{L}=R_{c}+1.5 \\
d_{L}=\pi\left(R_{c}+1.5\right)
\end{gathered}
$$


Where,

$\mathrm{R}_{\mathrm{L}}=$ the left turn path radius (m), and

$d_{L}=$ the distance traveled in the roundabout by the left turn vehicle $(m)$.

The time spent in the roundabout for each movement can be determined from the distance traveled in the roundabout and the operation speed. The combination of the three speed profiles in Figure 6-1 and the three movements gives nine different speed profiles, as shown in Figure 6.6 .

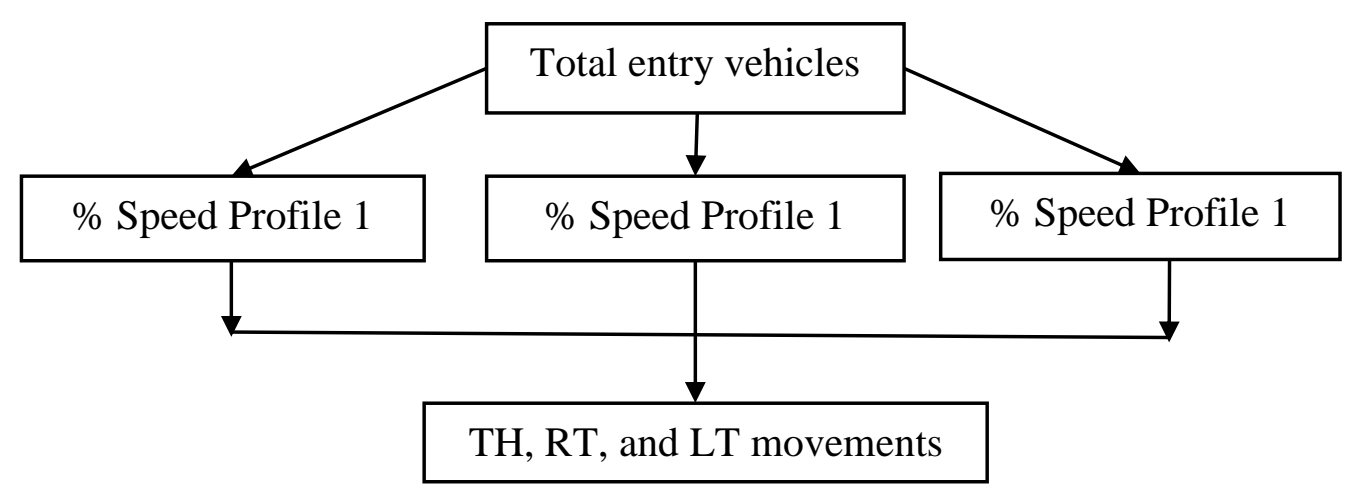

Figure 6-6: The typical nine-speed profiles of a single-lane roundabout

\subsubsection{Modeling Vehicle Emissions}

Vehicle specific power methodology is used to calculate vehicle emissions using Equation 6.21. The movement trajectories are divided into three stages: 1) a deceleration from the downstream approach speed to the roundabout operation speed, 2) crossing the roundabout at the operation speed for a distance that differs for each movement, and 3) acceleration from the roundabout operation speed to the upstream approach speed.

The vehicle specific power is determined second by second using Equation 6.21 for each speed profile. According to the VSP value, the vehicle emissions of $\mathrm{NOX}, \mathrm{HC}, \mathrm{CO} 2$, and $\mathrm{CO}$ are identified using Table 6.1. Frey specified the corresponding vehicle emission of NOx, HC, CO2 and CO emissions (g/s) for each VSP range (Frey et al. 2002; Frey et al., 2003). 
Table 6-1: The main emissions of VSP ranges

\begin{tabular}{|c|c|c|c|c|}
\hline \multirow[b]{2}{*}{ VSP* bins } & \multicolumn{4}{|c|}{ Emissions (g/s) } \\
\hline & NOX & $\mathrm{HC}$ & $\mathrm{CO} 2$ & $\mathrm{CO}$ \\
\hline VSP $<-2$ & 0.0009 & 0.0004 & 1.6711 & 0.0078 \\
\hline$-2<\mathrm{VSP}<0$ & 0.0006 & 0.0003 & 1.4580 & 0.0039 \\
\hline $0<\mathrm{VSP}<1$ & 0.0003 & 0.0004 & 1.1354 & 0.0033 \\
\hline $1<$ VSP $<4$ & 0.0012 & 0.0004 & 2.2333 & 0.0083 \\
\hline $4<\mathrm{VSP}<7$ & 0.0017 & 0.0005 & 2.9199 & 0.0110 \\
\hline $7<\mathrm{VSP}<10$ & 0.0024 & 0.0007 & 3.5253 & 0.0170 \\
\hline $10<\mathrm{VSP}<13$ & 0.0031 & 0.0008 & 4.1075 & 0.0200 \\
\hline $13<\mathrm{VSP}<16$ & 0.0042 & 0.0010 & 4.6350 & 0.0292 \\
\hline $16<\mathrm{VSP}<19$ & 0.0051 & 0.0011 & 5.1607 & 0.0355 \\
\hline $19<$ VSP $<23$ & 0.0059 & 0.0014 & 5.6325 & 0.0551 \\
\hline $23<\mathrm{VSP}<28$ & 0.0076 & 0.0021 & 6.5348 & 0.1138 \\
\hline $28<\mathrm{VSP}<33$ & 0.0121 & 0.0034 & 7.5852 & 0.2076 \\
\hline $33<\mathrm{VSP}<39$ & 0.0155 & 0.0049 & 9.0242 & 0.4418 \\
\hline $39<\mathrm{VSP}$ & 0.0179 & 0.0109 & 10.0884 & 0.8823 \\
\hline
\end{tabular}

* As calculated by Equation 6.8

Source: (Frey et al., 2002; Frey et al., 2003)

The approach $\mathrm{j}$ total emissions for $\mathrm{NOx}, \mathrm{HC}, \mathrm{CO} 2$, or $\mathrm{CO}$ is given by 


$$
\begin{aligned}
\mathrm{E}_{\mathrm{j}}=\sum_{k=1}^{3}\left[\% P_{k}\right. & *\left(Q_{T H, j} * \sum_{i=1}^{n^{t h}} E_{T H, j, k, i}+Q_{R T} * \sum_{i=1}^{n^{t h}} E_{R T, j, k, i}+Q_{L T}\right. \\
& \left.\left.* \sum_{i=1}^{n^{t h}} E_{L T, j, k, i}\right)\right]
\end{aligned}
$$

Where,

$\mathrm{E}_{\mathrm{j}}=$ approach emissions,

$\mathrm{Q}_{\mathrm{TH}}, \mathrm{Q}_{\mathrm{RT}}$, and $\mathrm{Q}_{\mathrm{LT}}=$ the through, right turn and left turn approach traffic, respectively, $\% P_{k}=$ the vehicles percentage of vehicles in the total entry traffic that experience speed profile $\mathrm{k}$,

$\mathrm{k}=$ the profile number 1,2 or 3 ,

$\mathrm{j}=$ the approach number $1,2,3$, or 4 ,

$\mathrm{I}=$ the second number from the first second to the last second at the end of the influenced length, and

$E_{t h}, E_{R T}, E_{L T}=$ the emissions of vehicles making through, right turn or left turn movements, respectively.

\subsection{Geometric Constraints}

The geometric constraints are given by Equations 6.54 to 6.58 :

$$
\begin{gathered}
\mathrm{D}_{\text {min }} \leq D \leq D_{\text {max }} \\
\mathrm{E}_{\text {min }, j} \leq E_{j} \leq E_{\text {max }, j} \\
\operatorname{Max}\left(\mathrm{E}_{\mathrm{j}}\right) \leq \mathrm{C} \leq 1.2 * \operatorname{Max}\left(\mathrm{E}_{\mathrm{j}}\right) \\
\mathrm{D}=2 \mathrm{R}_{\mathrm{c}}+2 \mathrm{C} \\
\mathrm{E}_{\mathrm{ex}, \min , \mathrm{j}} \leq E_{e x, j} \leq E_{\text {ex,max }, j}
\end{gathered}
$$

Where,

$\mathrm{D}=$ the inscribed circle diameter $(\mathrm{m})$,

$\mathrm{E}=$ the entry width $(\mathrm{m})$,

$\mathrm{C}=$ the circulated width (m), 
$E_{\text {ex }}=$ the exit width $(\mathrm{m})$,

$\mathrm{R}_{\mathrm{c}}=$ the central island radius in $(\mathrm{m})$, and

$\mathrm{j}=$ the leg number $(1,2,3$ or 4$)$.

Roundabouts - An Informational Guide recommends that the circulated width should be more than the maximum entry width of all legs and should not exceed $20 \%$ more than the maximum entry width. The guidelines define the minimum values of some geometric parameters based on the design vehicle, as explained in chapter 2.

\subsection{Multi-Objective Function}

The proposed objective function maximizes safety, mobility, and environmental sustainability. Safety is represented by the total collision frequency obtained using Equation 6.7, mobility is represented by the delay obtained using Equation 6.20, and environmental sustainability is represented by the total vehicle emissions obtained using Equation 6.53. Thus,

$$
\begin{gathered}
O F=\lambda 1 \sum_{j=1}^{j=4}\left(C F_{j}\right)+\lambda 2 \sum_{j=1}^{j=4}\left(d_{j}\right)+\lambda 3 \sum_{j=1}^{j=4}\left(N O X_{j}\right)+\lambda 4 \sum_{j=1}^{j=4}\left(H C_{j}\right) \\
+\lambda 5 \sum_{j=1}^{j=4}\left(C O 2_{j}\right)+\lambda 6 \lambda 1 \sum_{j=1}^{j=4}\left(C O_{j}\right)
\end{gathered}
$$

Where,

$C F_{j}=$ collision frequency for approach $\mathrm{j}$,

$\lambda_{1}=$ the weight applied to the total collision objective,

$\lambda_{2}=$ the weight applied to the total delay objective,

$\lambda_{3}=$ the weight applied to the NOx emissions objective,

$\lambda_{4}=$ the weight applied to the $\mathrm{HC}$ emissions objective,

$\lambda_{5}=$ the weight applied to the $\mathrm{HC}$ emissions objective,

$\lambda_{6}=$ the weight applied to the $\mathrm{CO}$ emissions objective,

NOX = Nitrogen oxide emissions,

$\mathrm{HC}=$ Hydrocarbon emissions, 
$\mathrm{CO} 2=$ Carbon dioxide emissions, and

$\mathrm{CO}=$ Carbon monoxide emissions

The objective function expressed by Equation 6.59 includes the collision rate, delay and vehicle emissions. To maximize safety, mobility, and environmental sustainability, the objective function is minimized. The solution of the model provides the optimal geometric parameters including the inscribed circle diameter, the central island radius, the entry width, the exit width, the circulated width, the approach half-width, the effective flare length, and the entry radius.

The optimization model consists of the objective function of Equation 6.59, the constraints of Equations 6.5 to 6.53 and the additional constraints of Equations 6.54 to 6.58. The multi-objective optimization model is solved by minimizing the objective function subjected to the defined constraints. The model can be solved using a Solver tool available as an add-on to Excel 2010 and later versions (Microsoft 2018). The Excel Solver changes the decision variables according to the objective function subjected to the constraints and modifies all cells that contain that decision variable using different algorithms. The generalized reduced gradient (GRG) is one of Solver algorithms that was used in this study. The algorithm finds global optimal solutions by implementing a multi-start strategy, where the starting points are randomly generated within the specified ranges of the decision variables. The clusters are formed from the points, and the process is run from the clusters, eliminating the solutions to the locally optimal solution. Ultimately, the algorithm converges the locally optimal solution to a globally optimal solution. 


\section{Chapter 7 Model Application}

\subsection{Introduction}

The design of roundabouts consists of several stages beginning with the planning stage explained in chapter 2 . In the planning stage, the required data including the traffic data and the physical constraints of the specific location are collected. The roundabout category is then defined based on the traffic demand and the number of lanes is determined based on the methodology explained in chapter 2 . Once the roundabout category and the number of lanes has been determined, the model can be applied.

In this study, the model was applied to an existing single-lane roundabout to evaluate the geometric design. The intersection was selected based on the design objectives that required improvement. The proposed intersection was located at Fountain Street (EW) and BLAIR RD/Morningside Drive (NS) in Waterloo. This intersection had an extreme number of collisions over the past five years (from January 1, 2012 to December 31, 2016) as retrieved from the data provided by Holly Kents, Marcos Kroker, and Malcolm Lister at the Waterloo Regional Municipality. The reported total collisions was 51, which is above 10 collisions per year. Evaluating an existing roundabout involves the same stages as designing a new one. The sizing and space requirements should be assessed during the planning stage, as explained in chapter 2. The model is applied to maximize safety performance, mobility, and environmental sustainability. The model provides the optimal decision variables (D, C, $E_{e n}, \mathrm{v}, l$ ', $r$ and $E_{e x}$ ), and the minimum collisions, delay, and vehicle emissions. Applying the model to the actual location was done in two stages. First, only the safety and environmental sustainability design objectives were considered. Second, the mobility design objective was added.

\subsection{Traffic Data Preparation}

The first step in applying the model is preparing the traffic data for use. The data was collected at different peak hour times during the day with different peak hour factors and different truck percentages for each movement. The intersection traffic volumes in vehicle per hour should be converted to passenger car per hour considering the heavy vehicle and peak hour factors for each movement using Equations 6.1 and 6.2. A spreadsheet model can be used to 
prepare the traffic data and to calculate the roundabout traffic, as shown in Figure 7-1. The entering traffic, which is the sum of the through, right turn and left turn movements, is calculated for each approach. The circulating traffic is calculated using Equation 6.4 for each approach. For example, the information for the West approach for through, right turn, and left turn movements was 261,291 , and $4 \mathrm{veh} / \mathrm{hr}$. The percentages of trucks was $6 \%, 4 \%$, and $0 \%$. The peak hour factors were $0.89,0.87$, and 0.5 . For each movement respectively, the FHV was calculated using Equation 6.2. The results were $0.943,0.962$, and 1 for through, right turn, and left turn movements, respectively. The volumes were then converted to the passenger car equivalent using Equation 6.1 which gives 311, 348, and 8 pce/hr. The West approach entering traffic is therefore the sum of 311,348 , and 8 , which is $667 \mathrm{pce} / \mathrm{hr}$. The circulating traffic for the West approach is the sum of the left turn traffic of the East approach (326), through traffic (12) and left turn traffic (8) of North approach, which is $346 \mathrm{pce} / \mathrm{hr}$. The process was repeated for the South, East and North approaches. The results are summarized in Table 7-1.

This step is the same for every analysis since the model application considers different design objectives with different assigned weights.

Table 7-1: Application example traffic data

\begin{tabular}{cccccc}
\hline Approach & $\begin{array}{c}\mathrm{Q}_{\mathrm{en}} \\
(\text { pce/hr. })\end{array}$ & $\begin{array}{c}\mathrm{Q}_{\mathrm{c}} \\
(\mathrm{pce} / \mathrm{hr} .)\end{array}$ & $\begin{array}{c}\mathrm{Q}_{\mathrm{TH}} \\
(\mathrm{pce} / \mathrm{hr} .)\end{array}$ & $\begin{array}{c}\mathrm{Q}_{\mathrm{RT}} \\
(\text { pce/hr. })\end{array}$ & $\begin{array}{c}\mathrm{Q}_{\mathrm{LT}} \\
(\text { pce/hr. })\end{array}$ \\
\hline West & 667 & 346 & 311 & 348 & 8 \\
South & 766 & 328 & 16 & 373 & 377 \\
East & 676 & 401 & 345 & 5 & 326 \\
North & 30 & 1048 & 12 & 8 & 10 \\
\hline
\end{tabular}




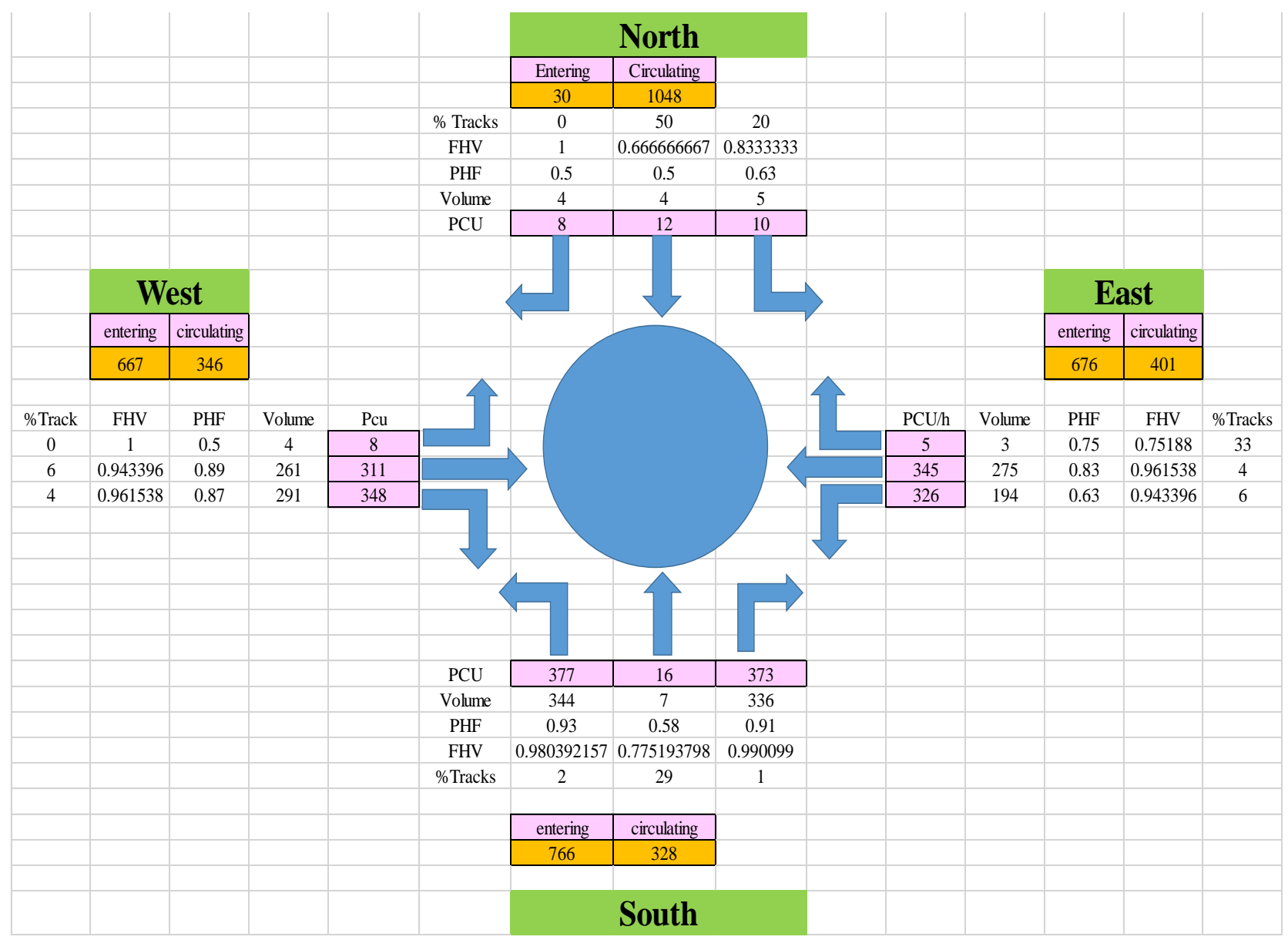

Figure 7-1: Preparation of roundabout traffic data

\subsection{Geometric Data Extraction}

- Maximum boundaries

The geometric data are retrieved from the aerial photographs of the intersection to define the maximum boundaries of the geometric parameters: the inscribed circle diameter, the entering width, the exiting width and the circulating width. The aerial photograph was downloaded from the Geo-Scholar portal library (Geo, 2018). The ArcGIS 10.4 software was used to measure the maximum ranges of geometric parameters that this specific location can accommodate. These 
measurements should be verified with a site survey to look at other physical constraints such as drainage, poles, and utilities.

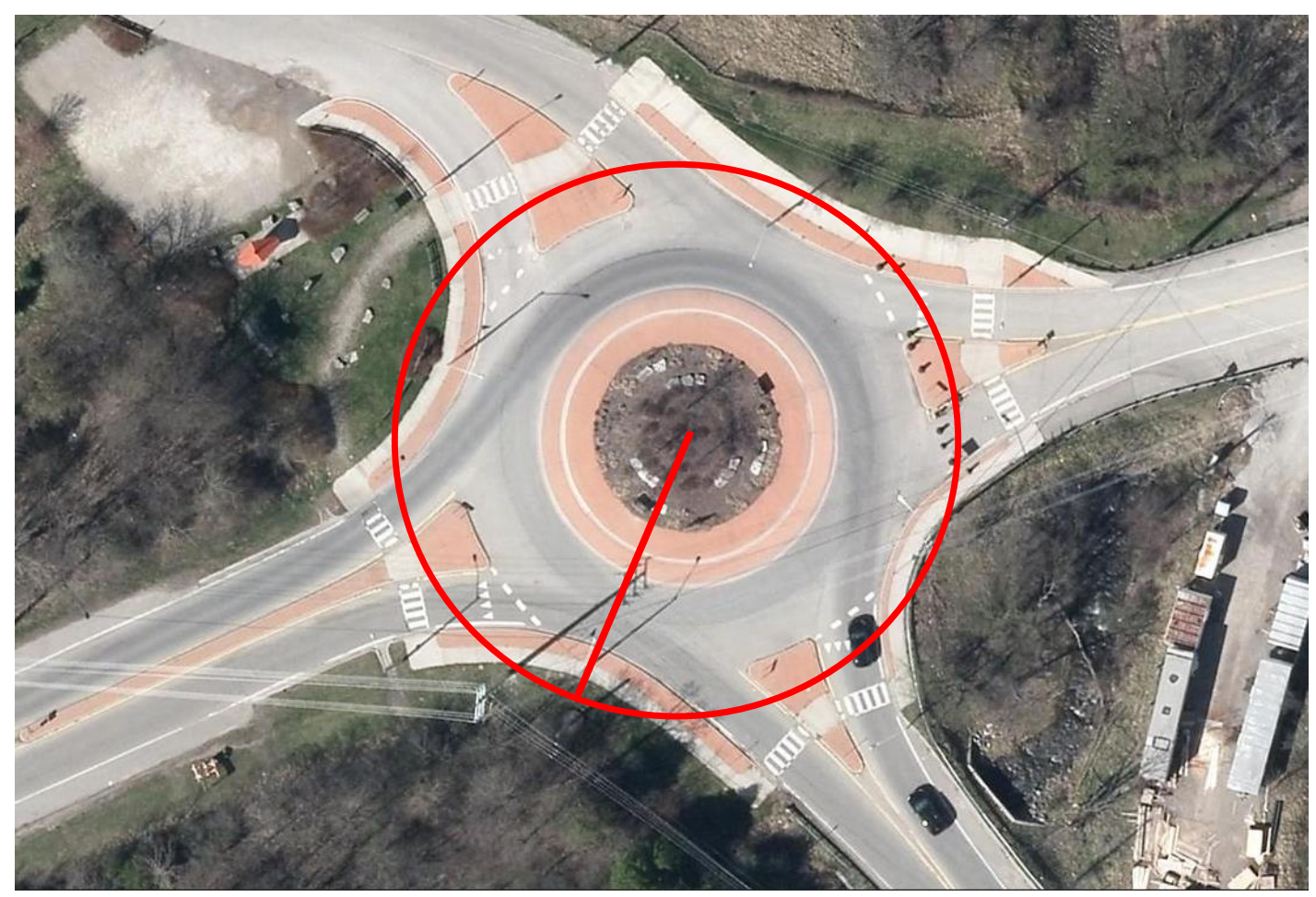

Figure 7-2: Location aerial photograph

- Minimum boundaries

The minimum values of the geometric parameters were defined by using the guidelines, "Roundabouts: An Information Guide" guidelines (Rodegerdts et al., 2010) based on the design vehicles. In this example, the design vehicle is WB50 (WB15), as the proposed site is an arterial road in an urban area. The guidelines give the minimum values of the geometric parameter values that can accommodate that type of vehicles. The minimum inscribed circle is $32 \mathrm{~m}$, as found in Table 2-2, and the entry width is recommended to be a minimum of $4.2 \mathrm{~m}$. The circulating width should be ranged range between the wide of the maximum entry width and $120 \%$ of the maximum entry width .The circulatory road width should provide comfort for passenger cars and accommodate the design vehicle. Entry radii range from $15 \mathrm{~m}$ to $30 \mathrm{~m}$ and are 
facilitated by the appropriate entry speed and the design vehicle. The recommended exit radii should be more than the entry radii and recommended to be not less than $15 \mathrm{~m}$ to provide adequate operational performance. The total length of the splitter island should be a minimum of $15 \mathrm{~m}$, and $30 \mathrm{~m}$ is preferred to provide adequate protection for pedestrians. The splitter island width should not be less than $1.8 \mathrm{~m}$ at the crosswalk to provide accommodation for pedestrians needs such as walking a bike, stroller users and wheelchairs users.

\subsection{Modeling Design Objectives}

\subsubsection{Safety}

The collisions for each approach are modeled using Equation 6.7 as a function of the entering traffic and the average approach speed. The average approach speed is modeled as a function of the inscribed circle diameter, the central island diameter, the exit width, the entry width, and the circulating width. Safety is modeled as a function of geometric parameters and the entering traffic for each approach.

\subsubsection{Mobility}

Mobility is represented by the capacity, delay, and level of service. The approach capacity is modeled using Equations 6.8 to 6.14. The entry capacity is a function of the geometric parameters and the circulating traffic for each approach. The delay is modeled using Equation 6.16 as a function of capacity and the entering traffic for each approach.

\subsubsection{Vehicle emissions}

The vehicle specific power is modeled using Equation 6.21 and the operating speed is modeled using Equation 6.22. Nine-speed profiles are modeled second by second using Equations 6.23 to 6.52. Emissions are modeled for each speed profile and each approach using Equation 6.53, as described in the methodology section in chapter 6 . The vehicle emissions are modeled as a set of functions including geometric parameter variables, entering traffic, circulating traffic, turning traffic, and the queue length.

The optimal geometric parameters are determined by minimizing the objective function, Equation 6.59, subjected to the defined constraints, and according to the assigned weight for each objective. The design objectives are quantified based on the needs of the proposed site. 


\subsection{Model validation and verification}

Because of the difficulties in including all of the factors that might affect the solutions obtained from the model, assumptions are needed to simplify the model. This is the reason that it is very useful to apply the model using actual data. It is very important to check the validity of the design objectives and to test the defined constraints and assumptions to ensure there are no conflicts in any of the factors that were used to develop the model. It is necessary to verify that the model is able to generate applicable solutions for actual situations and real location constraints. To validate the model, the model is applied on the actual location using real data and constraints. This was done by applying the model considering only safety in section 7.5.1, and only mobility in section 7.5.2.

\subsubsection{Considering only mobility}

The model was applied to the real data of the proposed location considering only the mobility objective by assigning a unit weight to mobility and zero weight to safety and vehicle emissions. The results are shown in Tables 7-2, 7-3, and 7-4.

Table 7-2: Maximizing mobility decision variables

\begin{tabular}{lllllllll}
\hline \multicolumn{7}{c}{ Design Vehicle: WB50 (WB15) } \\
\hline Approach & $\mathrm{E}_{\text {en }}(\mathrm{m})$ & $\mathrm{E}_{\mathrm{ex}}(\mathrm{m})$ & $\mathrm{v}(\mathrm{m})$ & $\mathrm{r}(\mathrm{m})$ & $\mathrm{l}^{\prime}(\mathrm{m})$ & $\phi\left(^{\circ}\right)$ & Delay & LOS \\
\hline West & 5.207 & 5.806 & 5.000 & 30.000 & 11.735 & 35.747 & 5.088 & $\mathrm{~A}$ \\
South & 5.705 & 5.59 & 4.35 & 30.000 & 15.125 & 40.680 & 5.225 & $\mathrm{~A}$ \\
East & 5.609 & 5.7085 & 4.622 & 25.900 & 14.764 & 45.375 & 5.147 & $\mathrm{~A}$ \\
North & 4.200 & 5.6877 & 4.837 & 28.463 & 1.000 & 38.179 & 0.421 & $\mathrm{~A}$ \\
\hline \multicolumn{7}{c}{$\mathrm{D}=\mathrm{D}_{\max }=52 \mathrm{~m}, \mathrm{C}=5.353, \mathrm{R}_{\mathrm{c}}=20.647 \mathrm{~m}$} \\
\hline
\end{tabular}


Table 7-3: The impact of maximizing mobility on vehicle emissions and crashes

\begin{tabular}{llllll}
\hline & NOX $(\mathrm{g})$ & $\mathrm{HC}(\mathrm{g})$ & $\mathrm{CO} 2(\mathrm{~kg})$ & $\mathrm{CO}(\mathrm{kg})$ & crash \\
\hline West & 100.070 & 45.120 & 13.686 & 1.942 & 0.540 \\
South & 72.647 & 580.016 & 555.379 & 2.063 & 0.592 \\
East & 39.321 & 332.648 & 479.734 & 0.667 & 0.550 \\
North & 52.989 & 817.863 & 629.507 & 0.915 & 0.106 \\
\hline
\end{tabular}

By considering the weight of the observed crashes and the dispersion factor, the predicted crashes are shown in Table 7-4.

Table 7-4: Considering observed crashes and dispersion factor

\begin{tabular}{cc}
\hline Approach & Predicted Crashes \\
\hline West & 2.263 \\
South & 2.703 \\
East & 2.344 \\
North & 0.941 \\
\hline
\end{tabular}

\subsubsection{Considering only safety}

The model was applied to the real data of the proposed location considering only the safety objective by assigning a unit weight to safety and zero weight to mobility and vehicle emissions. The results are shown in Table 7.5

Table 7-5: Maximizing safety impact on emissions and delay

\begin{tabular}{rccccccc}
\hline & NOX $(\mathrm{g})$ & $\mathrm{HC}(\mathrm{g})$ & $\mathrm{CO} 2(\mathrm{~kg})$ & $\mathrm{CO}(\mathrm{kg})$ & (Collisions/yr.) & Delay & LOS \\
\hline West & 63.754 & 32.001 & 58.130 & 2.081 & 0.303 & 105.3 & $\mathrm{~F}$ \\
South & 76.462 & 750.328 & 635.983 & 2.533 & 0.361 & 176.3 & $\mathrm{~F}$ \\
East & 48.353 & 421.249 & 544.435 & 1.416 & 0.312 & 143.9 & $\mathrm{~F}$ \\
North & 59.130 & 961.118 & 695.386 & 1.393 & 0.063 & 16.4 & $\mathrm{~B}$ \\
\hline
\end{tabular}


Table 7-6: Considering observed crashes and dispersion factor

\begin{tabular}{cc}
\hline Approach & Predicted Crashes \\
\hline West & 1.831 \\
South & 2.258 \\
East & 1.897 \\
North & 0.142 \\
\hline
\end{tabular}

\subsubsection{Discussion}

By considering mobility as the only design objective, the inscribed circle diameter was decided to be the defined maximum value. This decision confirms the reliability of the model. To minimize the delay, the inscribed circle needs to be maximized to allow more entry and increase the capacity. As shown in Table 7-2, the model determined the geometric parameters to be near the maximum values. The maximum values of the geometric parameters gave a minimum delay and very high level of service. All approaches had a high operational performance with LOS A.

On the other hand, the safety performance is affected as there is a trade-off between mobility and safety. The predicted crashes increased when consedering only mobility. The predicted crashes were almost double in all approaches compared to considering only safety. Improving mobility has a different effect on environmental sustainability. The NOX, HC, and $\mathrm{CO} 2$ emissions are decreased, but the $\mathrm{CO}$ emissions are increased in most approaches. This also proves the effectiveness of the model since mobility has a positive effect on vehicle emissions.

When the model was applied to the location considering only the safety objective, the geometric parameters took the minimum values. This result supports the theory that is found through the literature. The minimum values of the geometric parameters created an extreme increase in the delay (exceeding 100), resulting in LOS F in most of the approaches. The vehicle emissions are consequently increased. 
Figure 7-3 shows that the crashes are almost doubled when only mobility is considered.

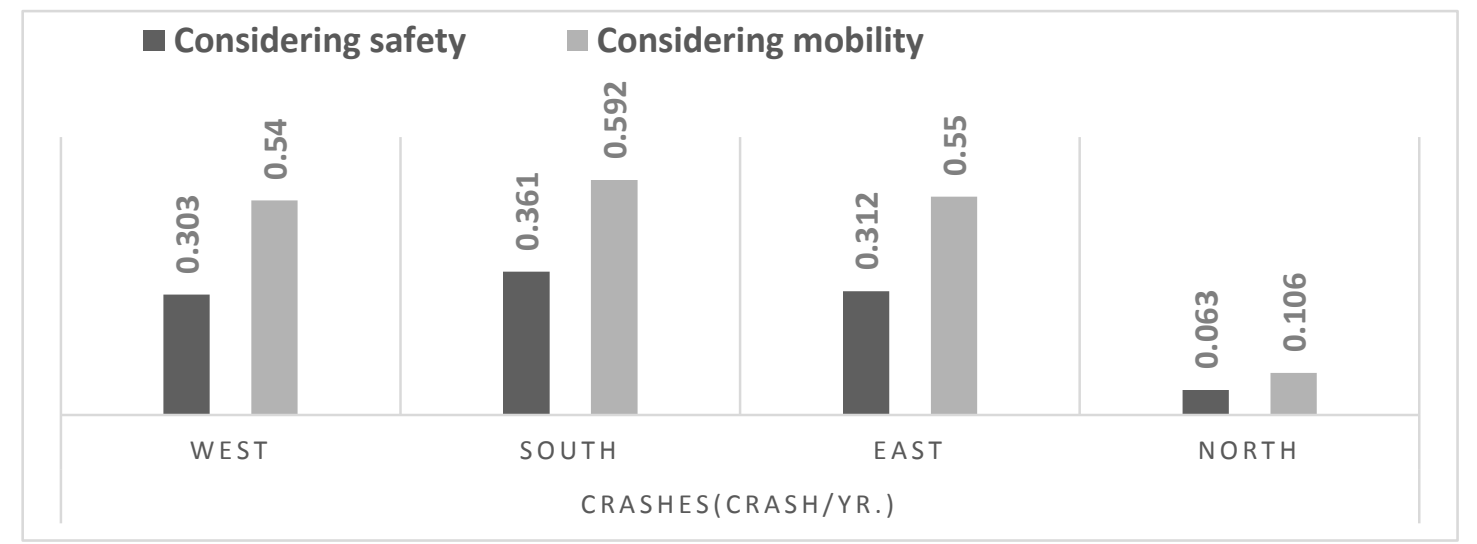

Figure 7-3 Comparing crashes in considering safety vs. considering mobility

Figure 7-4 shows that the delay is much higher when only safety is considered.

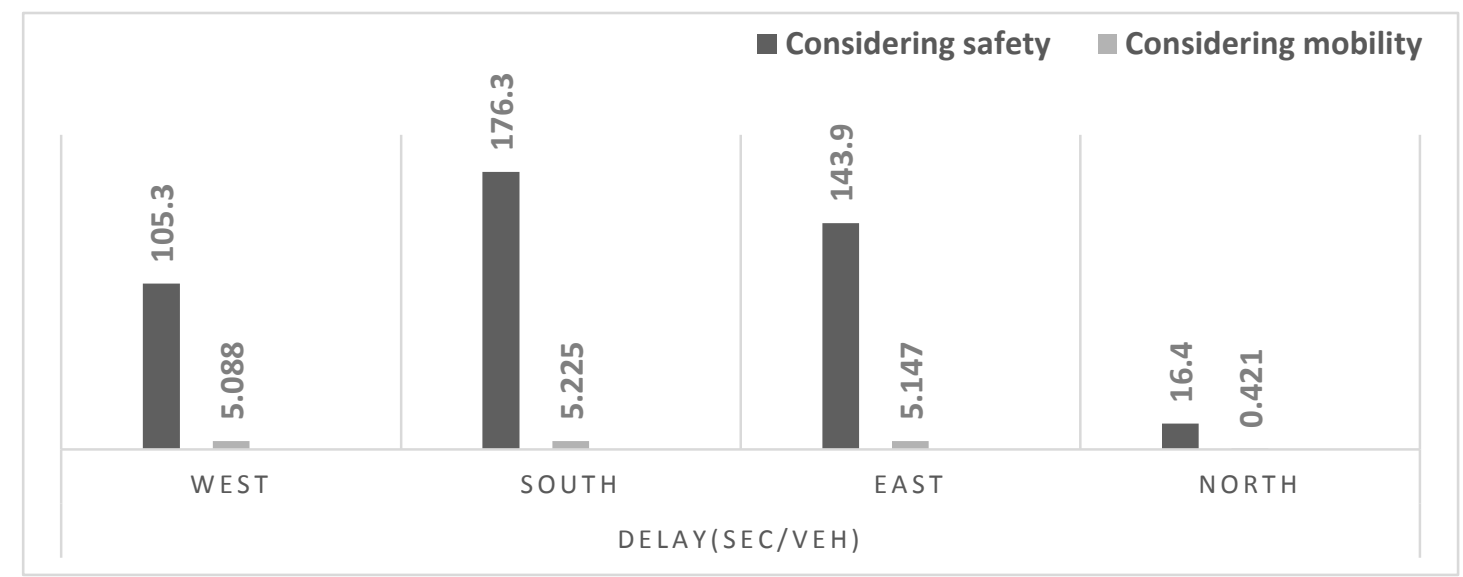

Figure 7-4: Comparing delay in considering safety vs. considering mobility 
Figure 7-5 reveals that improving mobility has a positive effect on the environmental impact. The figure shows that vehicle emissions are higher in most approaches when considering safety over mobility.

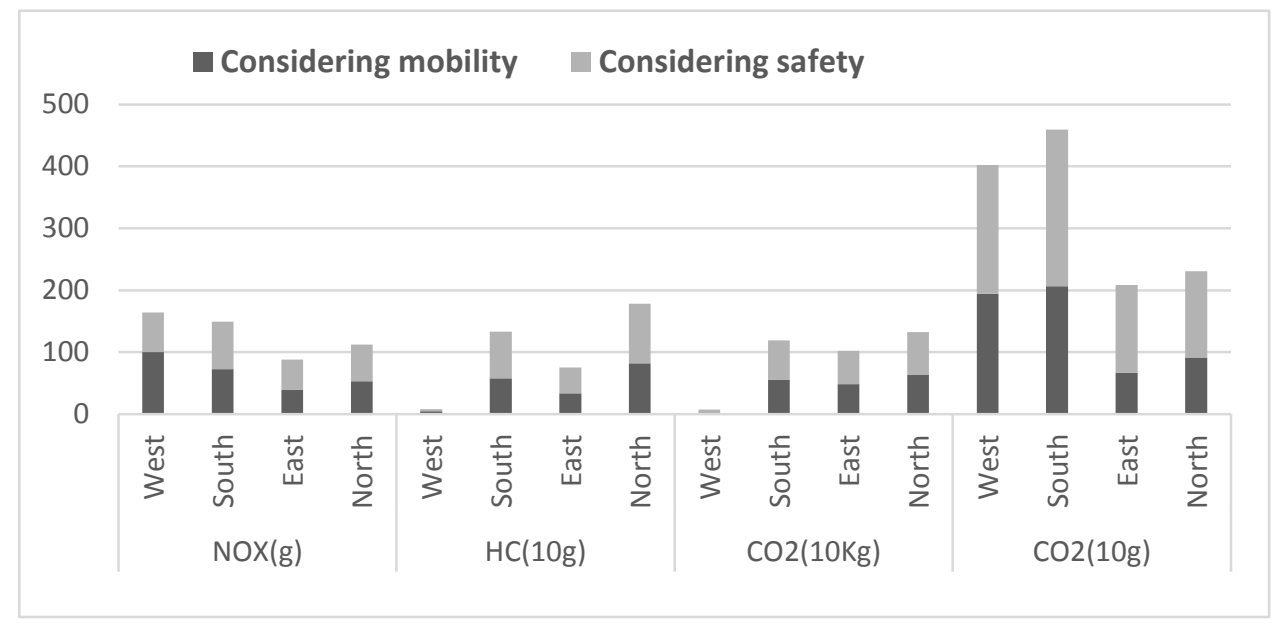

Figure 7-5: Comparing vehicle emissions in considering safety vs. considering mobility

The results reveal that there is a trade-off between safety and mobility and between safety and environmental impact. The main goal for designers is to find a balance between the different design objectives. The next section shows an attempt to find that balance by considering the three objectives with different assigned weights. In the next section, the model was applied to maximize safety and environmental sustainability without considering mobility.

\subsubsection{Considering safety and environmental sustainability}

In this application example, the weight assigned to both objectives is equal. 0.5 was the weight factor of the total crashes (safety) while 0.125 was the weight assigned to each vehicle emission type (environmental sustainability). The optimal geometric parameters are determined as decision variables when running the model and this process only takes a few minutes. The results are provided in Table 7-2 and give the optimal values for the inscribed diameter (D), circulated width $(\mathrm{C})$, the central island radius, the entering width, and the exiting width for each approach. 
Table 7-7: Application example output data

\begin{tabular}{cccccccc}
\hline \multicolumn{7}{c}{ Design Vehicle: WB50 (WB15) } \\
\hline & $\mathrm{E}_{\text {en }}(\mathrm{m})$ & $\mathrm{E}_{\mathrm{ex}}(\mathrm{m})$ & NOX $(\mathrm{g})$ & $\mathrm{HC}(\mathrm{g})$ & $\mathrm{CO} 2(\mathrm{~kg})$ & $\mathrm{CO}(\mathrm{kg})$ & Collisions/yr. $)$ \\
\hline West & 5.502 & 5.688 & 56.358 & 23.038 & 60.904 & 1.180 & 0.313 \\
South & 4.203 & 5.681 & 68.752 & 796.167 & 605.724 & 1.655 & 0.365 \\
East & 4.278 & 5.390 & 38.270 & 329.659 & 476.142 & 0.606 & 0.337 \\
North & 4.202 & 5.933 & 51.317 & 785.545 & 595.823 & 0.809 & 0.065 \\
\hline
\end{tabular}

The inscribed circle diameter is $35 \mathrm{~m}$, the circulating width is $5.8 \mathrm{~m}$, and central island radius is $11.7 \mathrm{~m}$. The roundabout designed with the new dimensions is shown in Figure 7-6.

The existing geometric parameters were used to test the model. The results revealed a significant improvement in the safety performance. The optimal geometric parameters obtained using the model decreased approach collisions by $25 \%, 21 \%, 18 \%$, and $23 \%$ for the West, South, East, and North approaches (respectively). The environmental impact was also improved by changing the existing geometric parameters to the optimal values determined by the model. The new roundabout decreased vehicle emissions by $4.2 \%, 4.3 \%, 4.3 \%$, and $14.2 \%$ for NOX, HC, $\mathrm{CO} 2$, and $\mathrm{CO}$ emissions (respectively). The new optimal geometric parameters of the roundabout are shown in Figure 7-3. 


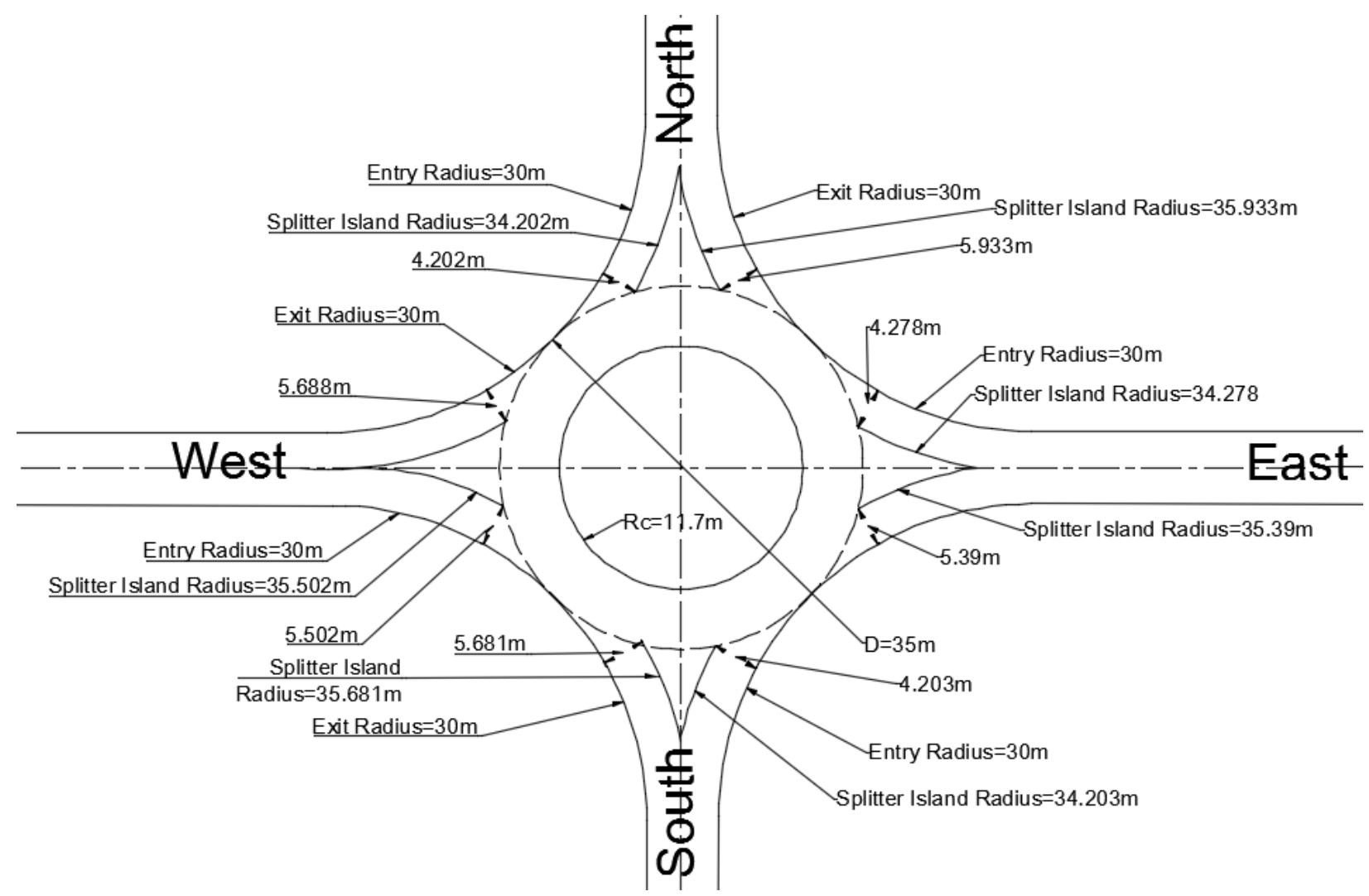

Figure 7-6: Optimum geometric design given by the optimization module example 3

\subsubsection{Considering safety, mobility, and environmental sustainability}

The same example was repeated using the same steps for all three design objectives: safety, mobility, and environmental sustainability. The model was applied to three options, the existing geometry, and two other options changing the assigned weight of the design objectives. The three options were used to conduct a sensitivity analysis and to test the improvement of the model. The existing geometry was used to compare the performance of the model to the traditional iterative method. The results are shown in the next section.

\subsubsection{Option 1}

In this case, the three objectives were considered with the following assigned weights: 
Safety $=0.5$, mobility $=0.3$, emissions $=0.2(0.05$ assigned to NOx, HC, CO2, and CO). The optimal geometric parameters of example 2 are provided in Table 7-7.

Table 7-8: Option 1 optimal geometric parameters

\begin{tabular}{lllllll}
\hline \multicolumn{7}{c}{ Design Vehicle: WB50 (WB15) } \\
\hline Approach & $\mathrm{E}_{\mathrm{en}}(\mathrm{m})$ & $\mathrm{E}_{\mathrm{ex}}(\mathrm{m})$ & $\mathrm{v}(\mathrm{m})$ & $\mathrm{r}(\mathrm{m})$ & $l^{\prime}(\mathrm{m})$ & $\phi\left(^{\circ}\right)$ \\
\hline West & 4.646 & 5.410 & 4.638 & 29.278 & 15.541 & 25.284 \\
South & 4.202 & 5.736 & 3.731 & 23.222 & 3.621 & 39.853 \\
East & 4.200 & 5.752 & 2.621 & 21.594 & 7.609 & 26.940 \\
North & 4.200 & 5.556 & 2.712 & 20.023 & 8.759 & 33.708 \\
\hline
\end{tabular}

The design objectives are summarized in Table 7-8.

Table 7-9: Option 1 design objectives results

\begin{tabular}{ccccccc}
\hline \multicolumn{7}{c}{ Design Vehicle: WB50 (WB15) } \\
\hline West & 0.318 & 6.216 & 55.916 & 23.439 & 55.981 & 1.363 \\
South & 0.365 & 12.634 & 61.195 & 573.144 & 546.493 & 1.566 \\
East & 0.319 & 12.564 & 38.627 & 332.176 & 478.226 & 0.659 \\
North & 0.064 & 6.347 & 52.934 & 817.630 & 629.097 & 0.914 \\
\hline
\end{tabular}

By considering the dispersion factor, the predicted crashes can be calculated using equations 6.8 to 6.11. The observed crashes were 52 over five years. The predicted crashes for the approaches are provided in Table 7-9. 
Table 7-10: Option 1 crashes considering the observed crashes and dispersion factor

\begin{tabular}{cc}
\hline Approach & Predicted Crashes \\
\hline West & 1.602 \\
South & 1.943 \\
East & 1.611 \\
North & 0.109 \\
\hline
\end{tabular}

\subsubsection{Option 2}

In this case, the emissions unit is in $\mathrm{kg}$ for all emissions types except $\mathrm{CO} 2$ which is in tons. This is done in order to create a balance between the vehicle emission values and the other design objective values. The assigned weights are:

Safety $=0.3$, mobility 0.3 , emissions 0.4 ( 0.1 for $\mathrm{NOX}, \mathrm{HC}, \mathrm{CO} 2$, and $\mathrm{CO})$. The results are presented in Tables 7-10 and 7-11.

Table 7-11: Option 2 optimal geometric parameters

\begin{tabular}{lllllll}
\hline \multicolumn{7}{c}{ Design Vehicle: WB50 (WB15) } \\
\hline Approach & $\mathrm{E}_{\mathrm{en}}(\mathrm{m})$ & $\mathrm{E}_{\mathrm{ex}}(\mathrm{m})$ & $\mathrm{v}(\mathrm{m})$ & $\mathrm{r}(\mathrm{m})$ & $\mathrm{l}^{\prime}(\mathrm{m})$ & $\phi\left(^{\circ}\right)$ \\
West & 5.500 & 5.020 & 4.500 & 29.958 & 19.759 & 25.010 \\
South & 5.699 & 5.719 & 4.998 & 29.935 & 19.943 & 25.011 \\
East & 5.999 & 5.524 & 4.995 & 29.864 & 19.955 & 25.003 \\
North & 5.849 & 5.564 & 5.000 & 29.881 & 19.677 & 25.000 \\
\hline
\end{tabular}

Table 7-12: Option 2 design objectives results

\begin{tabular}{ccccccc}
\hline \multicolumn{7}{c}{ Design Vehicle: WB50 (WB15) } \\
\hline \multirow{2}{*}{ West } & (Collisions/yr.) & Delay & NOX (g) & HC $(\mathrm{g})$ & CO2 $(\mathrm{kg})$ & CO (kg) \\
South & 0.321 & 4.380 & 60.727 & 29.014 & 57.559 & 1.818 \\
East & 0.361 & 4.562 & 72.912 & 657.278 & 589.759 & 2.267 \\
North & 0.338 & 3.984 & 43.321 & 375.751 & 513.345 & 1.027 \\
\hline
\end{tabular}


By considering the dispersion factor, the predicted crashes can be calculated using equations 6.8 to 6.11. The observed crashes were 52 over five years. The predicted crashes for the approaches are:

Table 7-13: Option 2 crashes considering the observed crashes and dispersion factor

\begin{tabular}{cc}
\hline Approach & Predicted Crashes \\
\hline West & 1.589 \\
South & 1.877 \\
East & 1.073 \\
North & 0.117 \\
\hline
\end{tabular}

It can be noticed that there is a significant reduction in predicted crashes compared to the observed crashes. The total predicted crashes are less than half of the observed crashes.

\subsubsection{Option 3}

This option involved the application of the model to the existing geometric parameters without running the model. In this case, the geometric parameters are used as input, and the outputs are the design objectives. The existing geometric parameters are provided in Table 7:13.

Table 7-14: The existing geometric parameters of the actual roundabout

\begin{tabular}{lllllll}
\hline \multicolumn{6}{l}{ Design Vehicle: WB50 (WB15) } \\
\hline Approach & $\mathrm{E}_{\mathrm{en}}(\mathrm{m})$ & $\mathrm{E}_{\mathrm{ex}}(\mathrm{m})$ & $\mathrm{v}(\mathrm{m})$ & $\mathrm{r}(\mathrm{m})$ & $\mathrm{l}^{\prime}(\mathrm{m})$ & $\phi\left(^{\circ}\right)$ \\
West & 4.9 & 5.5 & 3.6500 & 40.3000 & 122.5900 & 17.7900 \\
South & 5.6400 & 5.5000 & 3.3500 & 16.3000 & 9.1300 & 27.7000 \\
East & 4.9200 & 5.5000 & 3.3500 & 30.3000 & 13.2000 & 13.1400 \\
North & 4.9500 & 5.5000 & 3.2000 & 20.3000 & 33.4100 & 22.2300 \\
\hline
\end{tabular}


Table 7-15: The design objectives given by the model based on the existing geometry

\begin{tabular}{|c|c|c|c|c|c|c|}
\hline \multicolumn{7}{|c|}{ Design Vehicle: WB50 (WB15) } \\
\hline & (Collisions/yr.) & Delay & NOX $(g)$ & $\mathrm{HC}(\mathrm{g})$ & $\mathrm{CO} 2(\mathrm{~kg})$ & $\mathrm{CO}(\mathrm{kg})$ \\
\hline West & 0.397 & 5.179 & 61.153 & 29.257 & 58179.010 & 1829.165 \\
\hline South & 0.448 & 6.551 & 74.843 & 671.558 & 600661.791 & 2320.312 \\
\hline East & 0.401 & 6.012 & 43.379 & 373.702 & 511567.893 & 995.289 \\
\hline North & 0.081 & 4.318 & 56.698 & 939.771 & 679460.431 & 1337.685 \\
\hline
\end{tabular}

\subsection{Sensitivity analysis and comparison}

A sensitivity analysis and comparison were conducted using the results obtained from the three options in order to evaluate the performance of the model. Figure 7.7 reveals that options 1 and 2 produced almost the same crash frequencies and that both options performed better than the existing geometry. The model shows sensitivity to the geometric parameters, as shown in graphs 7-7, 7-9, and 7-11. The delay was more sensitive to the geometric parameters than safety. When the weight of safety was decreased from 0.5 to 0.3 , the change in crashes frequency was minor. When comparing the existing geometry, the model showed significant sensitivity to the inscribed circle diameter. Increasing the inscribed circle diameter causes a major increase in crash frequencies for all approaches.

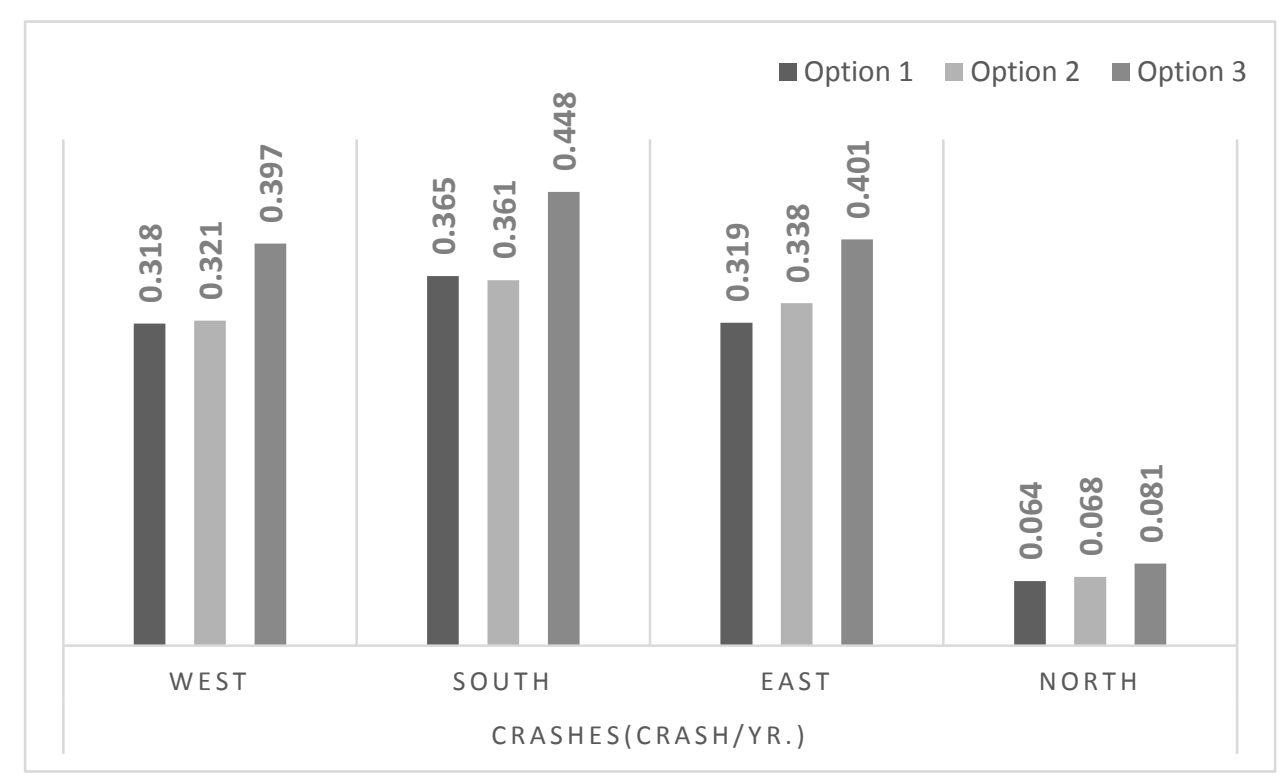

Figure 7-7 Predicted crashes comparison between the three options 
The model improved safety performance by providing a crash reduction for all approaches. The optimization model provided optimal geometric parameters that reduced crashes by $24 \%$ for the west and south approaches, and $19 \%$ for the east and north approaches. These results support the use of this model over the traditional models used to design roundabouts.

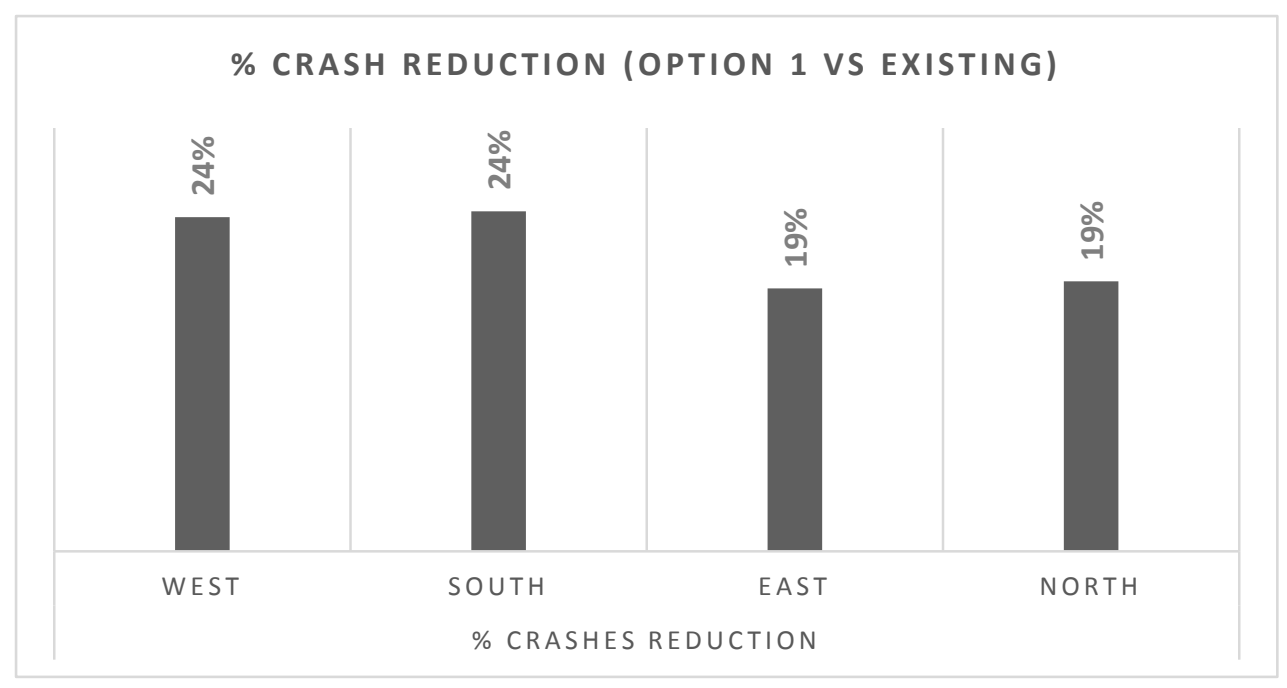

Figure 7-8: Crash reduction for option 1 vs. existing geometry

The delay was significantly affected by increases in the weight of safety, indicating the sensitivity of delay to geometric parameters, especially the inscribed circle diameter.

Although option 1 provided a higher delay than option 2 or the existing geometry option, the delay is still acceptable since the west and north approaches had LOS A and the south and east approaches had LOS B. Option 2 provided a lower delay than option 1 and the existing geometry example. Figure 7-9 reveals that option 2 is the preferable option. 


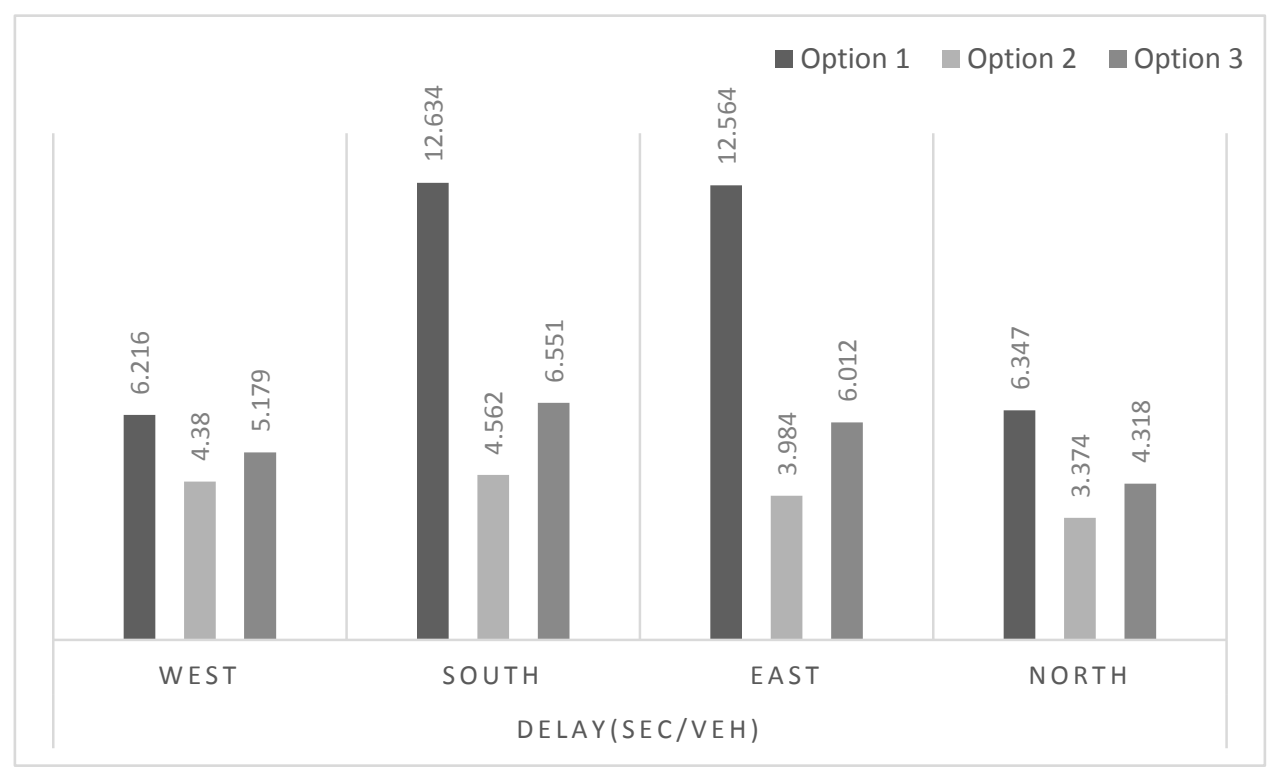

Figure 7-9-Delay comparison between the three options

The comparison between the three options revealed that using the model in option 2 provided a significant reduction in delay. The reduction as shown in Figure 7-10 shows that the reduction was as high as 34\% and 30\% for the west and south approaches and 22\% and 15\% for the East and north approaches. 


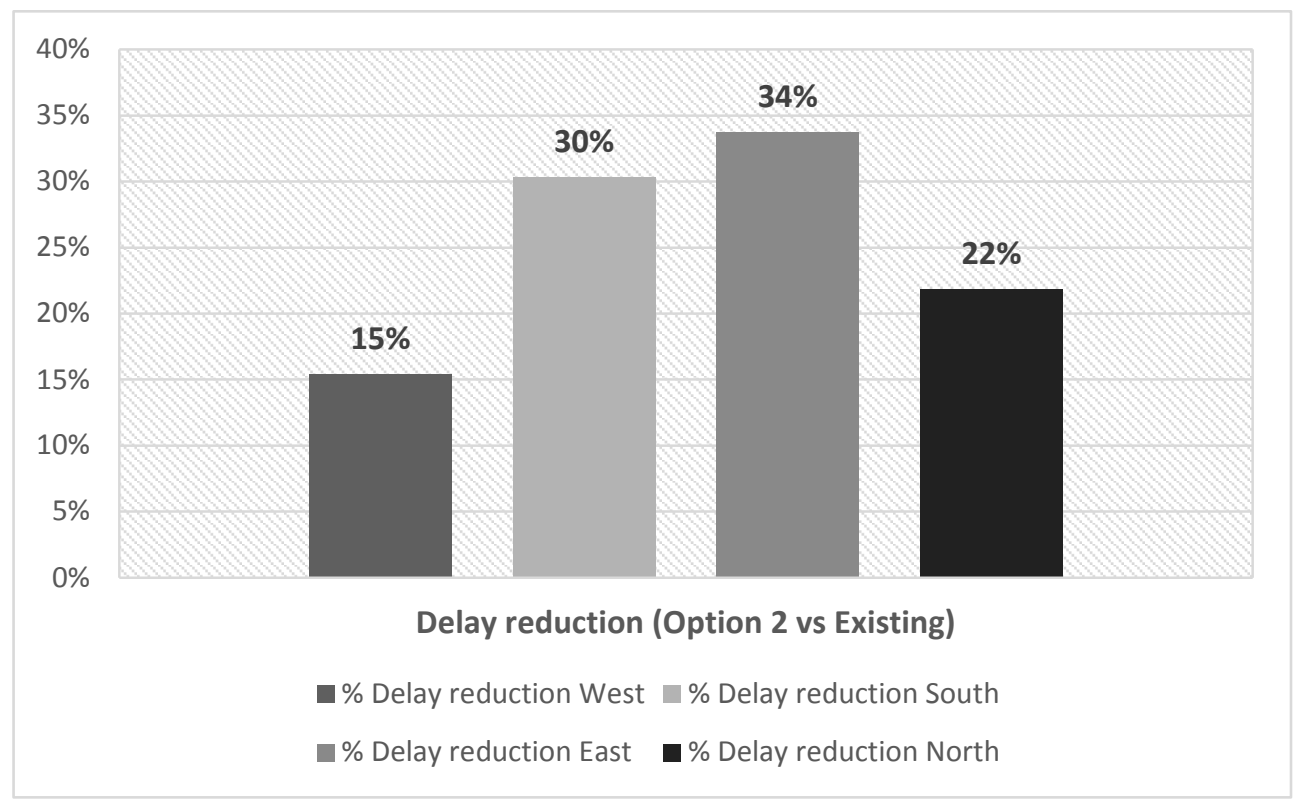

Figure 7-10: Delay reduction for option 2 vs. the existing geometry option

In order to assess the impact of using the optimization model on the environmental sustainability objective, a comparison between the model and the existing geometry was conducted. The model was applied using the settings of option 1 and 2 . The model was applied to option 3 using the existing geometric parameters as inputs. A comparison of the vehicle emissions obtained by the three options is explained in the next section. 
Figure 7-11 shows the differences between the three options for the four types of vehicle emissions.

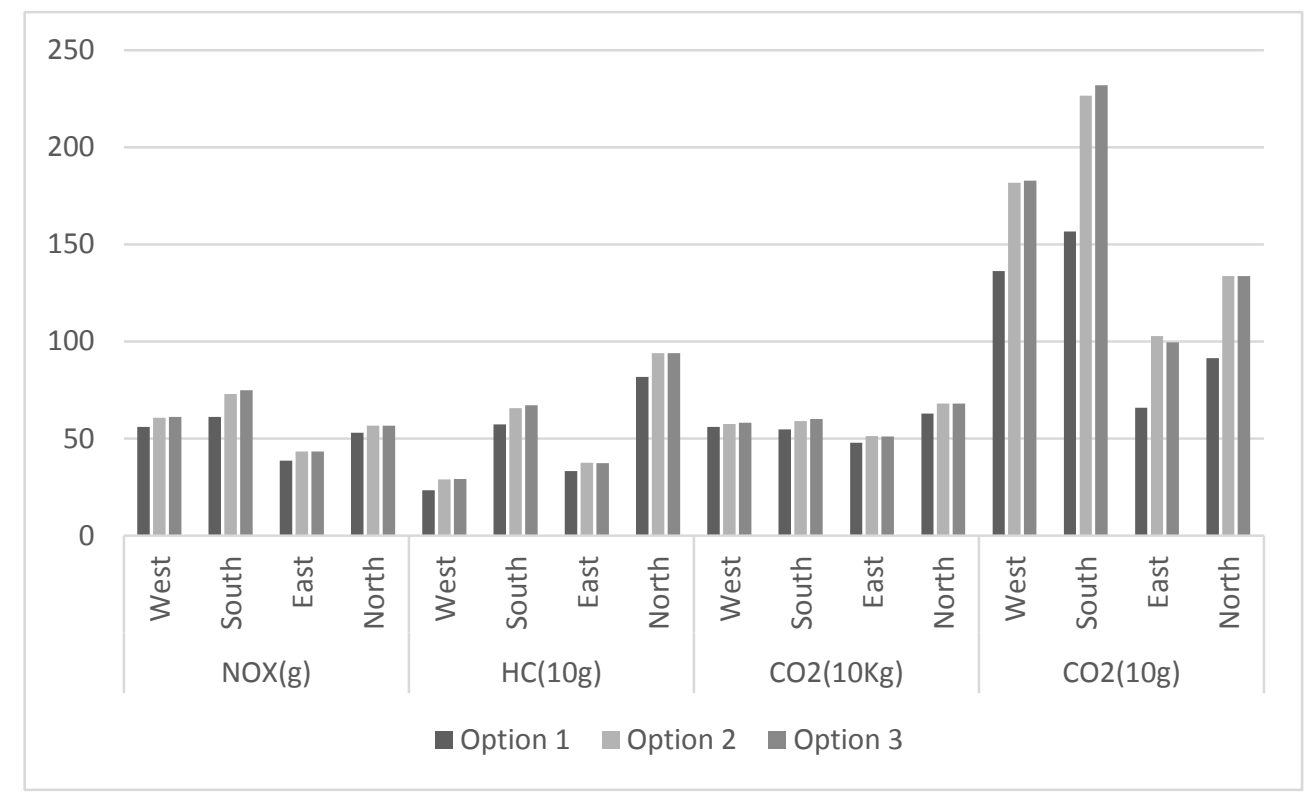

Figure 7-11: Vehicle emissions comparison between the three options

The use of the model for the optimization of the geometric parameters revealed a significant improvement in environmental sustainability compared to the existing geometry. Figure 7-12 reveals that the reduction in $\mathrm{CO} 2$ emissions was $34 \%, 33 \%, 32 \%$ and $25 \%$ in east, south, north, and west approaches, respectively. The model also provided reductions between $20 \%$ and $4 \%$ for NOX, HC, and CO2 emissions in all approaches, as shown in the figure below. 


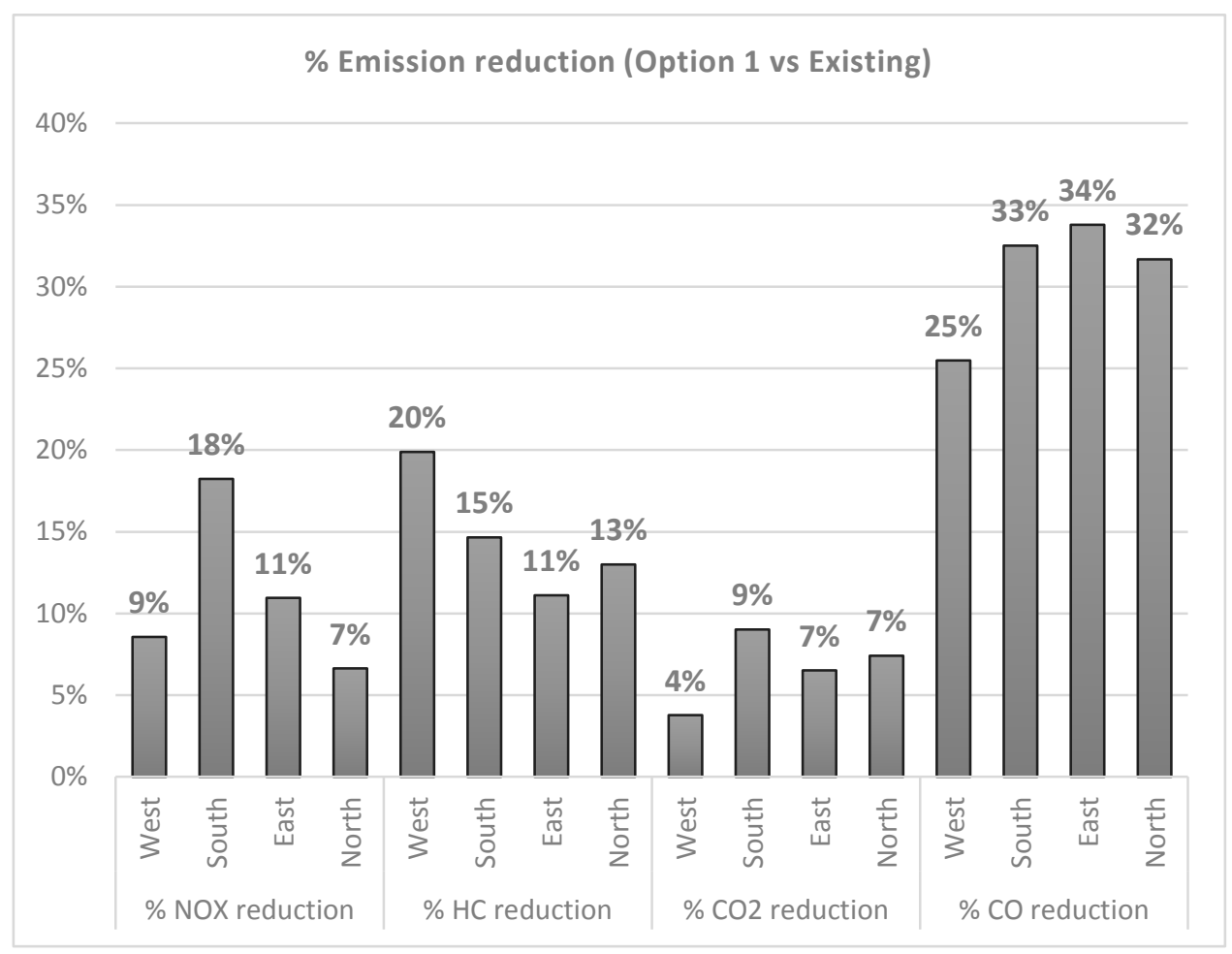

Figure 7-12: Vehicle emissions reduction for option 1 vs. the existing geometry option

In order to evaluate the sensitivity of vehicle emissions to the geometric parameters of the roundabout, the model was applied to different ranges of the inscribed circle diameter, entry width, and circulated width. The sensitivity analysis was conducted for the west approach based on increasing and decreasing the optimal geometric parameters by $5 \%$ and $10 \%$. The results are shown in Table 7-16 and illustrated by Figure 7-13.

Table 7-16: Sensitivity analysis results

\begin{tabular}{lrlll}
\hline West Approach. & NOX $(\mathrm{g})$ & $\mathrm{HC}(\mathrm{g})$ & $\mathrm{CO} 2(\mathrm{~kg})$ & $\mathrm{CO}(\mathrm{g})$ \\
\hline$-10 \%$ of the optimal & 51.146 & 24.310 & 48.734 & 1512.574 \\
$-5 \%$ of the optimal & 51.492 & 24.478 & 48.828 & 1526.238 \\
Optimal parameters & 47.710 & 21.070 & 45.370 & 1305.644 \\
$+5 \%$ of the optimal & 52.830 & 26.373 & 48.110 & 1714.412
\end{tabular}


$+10 \%$ of the optimal

1726.685

As shown in Table 4-1, increasing the optimal geometric parameters by $5 \%$ resulted in an increase of approximately, $10.7 \%, 25 \%, 6 \%$, and $31 \%$ for the NOX, $\mathrm{HC}, \mathrm{CO} 2$, and $\mathrm{CO}$ emissions, respectively. The results also revealed that decreasing the optimal geometric parameters resulted in an increase in the vehicle emissions. The sensitivity analysis revealed that the optimal geometric parameters identified by the model improved environmental sustainability, decreasing vehicle emissions.

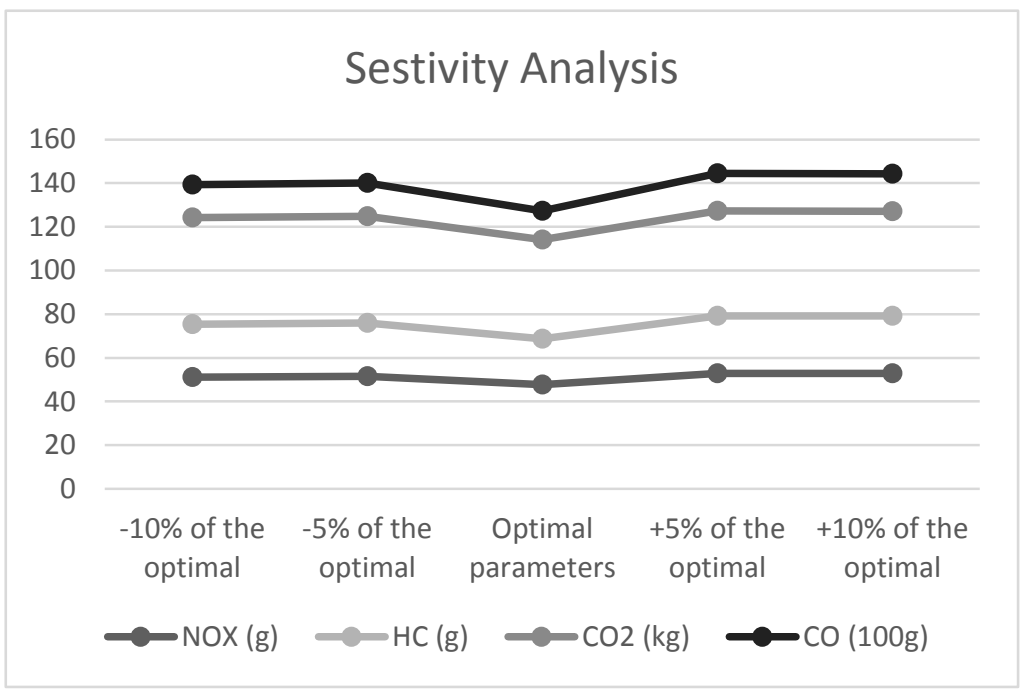

Figure 7-13: The sensitivity of vehicle emissions to the geometry 


\section{Chapter 8 Concluding Remarks and Future Research}

Numerous researchers have linked the geometric parameters of roundabouts to important aspects of roundabout design such as speed and safety performance. There is ample evidence that good geometric design of roundabouts leads to improved safety and operational performance. The traditional iterative process used in the geometric design of roundabouts is based on trying different geometric parameter values and the use of software tools to evaluate performance. This study presents a multi-objective optimization model for the geometric design of single-lane roundabouts based on minimizing crashes rates, delay, and vehicle emissions to improve safety performance, mobility, and environmental sustainability. The model was applied to an existing roundabout to test for potential improvements and the results revealed that the optimization approach led to significant improvements in the design objectives compared to the traditional process.

Three design objectives were modeled: safety, mobility and environmental sustainability. The three design objectives were represented by total collisions, total delay, and total vehicle emissions, respectively. The following conclusions were drawn from the results:

1. The geometric design of roundabouts is the most complicated process in road design. The design of roundabouts involves trade-offs between delay, safety, and environmental sustainability. The proposed model takes all three of these design objectives into account. The users need access to geometric data and traffic data for the selected site and programming through a spreadsheet makes the model simple to use. All of the defined constraints affect each other and work as a unit when finding the optimal solution. The parameters are related to one another, as changing one parameter affects the other parameters.

2. This study was conducted using multi-objective optimization. The steps of the model are summarized below.

- The safety performance is modeled using a speed-based safety performance function 
- The UK empirical model relates geometric parameters to entry capacity. The use of this function enables the model to effectively optimize the geometric parameters of the roundabout.

- Based on different vehicle trajectories and movements, nine speed profiles were modeled for each approach.

- The operating speed is modeled second by second through the influenced length of the roundabout which starts when the vehicle decelerates from the upstream approach speed and ends when the vehicle reaches the downstream approach speed for each speed profile.

- The vehicle specific power is then calculated based on the second by second speed and the assumed acceleration/deceleration.

- The NOX, HC, CO2, and $\mathrm{CO}$ vehicle emissions are determined based on the specific power values for each speed profile.

- The total emission is calculated by considering the percentage of vehicles that experience each profile and the number of vehicles in each movement.

- The total crash rates are modeled based on a predicted speed and a safety performance function.

- The model is solved based on minimizing total emissions, crashes and delay to obtain the optimal geometric parameters.

3. The model can be applied based on the design objectives of a specific location, and each objective can be assigned a suitable weight. The model was validated and a sensitivity analysis was conducted. The model proved its reliability and validity when it was applied considering only one objective. The model was applied to an actual location with three different options to compare different objective weights versus the existing geometry. The model was applied considering the three design objectives. The first two options were with different weights assigned to the design objectives and the third option was using the existing geometric parameters of the actual roundabout as input. The model provided a significant improvement in the three design objectives. A comparison between the three options (two options using the model and one option using the existing geometry) revealed a reduction in 
crashes, delay, and vehicle emissions for all approaches. The predicted crash reduction for all approaches varied from $24 \%$ to $19 \%$. The predicted reduction in the delay for all approaches varied from $34 \%$ to $15 \%$. The predicted reduction in vehicle emissions for NOX, HC, CO2, and $\mathrm{CO}$ for all approaches varied from $34 \%$ to $4 \%$.

4. The following are suggestions for future work based on the limitations of the present model in order to improve the accuracy of the outputs:

- In the emission calculations, the acceleration and deceleration were assumed to be constant, as recommended by the guidelines. The acceleration and deceleration can be modeled and related to the geometric parameters of a particular roundabout.

- The model used operating speed, predicted speed, and safety performance models that were not correlated to local conditions. The model can be fed with more realistic information.

- More design objectives can be added to the model to suit any site needs.

- The model can be modified for different types of roundabouts instead of limiting it to single-lane roundabouts

- The model can be improved by adding more conditions and constraints and more models can be added to obtain accurate optimal values.

- The model can be improved by adding sight distances which will optimize the available right-of-way.

- The turning requirements of large vehicles can be added to enhance the performance of the model instead of using CAD-based programs to assess space requirements.

- New criteria can be added into the model considering Autonomous Vehicles (AVs) as a part of the everyday traffic by using new models for capacity, delay, predicted speed, operating speed, and other factors that account for the presence of AVs.

- Using other optimization techniques such as genetic algorithms will improve the optimal solutions since identifying the objectives' assigned weights is a challenge in Solver optimization. 
- Including the human factors effect such as stress can improve the model providing more realistic solutions.

- Validating the model by calibrating all the used models and applying the model on actual data including not only the traffic and geometric data but also the delay, emissions, and collision data. 


\section{References}

Ahn, K., Rakha, H., Trani, A. and Van Aerde, M. (2002) 'Estimating vehicle fuel consumption And emissions based on instantaneous speed and acceleration levels', Journal of Transportation Engineering, Vol. 128, No. 2, pp. 182-190.

Akcelik and Associates Pty Ltd, 1999-2004 aaSIDRA. Greythorn, Victoria, Australia.

Akçelik, R., \& Troutbeck, R. (1991, July). Implementation of the Australian roundabout analysis method in SIDRA. In Highway Capacity and Level of Service-Proceedings of the International Symposium on Highway Capacity (pp. 17-34). U. Brannolte). AA Balkema, Rotterdam.

Akcelik, R., Chung, E., \& Besley, M. (1998). Roundabouts: Capacity and performance analysis (No. ARR 321).

Alek, P., Andy, P., \& Rodegerdts Lee A. (2016). Roundabout Practices-A Synthesis of Highway Practice (NCHRP Synthesis 488). Transportation Research Board.

Arndt, O. (1994). Relationship between roundabout geometry and accident rates (Doctoral dissertation, Queensland University of Technology).

Arndt, O., \& Troutbeck, R. J. (1998). Relationship between roundabout geometry and accident rates. Transportation research circular, (E-C003), 28-1.

Bachman, W., Sarasua, W., \& Guensler, R. (1996). Geographic information system framework for modeling mobile-source emissions. Transportation Research Record: Journal of the Transportation Research Board, (1551), 123-132.

Barati, R. (2013). Application of excel solver for parameter estimation of the nonlinear muskingum models. KSCE Journal of Civil Engineering, 17(5), 1139-1148. $10.1007 / \mathrm{s} 12205-013-0037-2$

Barth, M., \& Norbeck, J. (1997). NCHRP project 25-11: the development of a comprehensive modal emission model. In Proceedings of the Seventh CRC On-Road Vehicle Emissions Workshop (pp. 6-53).

Bassani, M., \& Sacchi, E. (2011). Investigation into speed performance and consistency of urban roundabouts: an Italian case study. Proceedings of the TRB 3rd International Roundabout Conference, Carmel, Indiana. 
Bovy, H., Dietrich, K., \& Harmann, A. (1991). Guide Suisse des Giratoires, mandat de recherche 9/98. VSS/FSR/EPFL.

Boxill, S.A. and Yu, L. (2000) 'An evaluation of traffic simulation models for supporting its development', Technical Report \# SWUTC/00/167602-1, Center for Transportation Training and Research, Texas Southern University.

Brilon, L. Bondzio, K. Courage, M. Kyte, J. Mason, A. Flannery, E. Myers, J. Bunker, and G. Jacquemart (2000). Roundabouts: An Informational Guide. Report FHWA-RD-00-067. FHWA, U. S. Department of Transportation.

Brilon, W. (1988). Recent developments in calculation methods for unsignalized intersections in West Germany. In Intersections without Traffic Signals (pp. 111-153). Springer, Berlin, Heidelberg.

Brude, U. (2000). WHAT ROUNDABOUT DESIGN PROVIDES THE HIGHEST POSSIBLE SAFETY? Nordic Road and Transport Research.

Canada, E. (2017). “Air pollution from cars, trucks, vans and suvs 388 canada.ca, $<$ https://www.canada.ca/en/environment-climate-change/services/air389 pollution/sources/transportation/cars-trucks-vans-suvs.html> (Nov. 5, 2017).

Chen, Y, Persaud, B, Sacchib, E, Bassani, M. (2013)."Investigation of models for relating roundabout safety to predicted speed, "Accident; Analysis and Prevention, vol. 50, pp. 196-203.

Coelho, M, Farias, T, and Rouphail, N. (2006). "Effect of roundabout operations on pollutant emissions," Transportation Research Part D, vol. 11, (5), pp. 333-343. Consistency analysis. Canadian Journal of Civil Engineering 31 (6): 1024-38.

Ding, Y. and Rakha, H. (2004) 'Trip-based explanatory variables for estimating vehicle fuel consumption and emission rates', Journal of Water, Air, \& Soil Pollution: Focus, Vol. 2, Nos. 5-6, pp.61-77.

Dong, C., Clarke, D. B., Richards, S. H., \& Huang, B. (2014). Differences in passenger car and large truck involved crash frequencies at urban signalized intersections: An exploratory analysis. Accident Analysis \& Prevention, 62, 87-94.

Easa, S. M., \& Mehmood, A. (2007). Establishing highway horizontal alignment to maximize design consistency. Canadian Journal of Civil Engineering, 34(9), 1159-1168. $10.1139 / 107-043$

Easa, S. M., and Atif, M. (2004). Optimizing geometric design of single-lane roundabouts: 
Easa, S. M., and Atif, M. (2008). Optimizing design of highway horizontal alignments: New substantive safety approach. Computer-Aided Civil and Infrastructure Engineering 23 (7): 560-73.

Elvik, R. (2003). Effects on road safety of converting intersections to roundabouts: Review of evidence from non-U.S. studies. Transportation Research Record: Journal of the Transportation Research Board, 1847, 1-10. 10.3141/1847-01

Evans L. and Herman, R. (1978) 'Automobile fuel economy on fixed urban driving schedules', Transportation Science, Vol. 12, No. 2, pp.137-152.

Federal Highway Administration, FHWA-SA-10-006, Roundabouts: Technical Summary, 2010

FGSV. (2001). Handbuch für die Bemessung von Straßenverkehrsanlagen (German Highway Capacity Manual). Forschungsgesellschaft für Straßen- und Verkehrswesen (Hrsg.), No. 299. FGSV Verlag GmbH, Köln, Germany.

Frey, H., Unal, A., Chen, J., Li, S. (2003). Modeling Mobile Source Emissions Based Upon InUse and Second-by-Second Data: Development of Conceptual Approaches for EPA's New MOVES Model. Presented at Air and Waste Management Association 96th Annual Conference and Exhibition, San Diego.

Frey, H.C., Rouphail, N.M., Zhai, H., Farias, T.L. and Gonçalves, G.A. (2007) 'Comparing realworld fuel consumption for diesel- and hydrogen-fueled transit buses and implication for emissions', Transportation Research Part D: Transport and Environment, Vol. 12, No. 4, pp.281-291.

Garder, P. (2016). The Modern Roundabouts: The Sensible Alternative for Maine. Maine Ministry of Transportation of Ontario. Ontario Road Safety Annual Report 2016

Geo Scholars portal. (2018). Available online at: http://geo2.scholarsportal.info.ezproxy.lib.ryerson.ca/print.html. Accessed (March, 2018)

Griffiths, J. D. (1981). A mathematical model of a non-signalized pedestrian crossing. Transportation Science, Vol. 15, No. 3, pp. 223-232.

Guensler, R.L., Washington, S.P., Sperling, D. (1993) 'A weighted disaggregate approach to modelling speed correction factors', Institute of Transportation Studies, University of California, Davis, Research Report \# UCD-ITS-RR-93-06. 
Guichet, B. "Roundabouts in France: Development, Safety, Design, andCapacity.” In Proceedings of the Third International Symposium on Intersections without Traffic Signals (M. Kyte, ed.), Portland, Oregon, University of Idaho, Moscow, Idaho, 1997.

Highway Capacity Manual. (2010). Transportation Research Board of the National Academies, Washington, D.C., 2010.

Highway Capacity Manual, Sixth Edition. (2016): A Guide for Multimodal Mobility Analysis (HCM). Transportation Research Board of the National Academies, Washington, D.C.

Highway Capacity Manual. (2000). TRB, National Research Council, Washington, DC.

Jacquemart, G. (1998). Modern roundabout practice in the United States (No. Project 20-5 FY 1996).

Jiménez-Palacios, J. L. (1999). Understanding and quantifying motor vehicle emissions with vehicle specific power and TILDAS remote sensing. Massachusetts Institute of Technology, U.S.

Johnson, M. T. (2018) Impact of Geometric Factors on the Capacity of Single-Lane Roundabouts.

Kent, J.H. and Mudford, N.R. (1979) 'Motor vehicle emissions and fuel consumption modelling', Transportation Research Part A: General, Vol. 13, No. 6, pp.395-406.

Kimber, R. M. (1980).The Traffic Capacity of Roundabouts. Laboratory Report LR 942. Transport and Road Research Laboratory, Crowthorne, Berkshire, United Kingdom.

Kimber, R. M., and E. M. Hollis. (1979).Traffic queues and delays at road junctions. Laboratory Report LR 909. Transport and Road Research Laboratory, Crowthorne, Berkshire, United Kingdom.

Kremser, H. (1964).Wartezeiten und Warteschlangen bei Einfaedelung eines Poissonprozesses in einen anderen solchen Prozess (Delays and queues with one poisson process merging into another one). Oesterreichisches Ingenieur-Archiv, Vol. 18.

Lomax, T. J. (1997). Quantifying congestion (No. 398). Transportation Research Board.

Louah, G. (1993).Panorama Critique des Modeles Francais de Capacite des Carrefours Giratoires. Proc., Roundabouts 92, Nantes, France, October 1992. SETRA, Bagneux, France. 
Manual, H. C. (2016). A Guide for Multimodal Mobility Analysis. Transportation Research Board, Washington, DC.

Marlow, M., and G. Maycock. (1982). The effect of zebra crossing on junction entry capacities. Special Report SR 724. Transport and Road Research Laboratory, Crowthorne, Berkshire, United Kingdom.

Maycock, G., and R. D. Hall. (1984). Accidents at 4-arm roundabouts. Report LR 1120. Transport and Road Research Laboratory, Crowthorne, Berkshire, United Kingdom.

McLeod, D. S., Jin, L., \& Scorsone, T. (2016). Developing Florida Statewide Multimodal Mobility Performance Measures. Transportation Research Record: Journal of the Transportation Research Board, (2563), 51-61.

Mehmood, A. and Easa, S. M. (2006). Optimizing geometric design of roundabouts: Multi objective analysis. Canadian Journal of Civil Engineering 33 (1): 29-40.

Microsoft (2018). Microsoft Excel 2010 user guide. Internet: https://support.office.com/en-US/article/Getting- ed-with-Excel-2010-D8708FF8-2FBD4D1E-8BBB-5DE3556210F7 (accessed on February 23, 2018).

North Carolina State University. (2002). Methodology for Developing Modal Emission Rates for EPA's Multi-Scale Motor Vehicle and Equipment Emission System. EPA Contract No. PR-CI-02-10493. Office of Transportation and Air Quality, US Environmental Protection Agency, Washington DC.

Pochowski, A, Paul, A, Lee, A, Rodegerdts, Kittelson and Associates, Inc. (2016). NCHRP SYNTHESIS 488, Roundabout Practices, Project 20-05, Topic 46-02, ISSN 0547-5570, ISBN 978-0-309-27208, Library of Congress Control No. 2016959599.

Pochowski, A. (2010). An Analytical Review of Statewide Roundabout Programs and Policies, Master's thesis, Georgia Institute of Technology, Atlanta, Ga.

Rakha, H. and Ahn, K. (2004) 'Integration modelling framework for estimating mobile source emissions', Journal of Transportation Engineering, Vol. 130, No. 2, pp.183-193.

Ran, H., Thomas, R. and Mavris, D. (2007) 'A mean value based sizing and simulation model of a hydrogen fueled spark-ignition internal combustion engine', Proceedings of the Society of Automotive Engineers SAE 2007 AeroTech Congress \& Exhibition, USA, paper \# 2007-01-3789.

Rao, Q, Zhang, L, Yang, W, Fang, B. (2014). Analysis of Instantaneous Vehicle Emissions 
Models Based on Speed and Acceleration. 14th COTA International Conference of Transportation Professionals, American Society of Civil Engineers, pp 2736-2747

Retting, R., Persaud, B., Garder, P., \& Lord, D. (2001). Crash and injury reduction following installation of roundabouts in the United States. American Journal of Public Health, 91(4), 628-631. doi:10.2105/AJPH.91.4.628,2001

Robinson, B. W., L. Rodegerdts, W. Scarborough, W. Kittel son, R. Troutbeck, W. Brilon, L. Bondzio, K. Courage, M. Kyte, J. Mason, A. Flannery, E. Myers, J. Bunker, and G. Jacquemart. (2000). Roundabouts: An Informational Guide. Report FHWA-RD-00-067. FHWA, U. S. Department of Transportation.

Robinson, B. W., L. Rodegerdts, W. Scarbrough, W. Kittelson, R. Troutbeck, W. Rodegerdts, L, Justin, T, Christopher, K, Julia, M, Edward, J, Mark, M, Persaud, B, Lyon, C, Shauna I, Hillary, C, Barry, G, Bernard, O'Brien, Andrew. (2010). Roundabouts - An Informational Guide (2nd Edition): (NCHRP Report 672). Transportation Research Board. . Online version available at: http://app.knovel.com/hotlink/toc/id:kpRAIGENCA/roundabouts-aninformational/roundabouts-an-informational

Rodegerdts, L., M. Blogg, E. Wemple, E. Myers, M. Kyte, M. Dixon, G. List, A. Flannery, R. Troutbeck, W. Brilon, N. Wu, B. Persaud, C. Lyon, D. Harkey, and D. Carter. (2007). NCHRP Report 572: Roundabouts in the United States. Transportation Research Board of the National Academies, Washington, D.C.

Salamati K, Coelho M, Fernandes P, Rouphail N, Frey H, Bandeira J. (2013). Emission Estimation at Multilane Roundabouts: Effect of Movement and Approach Lane. Transportation Research Board 92nd Annual Meeting, Washington, DC. Service d'Etudes Techniques des Routes et Autoroutes (SETRA). Accidents at intersections: the use of models to predict average accidents rates. Memorandum. Bagneux Cedex, France, 1998

Small, K. A., Verhoef, E. T., \& Lindsey, R. (2007). The economics of urban transportation. Routledge.

Smit, R., Smokers, R. and Rabe, E. (2007) 'A new modelling approach for road traffic emissions:VERSIT+', Transportation Research Part D: Transport and Environment, Vol. 12, No. 6, pp.414-422.

Sommer, C., German, R. and Dressler, F. (2011) 'Bidirectionally coupled network and road traffic simulation for improved IVC analysis', IEEE Transactions on Mobile Computing, Vol. 10, No. 1, pp.3-15. 
Song, G, Zhou, X and Yu, L. (2015). "Delay correction model for estimating bus emissions at signalized intersections based on vehicle specific power distributions," The Science of the Total Environment, vol. 514, pp. 108-118.

Song, G., Yu, L. and Wang, Z. (2009) 'Aggregate fuel consumption model of light-duty vehicles for evaluating effectiveness of traffic management strategies on fuels', Journal of Transportation Engineering, Vol. 135, No. 9, pp.611-618.

Stuwe, B. (formerly Hartz, B.). (1992). Untersuchung der Leistungsfähigkeit und Verkehrssicherheit an deutschen Kreisverkehrsplätzen. Schriftenreihe des lehrstuhls für Verkehrswesen der Ruhr-universität Bochum, Heft 10, Ruhr-University Bochum, Bochum, Germany.

Taylor, N.B. (2003) 'The CONTRAM dynamic traffic assignment model', Networks and Spatial Economics, Vol. 3, pp.297-322.

Wang, H., Fu, L., Zhou, Y. and Li, H. (2008) 'Modelling of the fuel consumption for passenger cars regarding driving characteristics', Transportation Research Part D: Transport and Environment, Vol. 13, No. 7, pp.479-482.

WHO, 2011. World Health Organization Fact sheet N313. Air Quality and Health. Updated September 2011. http://www.who.int/mediacentre/factsheets/fs313/ en/index.html

World Health Organization. (2009). Global Status Report on Road Safety-Time for Action. Geneva, Switzerland: World Health Organization.

Wu, N. (1994). An Approximation for the Distribution of Queue Lengths at Unsignalized Intersections. Proc., 2nd International Symposium on Highway Capacity (R. Akçelik, ed.), Vol. 2, Sydney, Australia, Vol. 2, Australian Road Research Board.

Wu. N. (2001). A Universal Procedure for Capacity Determination at Unsignalized (prioritycontrolled) Intersections. Transportation Research B, No. 35, Issue 3. Elsevier Science Ltd., New York, Tokyo, Oxford.

Yeo, G. F. (1962). Single-server queues with modified service mechanisms. Journal Australia Mathematics Society, Vol. 2, pp. 499-502.

Zallinger, M., Anh, T.L. and Hausberger, S. (2005) 'Improving an instantaneous emission model for passenger cars', Proceedings of the 14th International Conference on Transport and Air Pollution, Graz, Austria, pp.167-176. 
Zhai, H, Frey, H and Rouphail, N. (2008). "A vehicle-specific power approach to speed- and facility-specific emissions estimates for diesel transit buses," Environmental Science \& Technology, vol. 42, (21), pp. 7985-7991.

Zhou, B., Roshandeh, A.M., Zhang, S. (2014). Safety impacts of push-button and countdown timer on non motorized traffic at intersections. Mathematical Problems in Engineering $2014,460109$. 